\title{
STATUS AND MANAGEMENT OF WORLD SEA URCHIN FISHERIES
}

\author{
N. L. ANDREW ${ }^{1}$, Y. AGATSUMA ${ }^{2}$, E. BALLESTEROS ${ }^{3}$, \\ A. G. BAZHIN ${ }^{4}$, E. P. CREASER ${ }^{5}$, D. K. A. BARNES 6 ,
}

L. W. BOTSFORD ${ }^{7}$, A. BRADBURY ${ }^{8}, A \cdot$ CAMPBELL $^{9}$, J. D. DIXON ${ }^{10}$,

S. EINARSSON ${ }^{11}$, P. K. GERRING ${ }^{1}, \mathrm{~K} . \mathrm{HEBERT}^{12}, \mathrm{M}$ HUNTER $^{5}$,

S. B. HUR ${ }^{13}$, C. R. JOHNSON ${ }^{14}$, M. A. JUINIO-MENEZ ${ }^{15}$,

P. KALVASS ${ }^{16}$, R. J. MILLER ${ }^{17}$, C. A. MORENO ${ }^{18}$, J. S. PALLEIRO ${ }^{19}$,

D. RIVAS ${ }^{20}$, S. M. L. ROBINSON ${ }^{21}$, S. C. SCHROETER ${ }^{10}$,

R. S. STENECK ${ }^{22}$, R. L. VADAS ${ }^{23}$, D. A. WOODBY ${ }^{24}$ AND Z. XIAOQI ${ }^{25}$

${ }^{1}$ National Institute of Water and Atmospheric Research, P.O. Box 14-901, Kilbirnie, Wellington, New Zealand

email: n.andrew@niwa.cri.nz

${ }^{2}$ Laboratory of Applied Aquatic Botany, Graduate School of Agricultural Science,

Tohoku University, Tsutsumidori-Amamiya 1-1, Aoba, Sendai, Miyagi 981-8555, Japan

${ }^{3}$ Centre d'Estudis Avançats de Blanes-CSIC, E-17300 Blanes, Girona, Spain

${ }^{4}$ Kamchatka Research Institute of Fisheries and Oceanography, Naberezhnaya 18,

Petropavlovsk-Kamchatsky 683002, Russia

${ }^{5}$ Maine Department of Marine Resources, West Boothbay Harbor, ME 04575 USA

${ }^{6}$ Department of Zoology, University College Cork, Lee Maltings, Cork, Ireland

${ }^{7}$ Department of Wildlife, Fish and Conservation Biology, University of California,

Davis, CA 95616, USA

${ }^{8}$ Washington Department of Fish and Wildlife, Point Whitney Shellfish Laboratory, Brinnon, WA 98320, USA

${ }^{9}$ Fisheries and Oceans Canada, Pacific Biological Station,

Nanaimo, BC, Canada V9R 5K6

${ }^{10}$ Marine Science Institute, University of California, Santa Barbara, CA 93106, USA

${ }^{11}$ Marine Research Institute, P.O. Box 1390, Skúlagata 4, 121 Reykjavik, Iceland

${ }^{12}$ Alaska Department of Fish and Game, P.O. Box 667, Petersburg, AK 99833, USA

${ }^{13}$ Department of Aquaculture, Institute of Fisheries Science, Pukyong National University,

714 U 1-dong, Haewundae, Pusan, 612-021, South Korea

${ }^{14}$ Tasmanian Aquaculture and Fisheries Institute, University of Tasmania,

GPO Box 252-05, Hobart, TAS 7001, Australia

${ }^{15}$ Marine Science Institute, University of the Philippines, Diliman,

Quezon City, Philippines 1101

${ }^{16}$ California Department of Fish and Game, 19160 South Harbor Drive,

Fort Bragg, CA 95437, USA

${ }^{17}$ Fisheries and Oceans Canada, Dartmouth, Nova Scotia, Canada B2Y $4 A 2$

${ }^{18}$ Instituto de Ecologia y Evolucion, Universidad Austral de Chile, Casilla 567, Valdivia, Chile

${ }^{19}$ Calle 16 No. 25, Centro, Ensenada, Baja California, Mexico, C.P. 22880 
N. L. ANDrew, Y. Agatsuma, E. BAllesteros, A. G. BAZhin, ET AL.

${ }^{20}$ Departamento de Pesquerías, Subsecretaria de Pesca, Bellavista 168, Piso 17, Casilla 100-V, Valparaiso, Chile

${ }^{21}$ Fisheries and Oceans Canada, St Andrews, NB, Canada E5B $2 L 9$

${ }^{22}$ Darling Marine Center, University of Maine, Walpole, ME 04573, USA

${ }^{23}$ Department of Biological Sciences, University of Maine, Orono, ME 04469, USA

${ }^{24}$ Alaska Department of Fish and Game, PO Box 240020, Douglas, AK 99824, USA

${ }^{25}$ Fisheries College, Ocean University of Qingdao, 5 Yushan Road,

Qingdao, China 266003

\begin{abstract}
World production of sea urchins peaked in 1995, when $120306 \mathrm{t}$ were landed. Chile dominates world production, producing more than half the world's total landings of $90257 \mathrm{t}$ in 1998. Other important fisheries are found in Japan, Maine, British Columbia, California, South Korea, New Brunswick, Russia, Mexico, Alaska, Nova Scotia, and in a number of countries that produced less than $1000 \mathrm{t}$ in 1998. Aside from the Chilean fishery for Loxechinus albus, most harvest is of Strongylocentrotus spp., particularly S. intermedius, S. franciscanus, and $S$. droebachiensis. Only a small minority of fisheries have been formally assessed and in the absence of such assessments it is difficult to determine whether fisheries are over-fished or whether the large declines observed in many represent the "fish down" of accumulated biomass. Nevertheless, those in Chile, Japan, Maine, California and Washington and a number of smaller fisheries, have declined considerably since their peaks and are likely to be over-fished. Fisheries in Japan, South Korea and the Philippines have been enhanced by reseeding hatchery-reared juveniles and by modifying reefs to increase their structural complexity and to promote the growth of algae. Sea urchin fisheries have potentially large ecological effects, usually mediated through increases in the abundance and biomass of large brown algae. Although such effects may have important consequences for management of these and related fisheries, only in Nova Scotia, South Korea and Japan is ecological knowledge incorporated into management.
\end{abstract}

\title{
Introduction
}

Most sea urchin fisheries are found in the temperate regions of the world and are concentrated on only a handful of genera. The harvested product of these fisheries is the gonad of both sexes (more usually and loosely termed "roe"). There are long traditions of consuming sea urchin roe in many cultures, particularly in Asia, Polynesia, in the Mediterranean, and in Chile. In addition to the many small artisanal and domestic commercial fisheries, modern commercial fisheries are now focused on the Japanese market which consumes more than $80 \%$ of the world's production (Kawamura 1993, Sonu 1995, Hagen 1996). Sea urchin roe is a premium food in Japan where it is eaten raw as sashimi, served with rice as sushi ("Uni Don" in Japanese), or preserved in small bottles mixed in brine or alcohol and salt ("Shio uni", "Tsubu uni" and "Ita uni"). Particularly well known are the "Echizen Uni" brand, processed since the 1600s in Fukui (Taki \& Higashida 1964), and "Shimonoseki Uni" which have been sold in Yamaguchi since the 1800s (Kan 1968). A baked casserole of roe served on the shells of the Japanese surf clam (Pseudocardium sybillae) or ezo-abalone (Haliotis discus hannai) is called "Kaiyaki Uni" and remains a popular regional dish.

Most sea urchin roe imported to Japan arrives fresh or frozen in various stages of processing from bulk packaged only to finished trays of uni (Table 1). Importation of fresh or frozen roe 


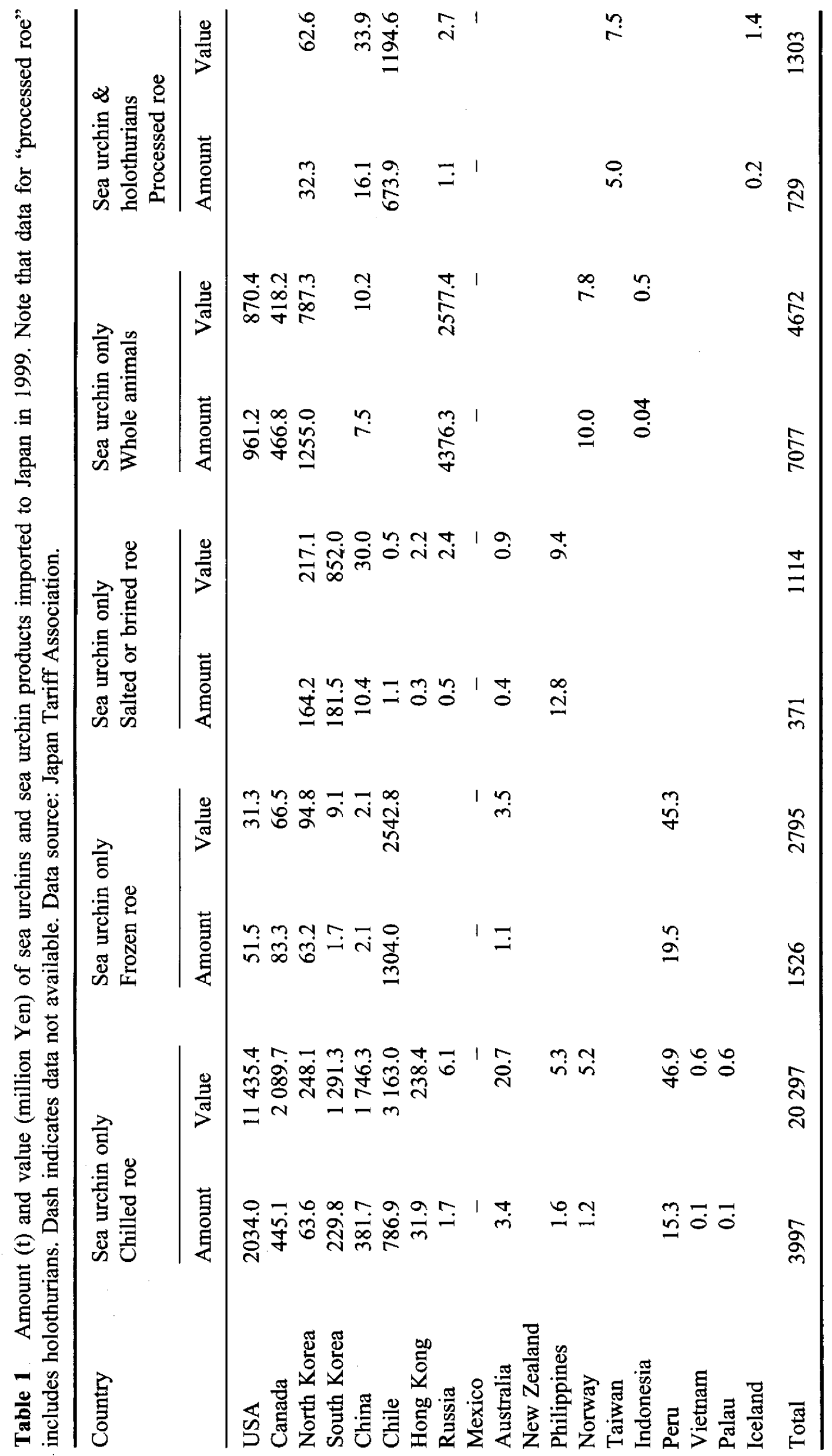


increased from $2643 \mathrm{t}$ in 1988 to $3367 \mathrm{t}$ in 1992 and $5523 \mathrm{t}$ in 1999 (Table 1, Sonu 1995, Hagen 1996, Keesing \& Hall 1998). Most of this roe came from the USA, Chile, South Korea and Canada. In contrast, imports of salted or brined roe, mostly from the Korean peninsula and China, decreased from $1248 \mathrm{t}$ in 1988 to $371 \mathrm{t}$ in 1999 (Table 1). Whole sea urchins are also imported from the USA, Canada and Russia; in $19997077 \mathrm{t}$ of whole sea urchin were imported.

France is the world's second largest consumer of sea urchin roe, consuming around $1000 \mathrm{t}$ per year (Hagen 1996). There are large domestic markets in many sea urchin producing countries, notably Chile, New Zealand and the Philippines.

In this review we provide an overview of the current status and management of the world's sea urchin fisheries. Summaries of trends in world production are followed by synopses of major fisheries, presented in declining order of production in 1998 (see Table 2). The level of detail is based on the relative importance of the fishery, whether lessons may be learnt from its management and the quantity of citable research done. Following these summaries, stock enhancement in sea urchin fisheries is summarised, and finally we make some general observations about the ecological effects of sea urchin fisheries and their management. This review is designed to complement the comprehensive reviews of the ecology of edible sea urchins provided in Lawrence (2001).

Unless noted, the term "recruitment" is used as it is in the ecological literature to mean "entry into the observable benthic population". In the fisheries literature it usually refers to "entry to the fishery"; where we use the term in this context we use qualifiers to make that usage clear. We use the term "barrens habitat" to describe areas of reefs in which sea urchins occur at high density and which are grazed clear of large brown algae. We use the term in preference to "isoyake" because that term more specifically describes the reduced fisheries production that comes from areas of barrens habitat (Taniguchi 1996). All weights are reported as whole animal wet weight unless specified otherwise and sizes are given as test diameter (TD in $\mathrm{mm}$ ). The acronym MLS refers to Minimum Legal Size, MxLS refers to Maximum Legal Size, and TAC refers to annual Total Allowable Catch.

\section{World production}

World production is difficult to estimate accurately because FAO statistics (FAO 2000a,b) are reported for all echinoderms combined; in some countries, particularly those in the tropics, there are significant holothurian fisheries (Sloan 1985, Conand \& Byrne 1993, Dalzell et al. 1996, Conand 2001). To estimate sea urchin production, we started with countries listed by FAO as having some echinoderm production, plus Australia, and from that list estimated catch as follows: (a) wherever possible estimates of catches were obtained directly from scientists and managers working on each fishery (see author list), (b) based on Conand's (2001) estimates of sea cucumber production between 1986 and 1996, countries in the tropics with significant catches of holothurians (Ecuador, Indonesia, Kenya, Madagascar, Malaysia, Maldives, Mozambique, New Caledonia, Palau, Papua New Guinea, Solomon Islands, Sri Lanka, Tanzania, Tonga, Vanuatu, and Yemen) were compared with the FAO statistics and excluded because the holothurians accounted for the echinoderm harvest, (c) Denmark was excluded because Sloan (1985) reported that a fishery for Asterias rubens was active in the 1970s and 1980s and there have been no reported landing of echinoderms since 
1984 (FAO 2000a), (d) Catch estimates for France were taken from Le Direac'h (1987) for the period 1954-84 and FAO thereafter, and (e) FAO catch estimates for echinoderms were used for China, Fiji, North Korea, Peru, Russia (and the former USSR), and Spain.

Catch statistics are reported for the period completely covered by FAO statistics (196398), and more extensive time series are reported where available. The estimates of harvest based on FAO statistics almost certainly underestimate true landings, particularly prior to the 1980s. Furthermore, excluded countries may have some sea urchin production, there may be under-reporting, and the FAO list may be incomplete. Estimated harvests may include some catches of asteroids in those countries for which specific records of sea urchin landings are not available.

World production of sea urchins steadily increased though the latter half of last century to a peak of $120306 \mathrm{t}$ in 1995 (Fig. 1, Table 2). Since 1995, total production has declined quickly and in 1998 was only $75 \%$ of its peak 3 yr earlier (Fig. 1, Table 2). Underlying the overall increase in production before 1995 was a series of expansions and declines of regional or national fisheries, particularly in Japan, the USA and Chile (see summaries below). Following an explosive development in the 1990s, Chile now accounts for more than half the world's production. If Chile is excluded, world production has been declining for the last $10 \mathrm{yr}$. In 1998, a total of $90257 \mathrm{t}$ was landed in the world's sea urchin fisheries.

Traditionally, sea urchins in the northern hemisphere genus Strongylocentrotus have accounted for most of the harvest (Fig. 2) but their contribution has steadily declined since 1990 and made up only $39 \%$ of the world's production in 1998. This decline was greatest in fisheries for $S$. franciscanus, $S$. droebachiensis and $S$. intermedius. After explosive growth of the Chilean fishery for Loxechinus albus, this species now dominates world production - in the decade from 1988, $382161 \mathrm{t}$ were harvested. Two species, Strongylocentrotus franciscanus and $S$. droebachiensis, are widely distributed in North America and Europe (see Scheibling \& Hatcher 2001, Tegner 2001 for recent reviews) and are much sought after by the Japanese

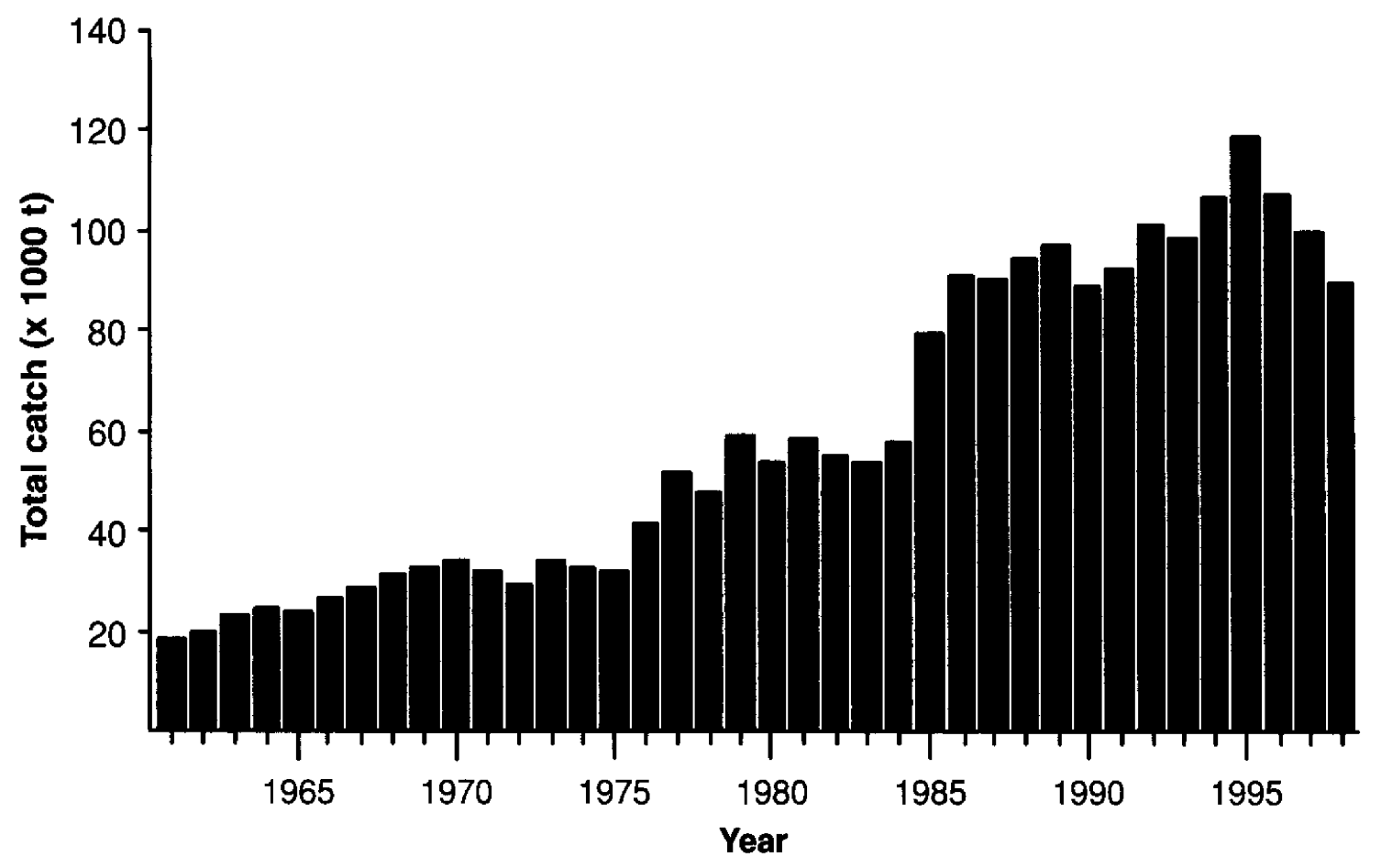

Figure 1 Total world sea urchin production (t) between 1961 and 1998. 
N. L. ANDREW, Y. AGATSUMA, E. BALlesteros, A. G. BAZHin, ET Al.

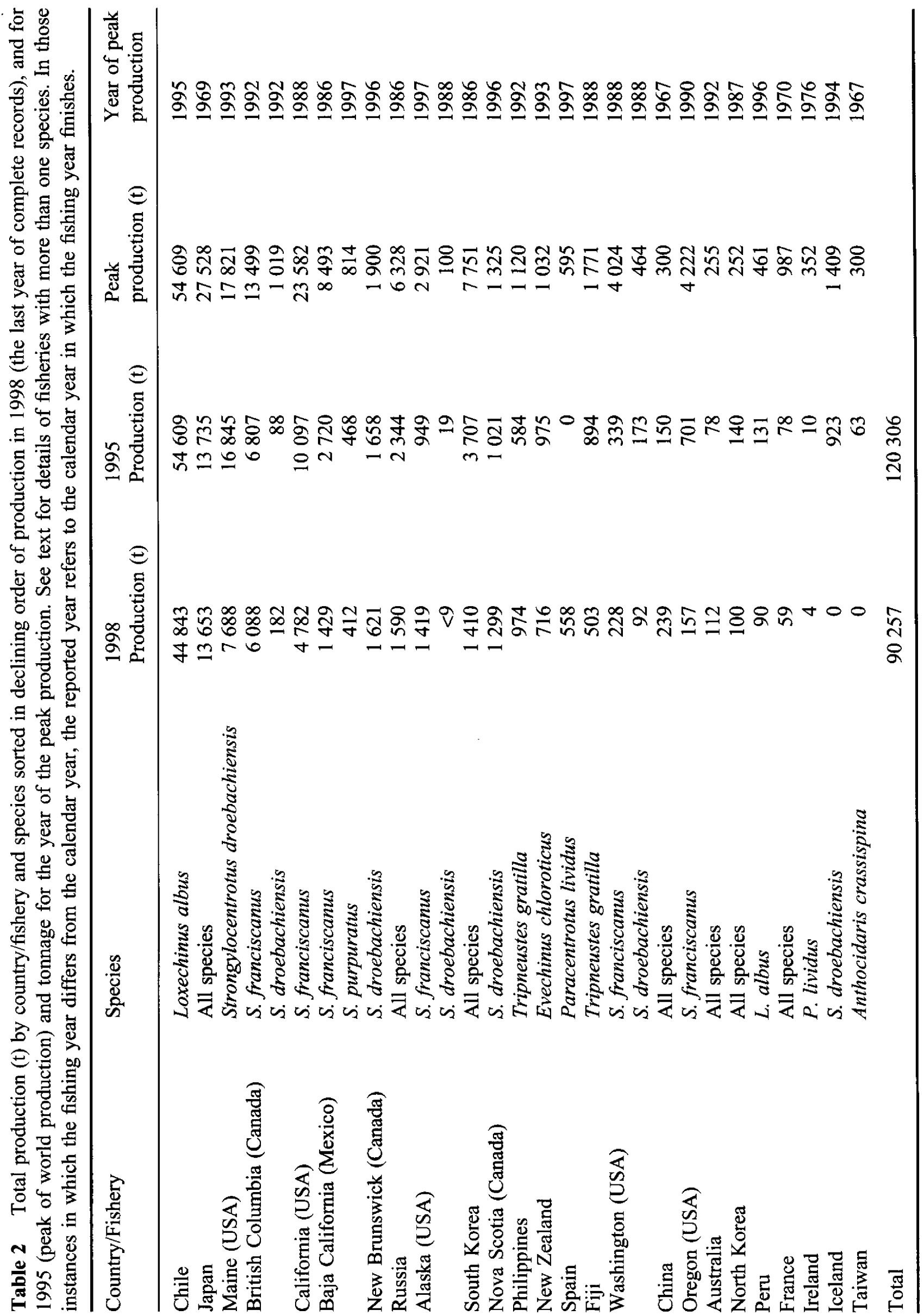




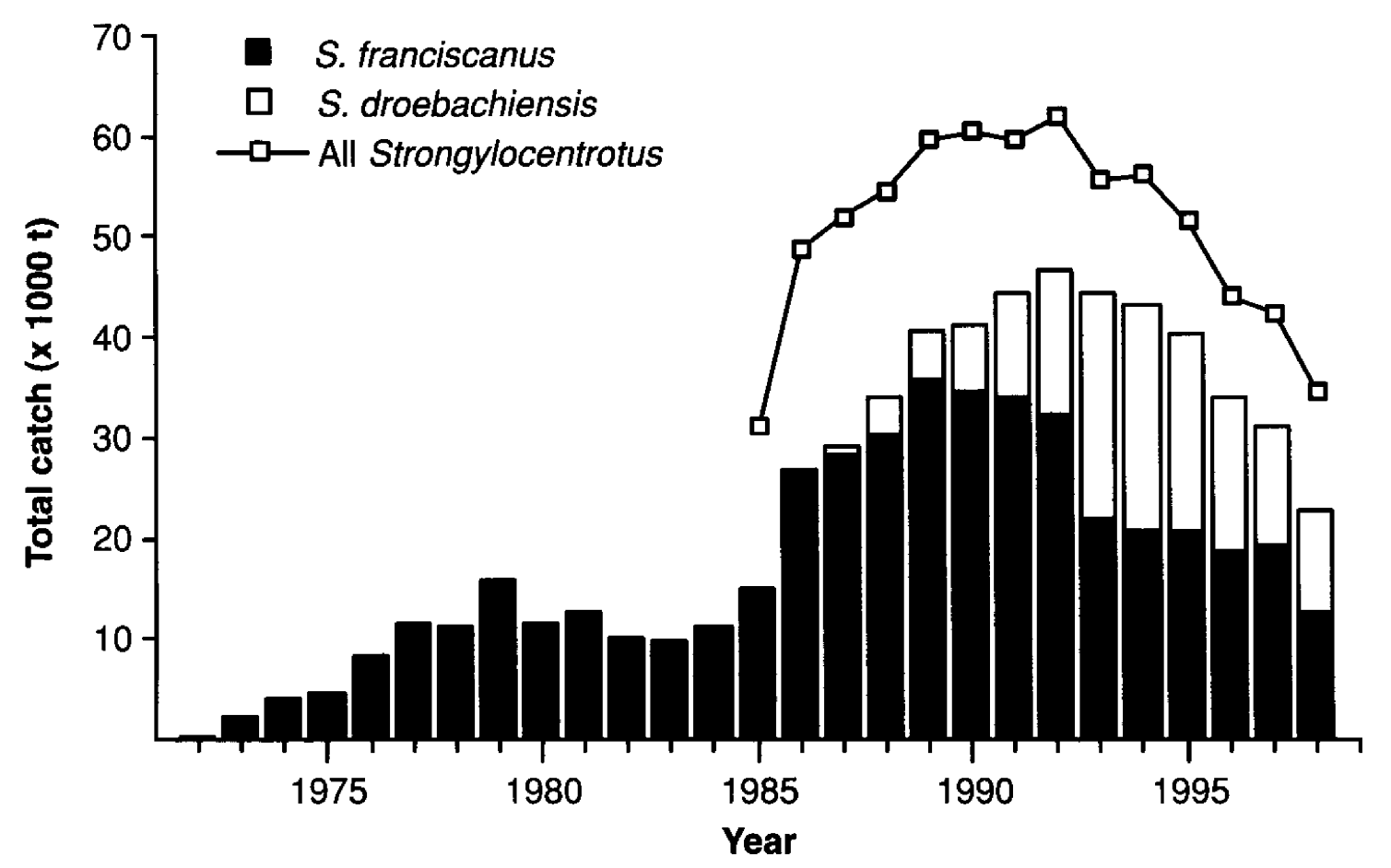

Figure 2 Total world production of Strongylocentrotus spp. (line) and by species (bars).

market. S. franciscanus is distributed along the western seaboard of North America from Baja California to Alaska and is harvested throughout its range. Catches have declined since peaking at about $35000 \mathrm{t}$ in 1989 to less than half that now (Fig. 2).

Fisheries for $S$. droebachiensis are concentrated in Maine and the Maritime Provinces of Canada, but smaller fisheries exist in Alaska, British Columbia, Washington and Iceland. Commercial harvesting, almost exclusively for the Japanese market, expanded rapidly in the late 1980s and peaked in 1993 at approximately $22454 \mathrm{t}$ (Fig. 2). Since then catches have fallen markedly, and in 1999 were 39\% of those in 1993. In his review of echinoderm fisheries in 1985, Sloan noted that ". . . S. droebachiensis is not the subject of an appreciable fishery." The rise of this species as a contributor to world production has been rapid and, although its contribution has declined, it remains an important species.

\section{Chile}

\section{The fishery}

The fishery for the endemic sea urchin Loxechinus albus is the largest in the world. L. albus are relatively slow growing and may live to be as old as $20 \mathrm{yr}$ and as large as $130 \mathrm{~mm}$ (Stotz et al. 1992, Zuleta \& Moreno 1994, Gebauer \& Moreno 1995, see Vásques 2001 for review). L. albus feed mainly on drifting algal material (Castilla \& Moreno 1984, Moreno \& Vega 1988 ) and are found in intertidal pools on rocky shores and on subtidal reefs to a maximum depth of $15 \mathrm{~m}$ (Vásques et al. 1984).

In common with many invertebrate fisheries, the development of the Chilean sea urchin fishery may be divided into three phases (Moreno \& Zuleta 1996), existing initially as a small fishery, followed by a phase of rapid expansion, and then a third phase of full exploitation 


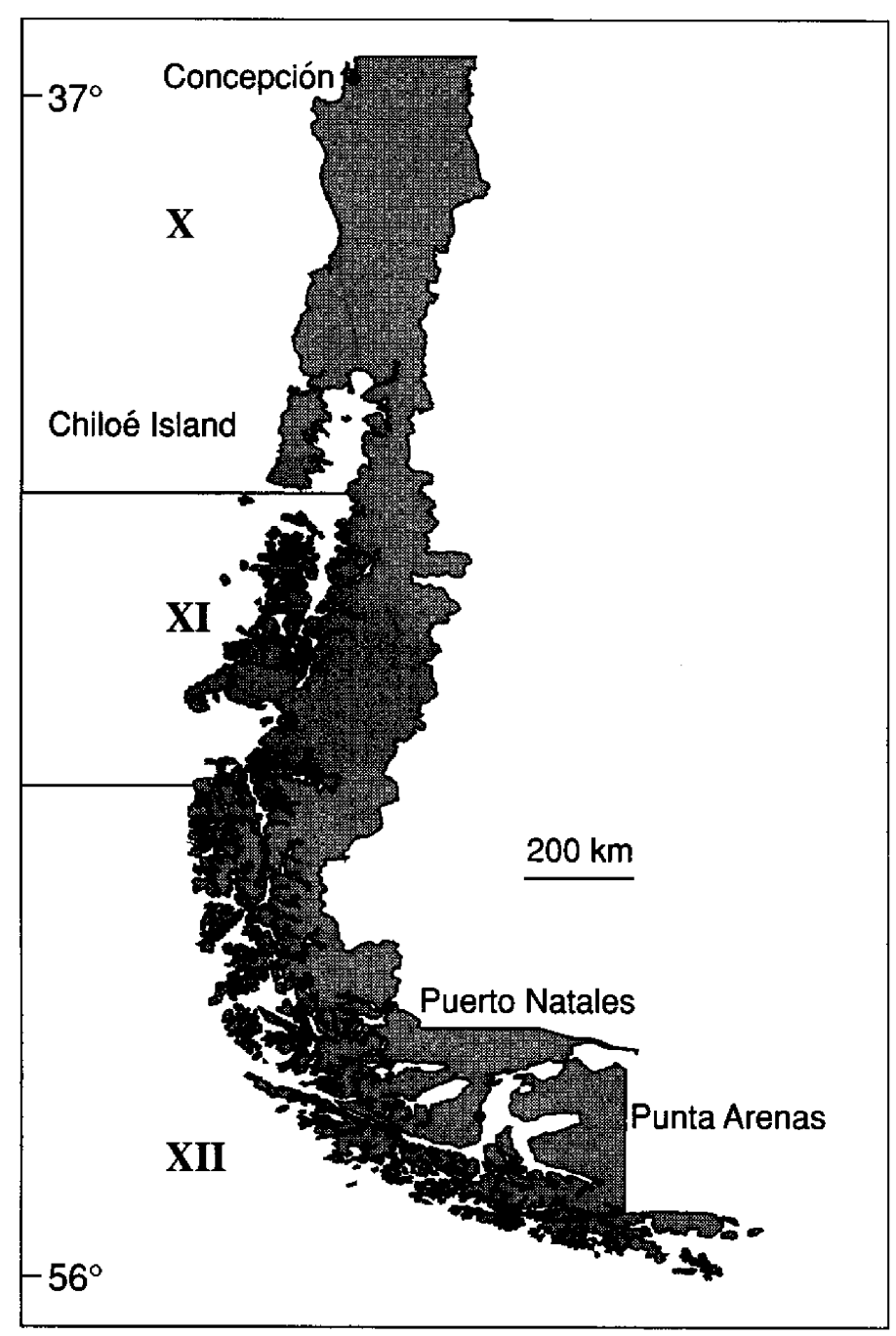

Figure 3 Map of southern Chile showing boundaries of Regions X to XII and important locations.

and probable decline. In the first phase, before $1975,<3000 \mathrm{t} \mathrm{yr}^{-1}$ was caught and sold as fresh roe for the domestic market. Chile is divided into 12 regions, and the most important sea urchin fisheries are in the three most southern regions (X-XII, Fig. 3). Catches were initially concentrated in the south in Region X (Fig. 4) and were taken mostly from the intertidal zone. The only regulation in place during this phase was a MLS of $100 \mathrm{~mm}$, introduced in 1974.

The fishery entered a decade of rapid expansion in 1976 in response to economic policies that promoted exports. Catches grew by $2800 \mathrm{t} \mathrm{yr}^{-1}$ as markets were developed in Asia (principally Japan) for frozen roe and preserved, dry-salted and dehydrated products. The fishery changed markedly as large numbers of new entrants switched from exhausted benthic fisheries in central and northern Chile and diving with surface-supplied air became the predominant method.

Historically, benthic fisheries in Region X, including those for sea urchins, loco (the muricid snail Concolepas concolepas), luga (Iridaea spp.), and bivalves such as huepo (Ensis macha) and culengue (Gari solida), were concentrated in the northern parts of the 


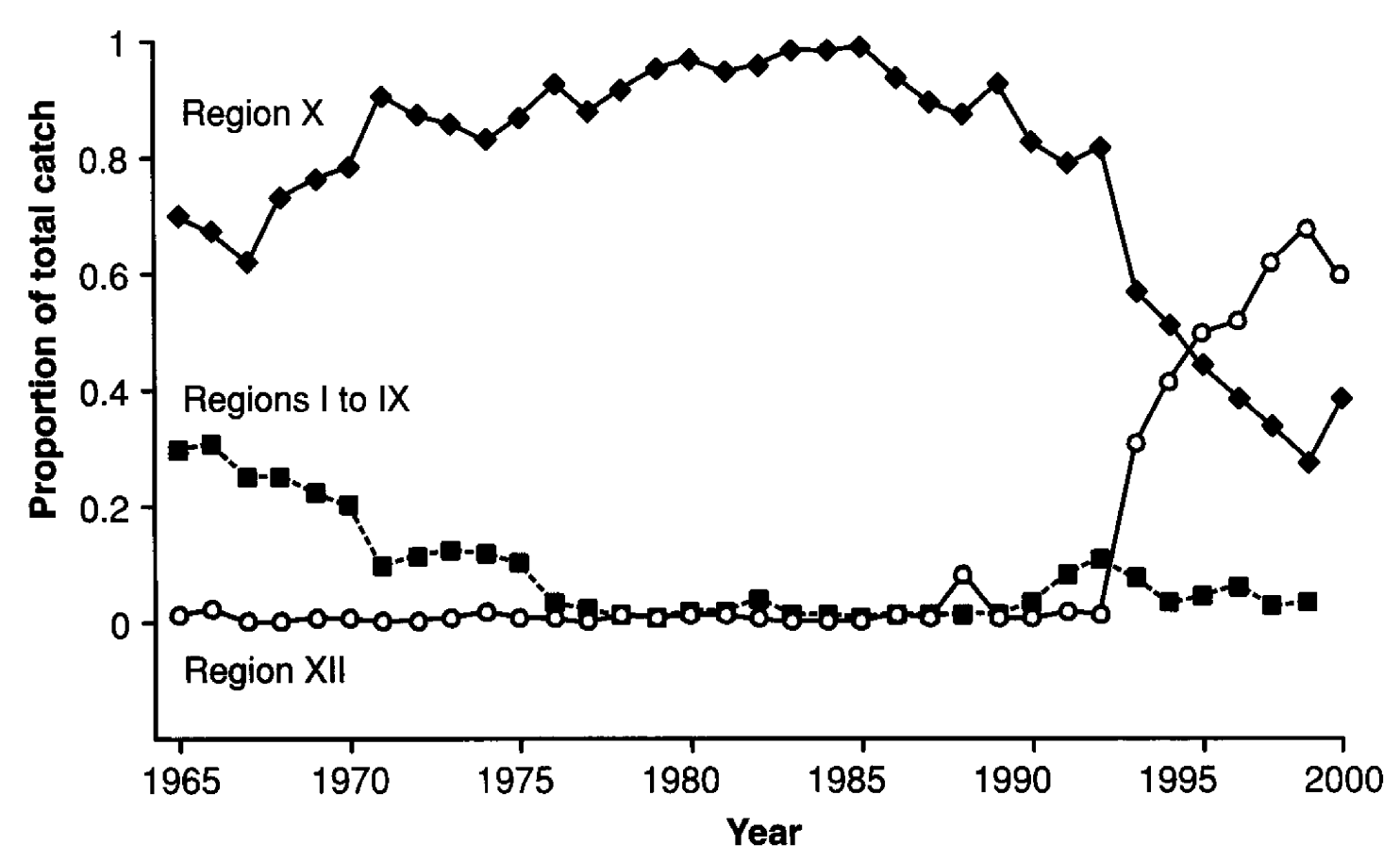

Figure 4 Catch in Regions I-IX, X, and XII as a proportion of total harvest in Chile.

Guaitecas Archipelago and Guafo Island. The main landing port was Quellón, at the end of the Pan-American highway on the southern tip of Chiloé Island. As these resources became depleted, fishing effort moved further south and production from Region X remained high, masking a large-scale decline in the resource. Eventually these areas too were over-fished and the fleet was driven south into Patagonia by falling catches. Processing facilities were established in Punta Arenas (see Fig. 3) and production from Region XII expanded a great deal, driven part by increased profitability of harvesting in remote areas. Sea urchins are now harvested from the full length of the Chilean coastline from the border with Peru to Cape Horn - the fishery is now well into its third phase of development, one of full exploitation and probable decline.

\section{Production}

Although small compared with what it was to become, the Chilean sea urchin fishery in 1976 was one of the world's largest. In the late 1970s and early 1980s the fishery expanded rapidly and peaked in 1995 when Chile produced $54609 \mathrm{t}$ of sea urchins, $45 \%$ of the world's production (Fig. 5). Since then the fishery has declined to $44843 \mathrm{t}$ in 1998 but this still represented half the world's production in that year (Table 2). Before the expansion of the fishery in the 1980s, most harvest came from Region X (>90\% between 1965 and 1999; Fig. 4). Region IX has produced only small quantities (22 $\mathrm{t}$ in $35 \mathrm{yr}$ of fishing) and Region XII produced an average of only $138 \mathrm{t} \mathrm{yr}^{-1}$ before 1993. Landings in Region X peaked in 1985 at $30261 \mathrm{t}$, and have slowly but erratically declined since then (Fig. 4). Between 1965 and 1999, Regions I to IX accounted for less than 4\% of the total harvest. Significant harvests were recorded in Regions I to IV in the 1990s but these were never more than $3050 \mathrm{t}$ per annum and have subsequently declined (Fig. 4). As catches from the southern regions have increased substantially, the significance of Regions I to IX has further declined. 


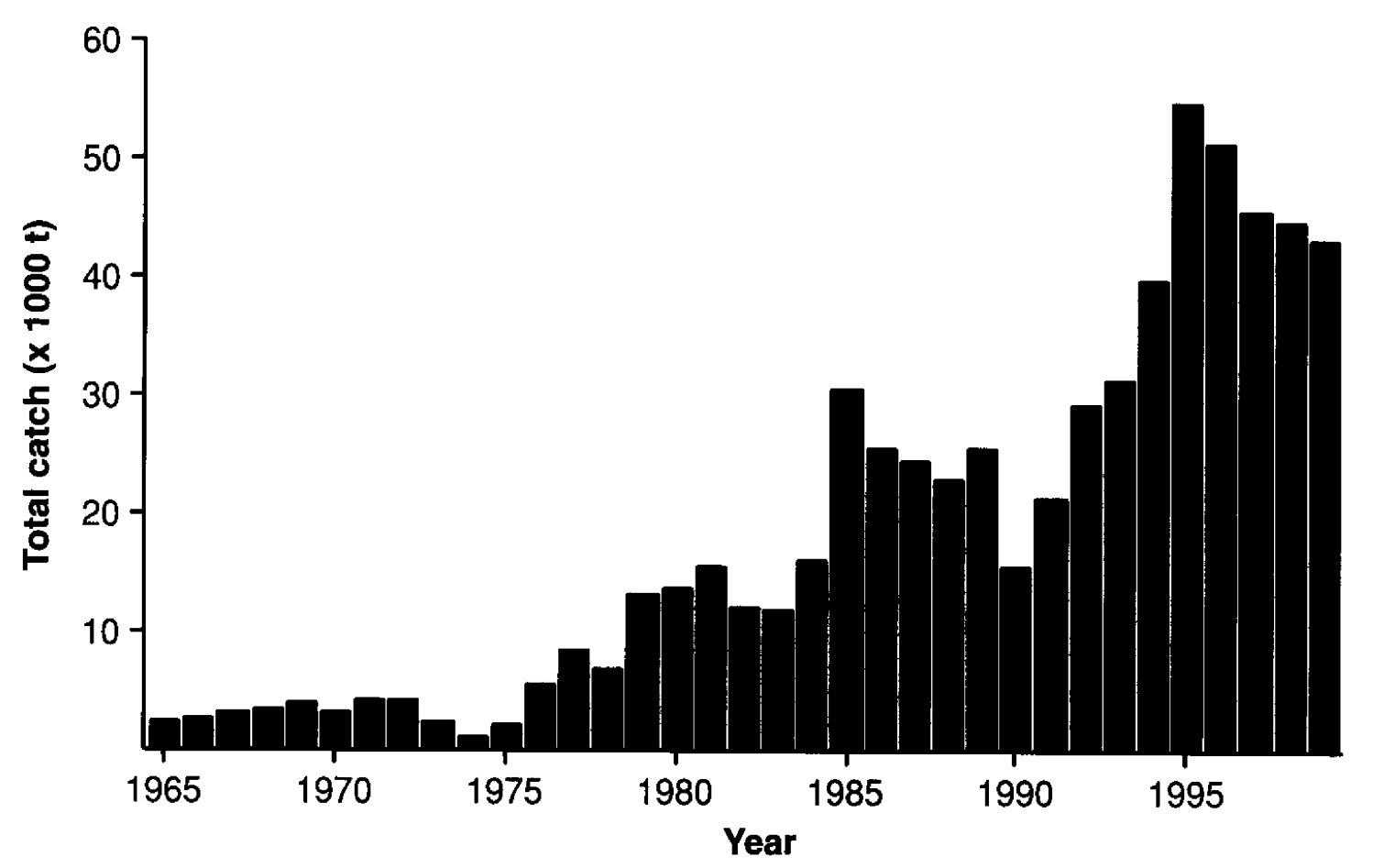

Figure 5 Total catch (t) of sea urchins in Chile.

Driven by declining catches in Regions X and XI, the fishery rapidly expanded into the most southern region, XII, in the mid-1990s (Fig. 4). Catches rose from $287 \mathrm{t}$ in 1992 to 26998 t 3 yr later. In 1999, 7848 registered divers worked in Region XII. As a result of this movement of fishing effort, the proportional contribution of Region $\mathrm{X}$ to the national harvest declined significantly (Fig. 4). In 1999, this trend was reversed for the first time in eight years but it remains to be seen whether this signals a return to previously fished regions. Within Region XII, fishing has radiated out from landing points such as Puerto Natales and Punta Areñas to the more exposed margins of the archipelagos and channels and, by 1999, fishing had extended to the furthermost reaches of the region.

\section{Management}

Management of coastal fisheries in Chile spans the range of management regimes and effectiveness. North of Valdivia, on the exposed coast, the "caleta" system of small-scale co-management has successfully conserved and managed artisanal fisheries for valuable species, including sea urchins. This system grew out of the poor state of Chile's benthic fisheries in the 1980s (Bustamante \& Castilla 1987), recoveries of exploited populations in two small marine reserves in central Chile (Moreno et al. 1984, 1987, Duran \& Castilla 1989) and the success of similar management seen in Japanese coastal fisheries. The 1991 Fisheries Law provided a legal basis for local syndicates of fishers to claim exclusive fishing rights in areas of coastline out to 5 nautical miles from shore. This system transformed the fortunes of near-shore fisheries (Castilla 1994, 2000, see Castilla et al. 1998 for review). Sea urchin fishing in these "Areas of Management and Exploitation" is based on a plan that requires fishers to make six-monthly projections of stock status that are used by the Under-secretary of Fisheries to set a quota for the area. The Fishers' Union then decides how that quota is caught. In December 1999, 184 areas were managed under this system, 
covering a total of 432 ha of near-shore reef. Of these, $57 \%$ contained sea urchins, as well as other sedentary species. Unfortunately, the total area managed this way represents a small fraction of the 73223 ha requested by fishers, and the estimated 4533442 ha available along the coast (Montecinos 2000). In June 2000, there were only 14 caletas in Regions X to XII.

In sharp contrast to this situation, most of the Chilean sea urchin fishery occurs without any effective management. With the large number of artisanal fishers in the sea urchin and other benthic fisheries, there remain few restrictions on fishing for most of the exposed coastline and the more complex coast south of Chiloé Island. There have, nevertheless, been several national management initiatives. These include:

1) Closure of Regions I and III from 1983 to 1987.

2) Creation of a National Register of Fishermen in 1995 and establishment of a moratorium on new entrants to benthic fisheries at that time.

3) Summer closures during the spawning season. The spawning season varies along the long coast of Chile. In the extreme north Loxechinus albus reproduce in the austral spring-summer and possibly autumn, while in the south spawning appears restricted to spring (Gutiérrez \& Otsu 1975, Bückle et al. 1978, Bay-Schmith et al. 1981, Zegers et al. 1983, Zamora \& Stotz 1992).

4) Introduction of a MLS of $100 \mathrm{~mm}$ in 1974, subsequently revised in 1980 and 1986 following estimates of fecundity and the size at maturity. L. albus matures between $40 \mathrm{~mm}$ and $60 \mathrm{~mm}$ (Guisado 1995). A 70-mm MLS, although introduced at the request of fishers has been widely ignored since its introduction; between 1995 and 1998, 27\% of the landed catch was less than the MLS.

The explosive development of the fishery in the south was largely unregulated. The introduction of fishery regulations on a national level (e.g. MLS and diver registration) have not constrained fishing effort or catch. The absence of reliable indices of abundance or fishery-derived data means that there is little information that can be used to improve management. Most important, there is no information on the replenishment of populations after fishing nor on the ecological effects of removing such a large biomass of herbivores. Although the area-based management developed for the central and northern regions of the fishery allows sustainable use there, it is inappropriate south of Chiloé Island, where the fishery is now concentrated. New and innovative management will be required to ensure the future of this fishery.

\section{Japan}

\section{The Fishery}

Sea urchin tests have been excavated from middens in Japan from the Jomon and Yayoi Neolithic periods, extending from at least 8000 BC to AD 200. Sea urchins or "gaze" were first recorded as foods in AD 833 in the "Ryonogike", an annotated edition of "Yoryo ritsuryo", a law enforced in AD 757 (Kawamura 1969). According to Kinoshita (1955), commercial sea urchin fisheries in Hokkaido began on the coast of the Sea of Japan between 1877 and 1886 but landings remained small for the next $50 \mathrm{yr}$. In 1932, the Rishiri Fisheries Co-operative Association in northern Hokkaido began buying sea urchins to 
Table 3 Species harvested and catch (t) in 1997 by prefecture. Abbreviations are: $\mathrm{Si}=$ Strongylocentrotus intermedius, $\mathrm{Sn}=S$. nudus, $\mathrm{Hp}=$ Hemicentrotus pulcherrimus, $\mathrm{Pd}=$ Pseudocentrotus depressus, $\mathrm{Ac}=$ Anthocidaris crassispina and $\mathrm{Tg}=$ Tripneustes gratilla .

\begin{tabular}{llllll}
\hline Prefecture & Catch (t) & Species & Prefecture & Catch (t) & Species \\
\hline Hokkaido & 6541 & $\mathrm{Si}, \mathrm{Sn}$ & Okinawa & 87 & $\mathrm{Tg}$ \\
Nagasaki & 1287 & $\mathrm{Hp}, \mathrm{Pd}, \mathrm{Ac}$ & Fukushima & 81 & $\mathrm{Sn}$ \\
Iwate & 1205 & $\mathrm{Si}, \mathrm{Sn}$ & Kochi & 54 & $\mathrm{Ac}$ \\
Miyagi & 1013 & $\mathrm{Sn}$ & Tottori & 50 & $\mathrm{Hp}, \mathrm{Pd}, \mathrm{Ac}$ \\
Aomori & 718 & $\mathrm{Si}, \mathrm{Sn}$ & Akita & 24 & $\mathrm{Sn}$ \\
Kagoshima & 446 & $\mathrm{Hp}, \mathrm{Pd}, \mathrm{Ac}$ & Fukui & 21 & $\mathrm{Hp}, \mathrm{Ac}$ \\
Yamaguchi & 441 & $\mathrm{Hp}, \mathrm{Pd}, \mathrm{Ac}$ & Kyoto & 20 & $\mathrm{Hp}, \mathrm{Pd}, \mathrm{Ac}$ \\
Miyazaki & 231 & $\mathrm{Ac}$ & Mie & 18 & $\mathrm{Hp}, \mathrm{Pd}$ \\
Kumamoto & 221 & $\mathrm{Hp}, \mathrm{Pd}, \mathrm{Ac}$ & Wakayama & 14 & $\mathrm{Pd}, \mathrm{Ac}$ \\
Fukuoka & 219 & $\mathrm{Hp}, \mathrm{Pd}, \mathrm{Ac}$ & Ishikawa & 9 & $\mathrm{Ac}$ \\
Hyogo & 214 & $\mathrm{Pd}, \mathrm{Ac}$ & Chiba & 7 & $\mathrm{Pd}$ \\
Ehime & 187 & $\mathrm{Hp}, \mathrm{Pd}, \mathrm{Ac}$ & Niigata & 7 & $\mathrm{Sn}, \mathrm{Pd}$ \\
Saga & 162 & $\mathrm{Hp}, \mathrm{Pd}, \mathrm{Ac}$ & Yamagata & 7 & $\mathrm{Sn}$ \\
Tokushima & 138 & $\mathrm{Hp}, \mathrm{Pd}, \mathrm{Ac}$ & Ibaragi & 3 & $\mathrm{Sn}$ \\
Oita & 123 & $\mathrm{Hp}, \mathrm{Pd}, \mathrm{Ac}$ & Kanagawa & 3 & $\mathrm{Pd}$ \\
Shimane & 99 & $\mathrm{Hp}, \mathrm{Pd}, \mathrm{Ac}$ & Aichi & 2 & $\mathrm{Pd}$ \\
\hline
\end{tabular}

protect the fishery for the kelp Laminaria ochotensis and roe processing began the following year. Landings increased during the 1930 s to about $1000 \mathrm{t}$ and increased further following World War II as the fishery expanded into new areas. Similar increases in production occurred in other prefectures and Japan's sea urchin fisheries developed to become the largest in the world prior to 1985. Sloan (1985) reviews much of the early literature on the Japanese sea urchin fishery. There are no recreational fisheries for sea urchins in Japan.

Six species: Strongylocentrotus intermedius, S. nudus, Hemicentrotus pulcherrimus, Pseudocentrotus depressus, Anthocidaris crassispina and Tripneustes gratilla account for most of commercial landings in Japan (Table 3). A further nine species are consumed but catches are small and restricted to local areas (Kawamura 1993). Sea urchins are harvested by diving, wading, scoop nets, hooks, and spears. In western Honshu and Kyushu, women divers (known as "ama") collect sea urchins using breath-hold diving; in other regions where there are substrata with very little relief, nets, beam trawls and other indirect methods are used. On the Hidaka coast, Strongylocentrotus intermedius is harvested from the intertidal zone using a net which entangles sea urchins as it is dragged along the bottom. In deeper waters $(>7 \mathrm{~m}$ ) off the coast of Aomori, $S$. nudus is harvested using traps baited with algae.

The Japanese market prefers firm roe so all fisheries are closed during the spawning season. These closures differ in their timing and duration and are based on an extensive understanding of the reproductive biology of harvested species (Fig. 6). For example, $S$. intermedius in Hokkaido spawns in the Sea of Japan in autumn, in Funka Bay in spring and autumn and in the Okhotsk Sea and the Pacific Ocean, over a long period from spring to autumn (Fig. 7). These differences have been attributed to genetic differences between populations (Agatsuma 2001a). Fishing along the coast of the Japan Sea, and western Tsugaru 


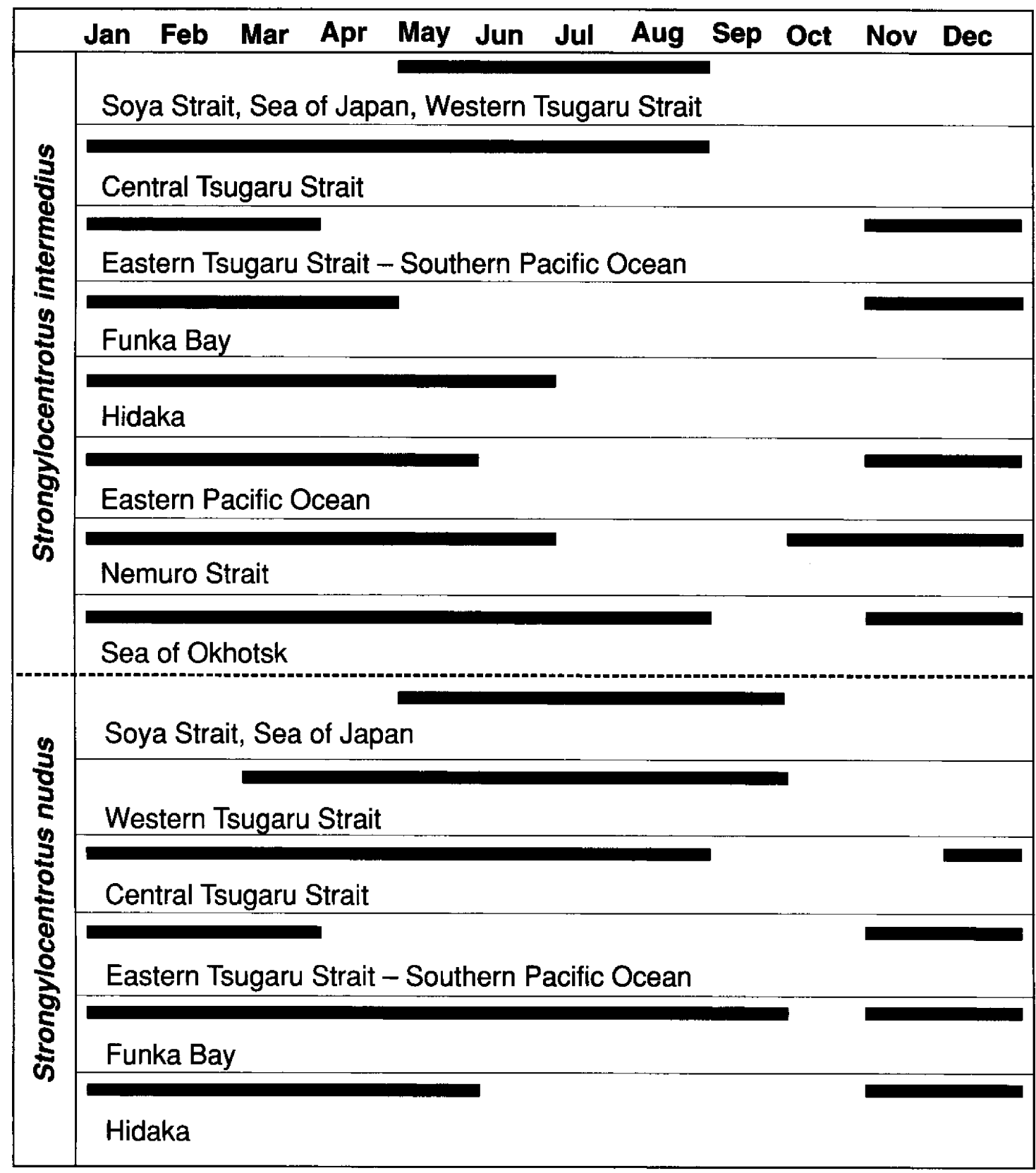

Figure 6 Fishing seasons (dark bars) and season closures for sea urchin fishing in Hokkaido.

Strait is restricted to May-August. At other localities in Hokkaido, harvesting is during winter to spring (Agatsuma 2001a).

The spawning season of $S$. nudus appears to be less dependent on oceanographic conditions and occurs during September-October throughout Hokkaido (see Agatsuma 2001b for review). Fishing is restricted to July-August except in the Tsugaru Strait and the Pacific Ocean where roe recovery is rapid (possibly because of abundant large brown algae) and the fishing season is closed until spring (Fig. 6). S. nudus are caught in April to August in Aomori, Iwate and Miyagi Prefectures (Kawamura 1993). Fishing seasons for Hemicentrotus pulcherrimus, Pseudocentrotus depressus and Anthcidaris crassispina are similarly based on the annual reproductive cycles (Nakamura \& Yoshinaga 1962, Kawamura 1993, Agatsuma 2001c). 


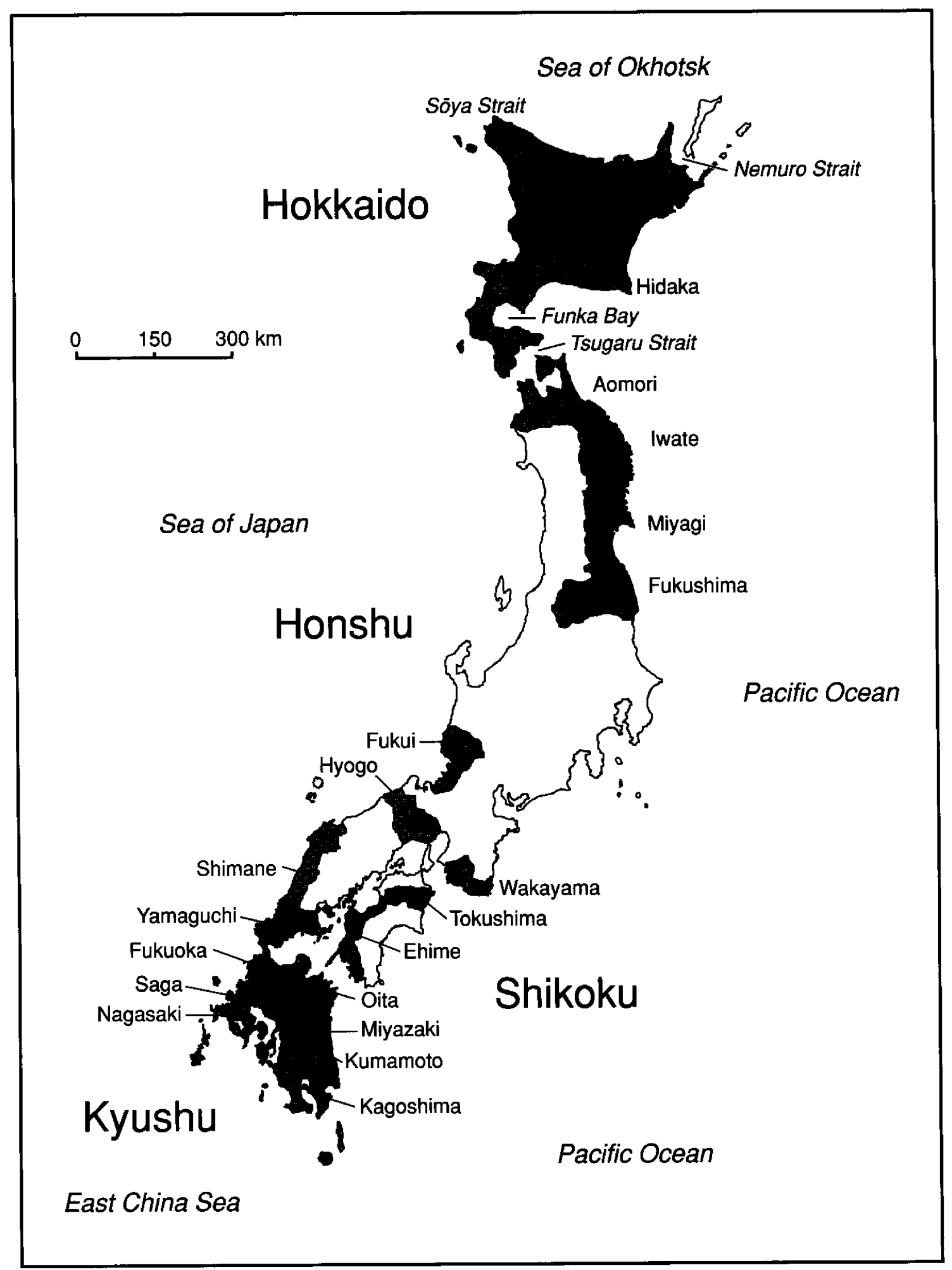

Figure 7 Map of Japan showing the major islands and most important sea urchin-producing prefectures.

\section{Production}

Total landings in Japan increased from $7200 \mathrm{t}$ in 1953 to a peak of $27528 \mathrm{t}$ in 1969 then catches fluctuated between $23000 \mathrm{t}$ and $27000 \mathrm{t}$ until 1987 when landings began to decline (Fig. 8). Catches during the 1990s fluctuated between $13000 \mathrm{t}$ and $15000 \mathrm{t}$. Sea urchin 


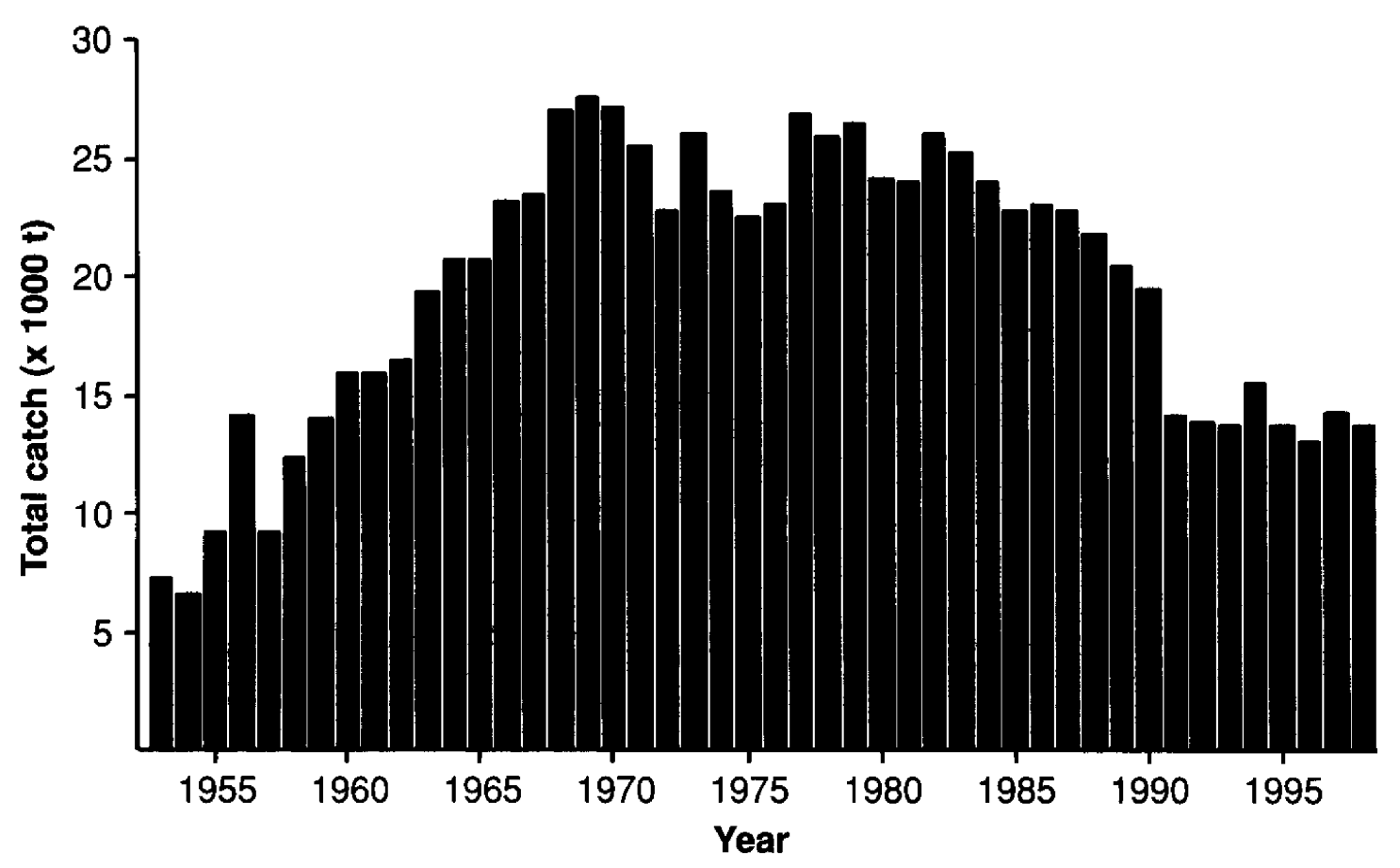

Figure 8 Total catch ( $\mathrm{t}$ ) of sea urchins in Japan (all species and prefectures).

fisheries are concentrated in Hokkaido, in northern prefectures facing the Pacific Ocean on Honshu, and to a lesser extent on Kyushu in southern Japan (Fig. 7, Table 3). Hokkaido accounted for $48 \%$ of the total landings in 1997 (Table 3). Catch statistics are generally not available by species but some reconstruction is possible given the disjunct distributions of several species. Strongylocentrotus intermedius is harvested from Hokkaido and the Pacific coast prefectures of Aomori and Iwate, while fisheries for $S$. nudus extend further south to Ibaragi on the Pacific coast and Yamagata prefecture in the Sea of Japan (see Agatsuma $2001 \mathrm{a}, \mathrm{b}$ for reviews). All of the landings from Hokkaido and the northern prefectures of Aomori, Akita, Iwate, Miyagi, and Fukushima are Strongylocentrotus spp. and together these accounted for $70 \%$ of national landings in 1997. Catches from prefectures on southern Honshu, Shikoku and Kyushu comprise a mixture of species: Hemicentrotus pulcherrimus, Pseudocentrotus depressus and Anthocidaris crassispina predominate. Tripneustes gratilla is landed only in Okinawa where $87 \mathrm{t}$ (6.3\% of national production) was landed in 1997. Landings in the southern prefectures have nearly halved since 1985 (Fig. 9).

Catches in Hokkaido began to decline in the mid-1980s, fell sharply between 1988 and 1991 (Fig. 10), then stabilised and increased in the latter half of the 1990s. Most of this harvest was Strongylocentrotus intermedius and the declines (in roe weight) were principally from this species (Fig. 10). Harvests of $S$. nudus roe followed a similar but less marked decline and recovery during this period. With the decline in landings of $S$. intermedius in Hokkaido (Fig. 10), S. nudus is now the most important species in Japan: the ratio of $S$. intermedius to $S$. nudus has changed from $4: 1$ in 1966 (Kawamura 1969) to $1: 1$ or less since 1990. S. nudus is the only species harvested in Miyagi and Fukushima. Landings in Miyagi have slowly declined over the last $20 \mathrm{yr}$ and $1013 \mathrm{t}$ whole weight was landed in 1998 - approximately $40 \%$ of that caught in 1982 (Fig. 11). Catches in Fukushima are considerably smaller and there is no consistent trend in landings in the last $20 \mathrm{yr}$ (Fig. 11). 


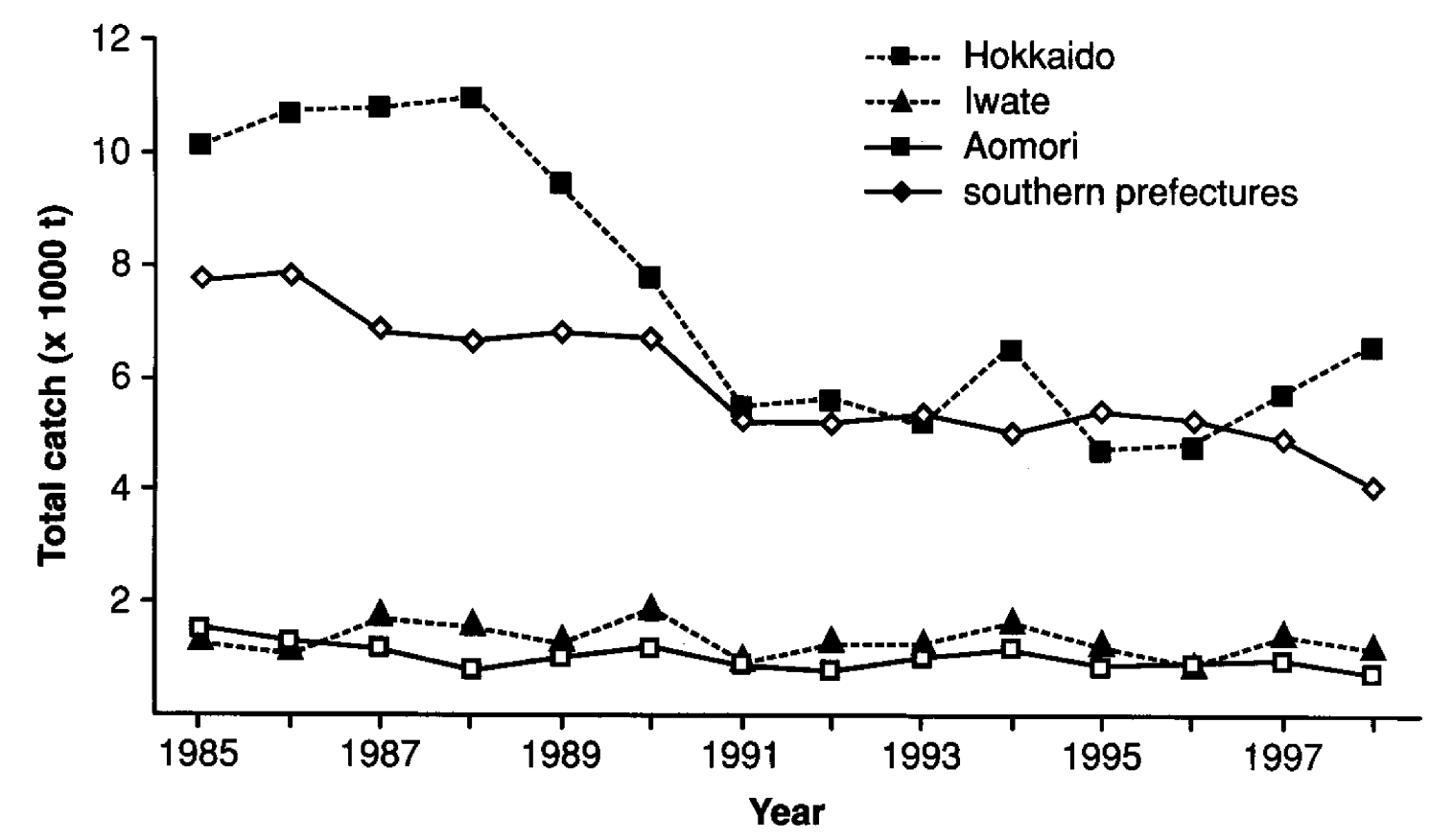

Figure 9 Total catch (t) of sea urchins (all species) from major prefectures in which more than one species is harvested, and the combined catch in prefectures south of Fukushima.

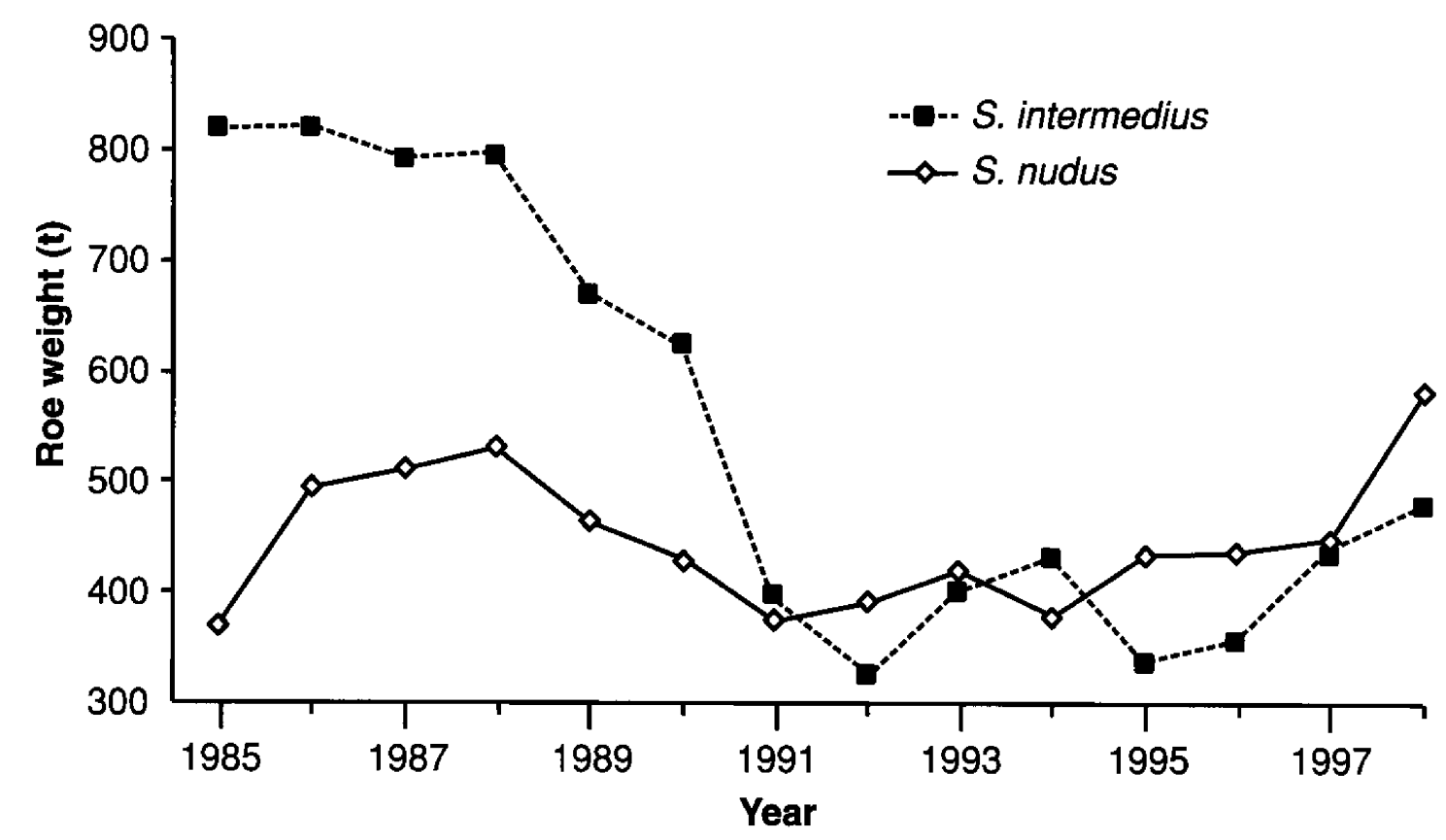

Figure 10 Harvest (t roe weight) of Strongylocentrotus intermedius and S. nudus in Hokkaido.

\section{Management}

Current management of coastal fisheries in Japan may be traced to the 1948 Fisheries Cooperative Association Law and the Fisheries Law of 1949 (see Ruddle 1987 for an English language summary). These laws amended and extended a 1901 statute that provided exclusive fishing rights to associations of fishers, which in turn was derived from the system of village guilds that managed fishing rights and privileges bestowed by feudal lords in earlier times (Ruddle 1987, Lim et al. 1995). The Fisheries Law cedes a property right to prescribed 


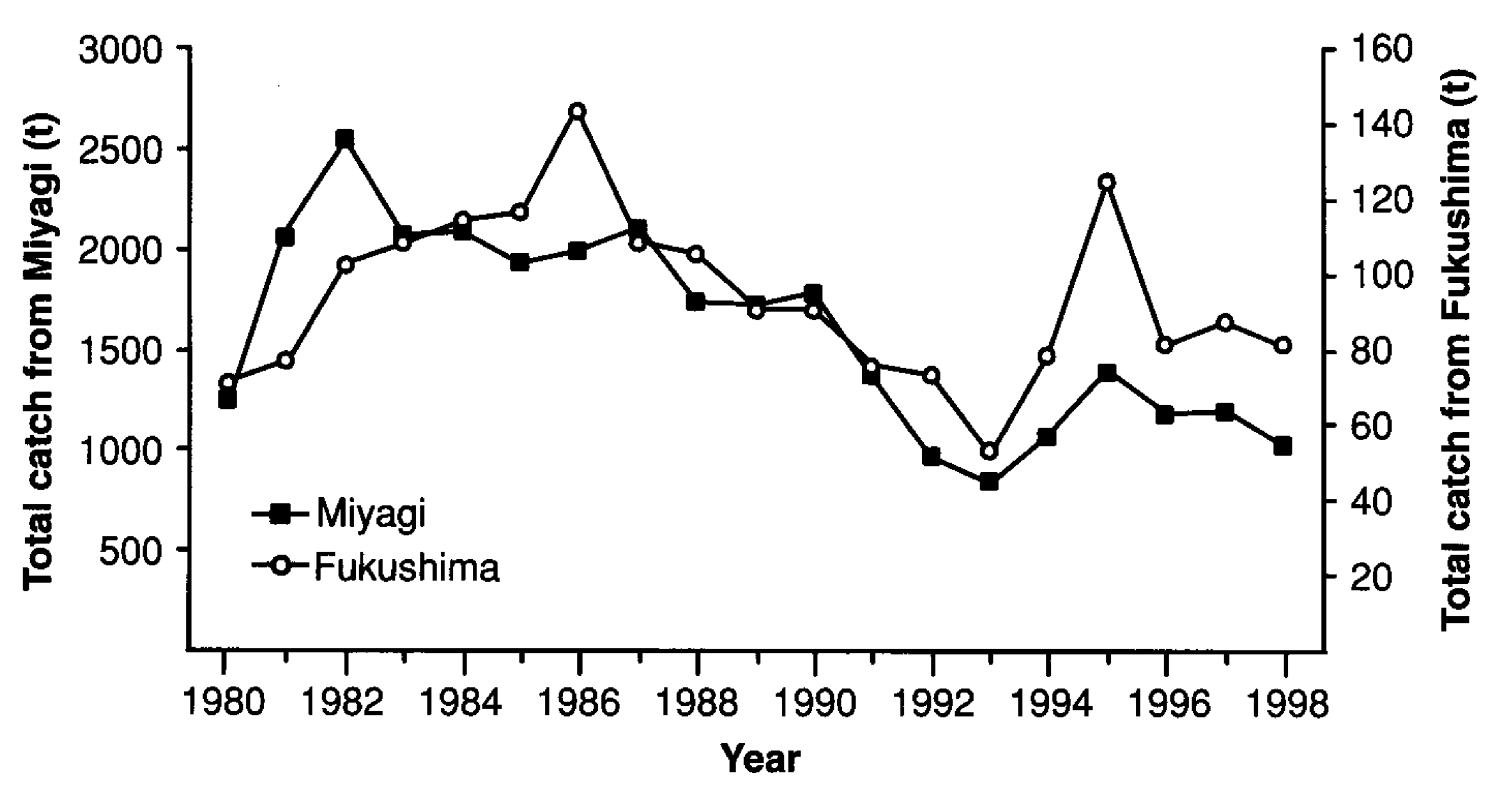

Figure 11 Total catch $(\mathrm{t})$ of Strongylocentrotus nudus in Miyagi and Fukushima prefectures.

areas of sea bed to Fisheries Co-operative Associations (FCAs) which in turn distribute fishing rights to individuals, such as "territories", daily catch limits, and the timing and duration of fishing trips. In addition to ownership of these resources (there is no legal distinction between tenure over land or sea floor), a web of interdependencies ("mutual help") and codes of conduct binds fishers and communities together (Ruddle 1987, Lim et al. 1995). Fishing rights are not tradable in a western sense but can be inherited or transferred in other ways although generalisations are impossible given the complexity of local customs and laws (Ruddle 1987). The 1974 Coastal Fishing Ground Improvement and Development Law provides the basis for stock enhancement in Japan and is pivotal in developing management policy (see pp. 393-397).

Government has considerable involvement in the management of coastal fisheries, particularly in providing subsidies for enhancement and infrastructure development and has an overall responsibility for co-ordinating management among Associations. The most important means for government involvement are "Sea Area Fisheries Adjustment Commissions" (SAFAC) which are composed of the relevant FCAs within a prefecture and two tiers of government - municipal and prefectural (Ruddle 1987). For each prefecture (or management area in Hokkaido), a plan for fishing within each "sea area" is developed, and includes resource management guidelines and policies such as MLSs, closed areas and seasons, method restrictions and so on. It is the responsibility of the Prefectural Fisheries Agency to establish those plans, which are interpreted and implemented by each FCA. In Hokkaido, for example, the prescribed MLS for $S$. nudus and $S$. intermedius have been increased from $40 \mathrm{~mm}$ and $50 \mathrm{~mm}$, respectively, in $49 \%$ and $25 \%$ of FCAs. Similarly, in Hokkaido, about one half the FCAs impose a daily catch limit on members for harvesting $S$. intermedius and $44 \%$ limit the daily harvest of $S$. nudus. Most FCAs restrict fishing to $2-5 \mathrm{~h} \mathrm{day}^{-1}$ ( $73 \%$ and $91 \%$ of FCAs limit fishing for the two species, respectively). TACs are much less popular and are imposed by less than $10 \%$ of FCAs. Because the FCAs manage all fishery resources within their sea area, management of sea urchins is integrated with that of other resources, such as seaweeds and abalone, and FCAs will often intervene to "manage" ecological relationships (e.g. crabs and sea stars are removed from reefs in $40 \%$ of FCAs). 
The persistence of Japan's sea urchin fisheries under the current management regime for more than fifty years attests to both the durability of the resource and the efficacy of management. However, production has declined in the last $20 \mathrm{yr}$ and in several of the more important prefectures. Japan is increasingly reliant on imports to satisfy its huge demand. Japan was overtaken as the world's largest producer of sea urchins in the mid-1980s by Chile in 1985 and USA in 1987 (it regained its rank behind Chile in 1998 because of sharp declines in the Maine fishery). Much of the reduction in catches stems from declines in the $S$. intermedius fishery in Hokkaido and that for $S$. nudus in Miyagi. Despite these long-term declines, no formal assessments of the status of stocks in any region or prefecture have been reported in the scientific literature. It is difficult to find evidence in the published literature of catch or effort restrictions in the face of declining catches. Enhancement is one of the most important management tools used to conserve and rebuild Japanese sea urchin fisheries (see pp. 393-397).

\section{Maine (USA)}

Sea urchins have been fished in Maine since at least 1929. Before the 1970s, catches were shipped to major cities on the eastern seaboard to supply the domestic market and catches remained less than $100 \mathrm{t}$. The fishery began in earnest in 1987 to supply processed roe to Japan and quickly became the world's largest fishery for $S$. droebachiensis. The fishery grew rapidly from 1987 to a peak of $17821 \mathrm{t}$ in 1992-93, then just as rapidly declined to less than a third of this size in 1999-2000 (Fig. 12). The fishery is divided into two zones for

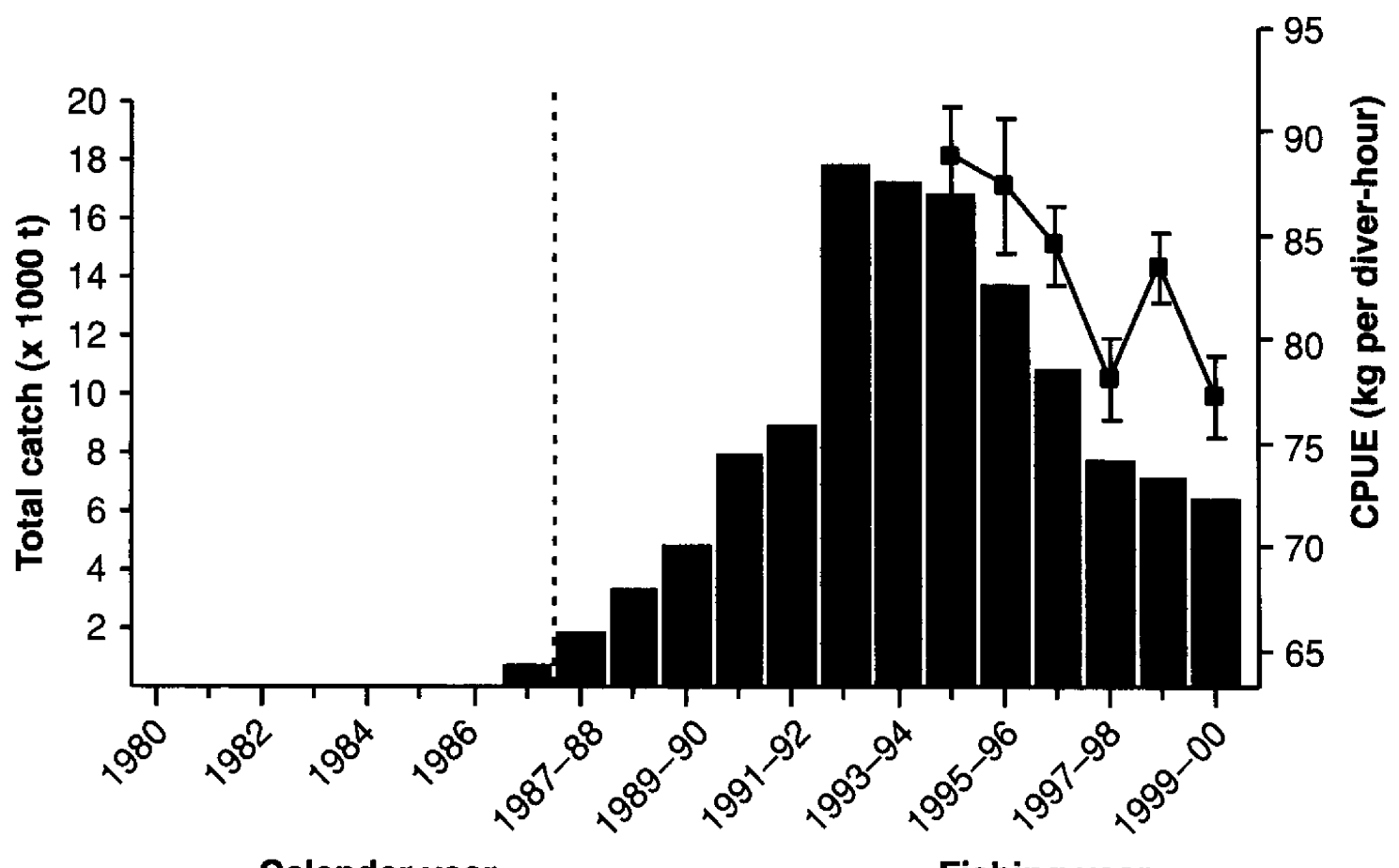

Calendar year

Fishing year

Figure 12 Total catch ( $\mathrm{t}$, bars) and catch rates (mean $\mathrm{kg}$ diver- $\mathrm{h}^{-1} \pm$ S.E., line) of sea urchins in Maine between 1980 and 2000 . Note change from calendar year to fishing year in 1988 . 


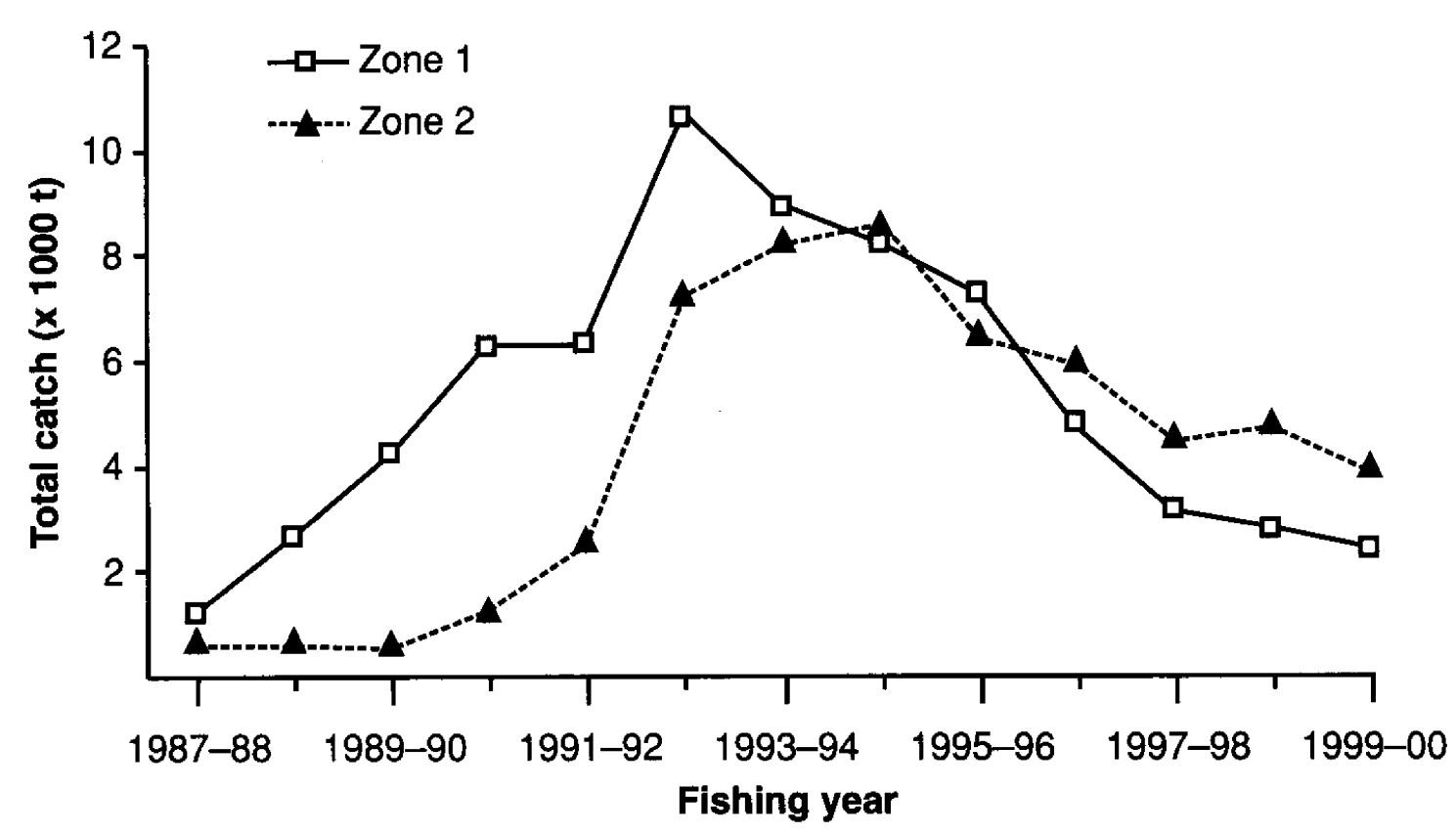

Figure 13 Total catch ( $t$ ) of sea urchins from Maine by zone between 1987-88 and 2000-01.

management purposes: southwest (Zone 1) and the northeast (Zone 2), divided at western Penobscot Bay. Zone 1 was the more important of the two for the first eight years of the fishery; the northeast zone now accounts for $61 \%$ of total catch (Fig. 13). Between 1994 and 1999 , mean catch rate of divers fell by $13 \%$, despite a $62 \%$ decline in catch (Fig. 12). Mean catch rates have fallen the most in Zone 2, but have also declined consistently in Cumberland County in Zone 1. Although mean catch rates in all counties in Zone 1 recorded in 1999-2000 are lower than those in 1994-95, they have fluctuated considerably among years.

In part, the designation of two zones was based on the reproductive and spawning cycle along the coast of Maine. Spawning can begin as early as February-March in the southwest and as late as May-June in the northeast. Typically, the major spawning periods are MarchApril and April-May, respectively, for the two zones (Vadas et al. 1997, Vadas \& Beal 1999). Following spawning there is a recovery of the gonad index to a baseline level (about $5 \%$ ), which is maintained throughout the summer. Recovery to harvestable levels (about $10 \%$ ) begins in early fall and accelerates in late fall. Until regulations were imposed, harvesting occurred from early August to June and essentially ignored the biological cycle of the species.

Divers using SCUBA catch approximately $80 \%$ of the total harvest, most of the remainder is caught using drags, and a very small amount (13 $t$ in 1999-2000) is caught using rakes in the intertidal zone. In 1999-2000 there were 339 draggers in the fishery, working mostly in the northeast of the State where the large Bay of Fundy tides make diving difficult. The average tows lasts 7 to $9 \mathrm{~min}$, typically in water between $5 \mathrm{~m}$ and $20 \mathrm{~m}$ deep. Four types of drags are commonly used, the most primitive of which, the "chain sweep", is a modified scallop dredge (Creaser \& Weeks 1998, Wahle 1999). Derivatives of this design have been developed specifically for sea urchins and are of lighter construction. Recently, dragging has accounted for a greater proportion of the total catch, increasing from $16.7 \%$ in 1997 to $20.6 \%$ in 2000 , reflecting a shift in the fishery from the southwest to the northeast. 


\section{Management}

In its early years, the Maine sea urchin resource was considered inexhaustible and the fishery developed rapidly, unfettered by management until 1992. Growing concerns about over-harvesting in that year prompted legislation and regulations that limited access to the fishery to licensed harvesters and restricted their methods. This constraint did little to limit fishing effort and the number of licensed harvesters increased rapidly, from 1075 in 1992 to 2725 in 1994. A perceived decline in the stock prompted more legislation and Department of Marine Resources regulations in the following years. Management of this fishery is based on restricting fishing effort; no limits are placed on individual or total catch. After the introduction of licenses failed to reduce fishing effort, a three-year moratorium on the issue of new permits was introduced in 1995. The moratorium was then replaced with a limited entry scheme that requires five licenses to be retired for each new entrant. In 2000, 1040 fishers were licensed to harvest sea urchins in Maine.

Other regulations included the restriction of drag width, banning night-time fishing, the creation, in 1994, of two zones that limit fisher's mobility, fishing seasons, and a MLS of 2 in $(51 \mathrm{~mm})$ introduced in 1993. In 2000-01, a MxLS of $3.5 \mathrm{in}(89 \mathrm{~mm})$ was introduced, then reduced to 3 in $(77 \mathrm{~mm})$ shortly thereafter. Six small areas, each extending along approximately $300 \mathrm{~m}$ of coastline were closed to fishing in 1999 to provide unfished reference sites for research. There are no marine reserves or other protected areas in Maine. An Industry Council was established in 1996 to advise on fishing seasons and its role was expanded in 1997 to consider all fishery-related issues. Virtually all new management initiatives have come from this Council.

The fishery in 1999-2000 was less than a third of the peak size. Trends in catch and effort perceived by the Industry Council and from preliminary analyses by the Department of Marine Resources provide evidence that the resource is in decline. In the absence of a formal stock assessment it is difficult to determine whether the current, diminished catches are sustainable or whether the decline in catch represents the "fishing down" of accumulated biomass. Reliance on fishery-derived information such as catch rates is risky as they are difficult to interpret. There have been many fishery-independent surveys of sea urchins in Maine (see Steneck 1997 for review), but their coverage is uneven and results have not been used in an assessment of the fishery.

In autumn 1999, harvesters reported an extensive mortality of legal-sized sea urchins in shallow water along the western end of the northeast zone (Zone 2). This event coincided with abnormally high water temperatures and the bloom of a common non-toxic dinoflagellate. A lesser mortality was reported in the autumn of 2000, east of the previous year's event, also in a year of unusually warm water. Its appearance was similar to those observed in Nova Scotia, but tests for Paramoeba invadens, the causative organism there, were negative (M. Hunter unpubl. data). The cause, areal extent and effect of the mortality on the fishery remain poorly understood.

Another potential industry concern is the presence of two growth forms of sea urchins in Maine. In one of two intensively studied populations, a slow growth morph has been identified growing sympatrically with the normally faster growing form in shallow subtidal waters (Vadas et al. 2001). The fast growing form lives $16-20 \mathrm{yr}$ and grows to the MLS in 4-6 yr, whereas the slow morph lives 8-12 yr and does not attain legal size. Both forms reproduce and therefore can be acted on by selection. Continued harvesting could select against the 
fast morph. The distribution and abundance patterns of the slow morph are unknown at present.

The wealth of information available on the ecology of shallow subtidal reefs in the Gulf of Maine, and the biology of important species there, provide a good basis for improved management of the Maine fishery. Refinements to the current management regime, such as further effort reductions and changes to the seasons and MLS (Vadas \& Beal 1999) may offer some prospect of improving the fishery but given the apparent large-scale changes in the ecology of reefs in the Gulf of Maine more radical approaches may be required. Co-management of the lobster and sea urchin fisheries by maintaining a mosaic of kelp forests and barrens habitats (Steneck 1997) may offer a better prospect of sustaining the sea urchin fishery. Such an approach to management would require the active co-operation of the fleets and closure of significant areas of coastline. In any event, a formal stock assessment, using all available information, would provide the necessary catalyst and foundation for change.

\section{British Columbia (Canada)}

Three species of sea urchin have been harvested in British Columbia - the first and most important is the red sea urchin, Strongylocentrotus franciscanus. A fishery for the green sea urchin $S$. droebachiensis, began in 1987. Small catches of the purple sea urchin S. purpuratus were recorded in the early 1990s but there is now no fishery for this species. Commercial harvesting for all species has always been by diving only. There are both First Nation and recreational harvests for red and green sea urchins. Each year, $2 \%$ of the province-wide TAC for red sea urchins is allocated to First Nations for social, food and ceremonial purposes. For management, the coastline of British Columbia is divided in two at Cape Caution, just north of Vancouver Island. The North Coast extends from Cape Caution to Alaska and the South Coast from Cape Caution to the border with Washington.

\section{Strongylocentrotus franciscanus}

Red sea urchins were first harvested in the 1970s (Breen 1979, Campbell \& Harbo 1991, Campbell et al. 1999). The fishery remained small ( $<500 \mathrm{t})$ until 1983 , then catches steadily increased until the early 1990s when catches doubled (Fig. 14). Initially, the fishery operated inside Vancouver Island but in 1986 catches were recorded on the North Coast. Landings peaked in 1992 when $13499 \mathrm{t}$ was landed, 85\% from the North Coast. In subsequent years catches have slowly declined, in large part because of the introduction and subsequent reductions of TACs.

The fishery was unrestricted until 1991 when participation was limited and nearly half the divers were removed from the fishery. In the late 1980s regulation became more complex and that used on the North and South coasts diverged. On the South Coast annual catch was limited by a largely arbitrary TAC, divided among small areas. Fishing was restricted to four days per week. On the North Coast an experimental rotational fishing regime was implemented, but after large catches in 1992 this was supplemented with an arbitrary competitive TAC.

The over- and under-catching of the TAC that was a problem through much of the 1990s has diminished as the industry matured and assessments improved. Rotational fishing was 


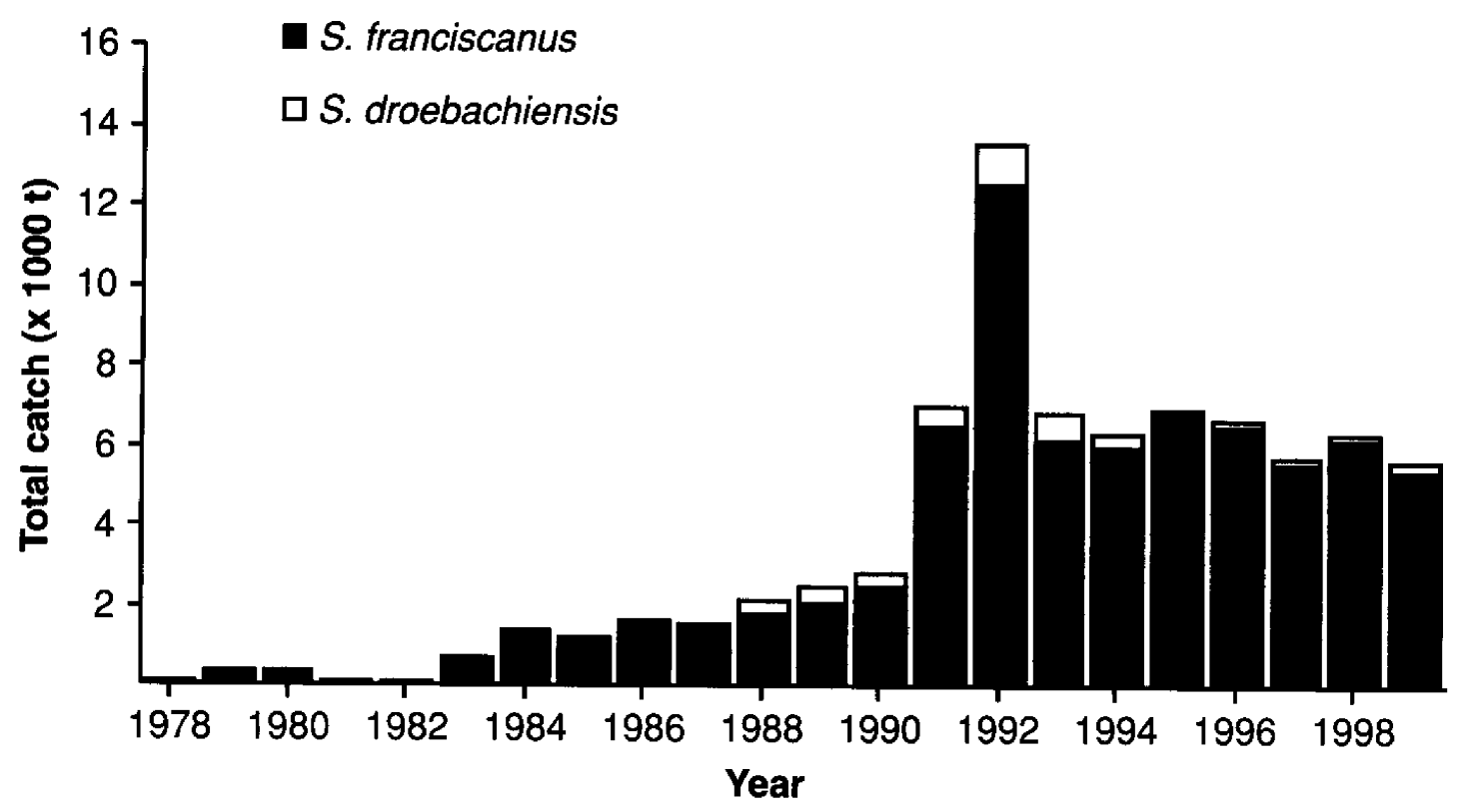

Figure 14 Total catch (t) of sea urchins by species in British Columbia.

retained in both regions and refined as knowledge of the resource grew. The two regions were formalised in 1994 and divers were required to choose between them. The province-wide $\mathrm{TAC}$ in 1996 was then equally apportioned among the 110 license holders remaining in the fishery, resulting in $81 \%$ of the catch being allocated to the North Coast and the remainder to the South Coast. A 100-mm MLS was introduced in 1987 to allow sea urchins to spawn 3-6 times before entering the fishery. In 2000, a trial reduction in MLS to $90 \mathrm{~mm}$ was implemented because of a market preference for 90 to $120-\mathrm{mm}$ sea urchins, accompanied by a $12 \%$ cut in the TAC as a precautionary measure. A MxLS of $140 \mathrm{~mm}$ was implemented in 1988 but abandoned in 1993.

\section{Strongylocentrotus droebachiensis}

In 1987, green sea urchins (S. droebachiensis) were also harvested (Harbo \& Hobbs 1990). Although catches of this species were much smaller than for the red sea urchin, they also peaked in 1992 at 1019 t (DFO 1999, Perry \& Waddell 1999). Annual landings then declined to only $88 \mathrm{t}$ in 1995; after introduction of a TAC they stabilised at around $160 \mathrm{t}$. Poor and inconsistent roe quality has hampered development of the green sea urchin fishery (Perry \& Waddell 1999). Green sea urchins larger than the MLS of $55 \mathrm{~mm}$ are harvested during winter from the South Coast. Green sea urchins from the north of the province have had poor roe and in 1997 the North Coast was closed to fishing except under exploratory permit.

Since 1995, the total harvest has been capped by a single TAC. In 1999 the assessments were refined and the fishery is now managed as four stocks based on known patterns of water circulation and the larval biology of $S$. droebachiensis (Perry \& Waddell 1998, Perry et al. 1998). Of the three South Coast stocks, only two - inside Vancouver Island and Juan de Fuca Strait - are important and model-based TAC advice is provided for these. There is negligible fishing for green sea urchins on the exposed west coast of Vancouver Island. Within each stock the annual TAC is apportioned among 3-5 areas based on the previous year's catch and non-transferable quotas are equally divided among divers within each area. 
Some management areas in the northern Strait of Georgia, between the two centres of fishing effort, are closed to fishing (Perry \& Waddell 1999).

\section{Assessment and status}

TACs for both species are estimated using deterministic surplus production methods (Campbell et al. 1999, Perry \& Waddell 1999). The assessments differ in the way biomass is estimated. For red sea urchins, Campbell et al. (1999) apply Gulland's (1971, from Schaefer (1954)) approximation $\mathrm{MSY}=\mathrm{XMB}_{\mathrm{o}}$, but substitute current biomass for pre-fishing biomass $\left(\mathrm{B}_{\mathrm{o}}\right)$ and use a "scaling factor" of $\mathrm{X}=0.2$ across a range of natural mortalities $(\mathrm{M})$ between 0.05 and 0.15. Current biomass is estimated as the product of densities and the area fished. Densities are estimated using stratified random surveys in beds known from logbook records. Different survey methods have been used in the almost $30 \mathrm{yr}$ sea urchin populations have been surveyed (Campbell et al. 1999); to address the uncertainty this introduces, the lower $90 \%$ confidence limit of the biomass estimate is used in TAC advice. The estimates of fishing area are assumed to be made without error, despite high uncertainty (Campbell et al. 1999). Recommended TACs for S. franciscanus for the North and South Coasts for 2000 were $4024 \mathrm{t}$ and $844 \mathrm{t}$, respectively.

Green sea urchins have been surveyed only in a subset of areas within the assessed stocks (Waddell et al. 1997) and the data are not used to estimate biomass (Perry \& Waddell 1999). Current biomass is estimated within a surplus production model (Schnute 1977, Polovina 1989) fitted to catch rates from the fishery. Information from the survey is used to provide independent estimates of catchability coefficients and biomass for the two areas surveyed (using the method described for red sea urchins). As for red sea urchins, the estimated MSY for each region is scaled as a precaution against the determinism of model dynamics and uncertainty in catch rates. Auxiliary information from surveys and from the literature is used to refine the recommended TAC within this range, in both cases towards the lower half of the range (Perry \& Waddell 1999). The 1999 assessment indicated that the stock centred on Queen Charlotte Strait was healthy but the status of the southern stock was both worse and more uncertain (Perry \& Waddell 1999).

\section{California (USA)}

\section{The fishery}

The sea urchin fishery in California is dominated by the red sea urchin, S. franciscanus. Small catches (14 $t$ in 1999) of the purple sea urchin, $S$. purpuratus, are landed but are less than $1 \%$ of landings in California and will not be considered further. The commercial fishery for red sea urchins began in southern California in the early 1970s. It remained south of Point Conception until 1985 when it expanded rapidly north of Bodega Bay (see Kato \& Schroeter 1985, Kalvass \& Hendrix 1997 for detailed reviews). Sea otters (Enhydra lutris) are now abundant along the coast between Point Conception and Bodega Bay and there are few harvestable sea urchins in this region (Ebert 1968, Estes \& Palmisano 1974, Estes \& Duggins 1995). The California fishery is exclusively a dive fishery. Typically, divers work alone or in pairs using surface supplied air and a line tender. In the northern region divers 
almost always make day-trips but in southern California the fishery is concentrated on the Channel Islands and trips may last several days. Recreational and customary fisheries for sea urchins in California are negligible and illegal harvesting is believed to be small (Kalvass \& Hendrix 1997).

In northern California, sea urchins are harvested from a relatively narrow strip of subtidal reef from the intertidal zone to about $22 \mathrm{~m}$ deep. Broadly, this distribution coincides with that of the bull kelp Nereocystis luetkeana and is estimated to be approximately $14.5 \mathrm{~km}^{2}$ in area (McLean 1962, Van Wagenen 1989). In southern California, an analogous minimum estimate can be made using the canopy coverage of Macrocystis pyrifera, which covers approximately $45 \mathrm{~km}^{2}$ along the coast between Point Arguello and the Mexican border, and the Channel Islands (Van Wagenen 1989).

The rapid growth of the fishery in the latter half of the 1980 s was partially due to a strengthening of the Japanese Yen against the US dollar in 1986 and the consequent increase in ex-vessel prices. In 1999, the commercial fishery was estimated to be worth US\$14.4 million. The catch is exported to Japan as either fresh or frozen roe, depending on quality. Roe recovery is greatest during autumn and winter. Prices are generally highest in the Japanese markets in December and May because roe quality and demand are high and Japanese domestic and imported roe supplies during winter months are relatively low (Reynolds 1994, Sonu 1995). Roe harvested from southern California commands a higher price than from the north.

\section{Production}

Catches steadily increased in southern California from the early 1970 s to a peak in 1981 of $11213 \mathrm{t}$ (Figs 15 and 16), but declined in 1982-83. This decline has been attributed to the

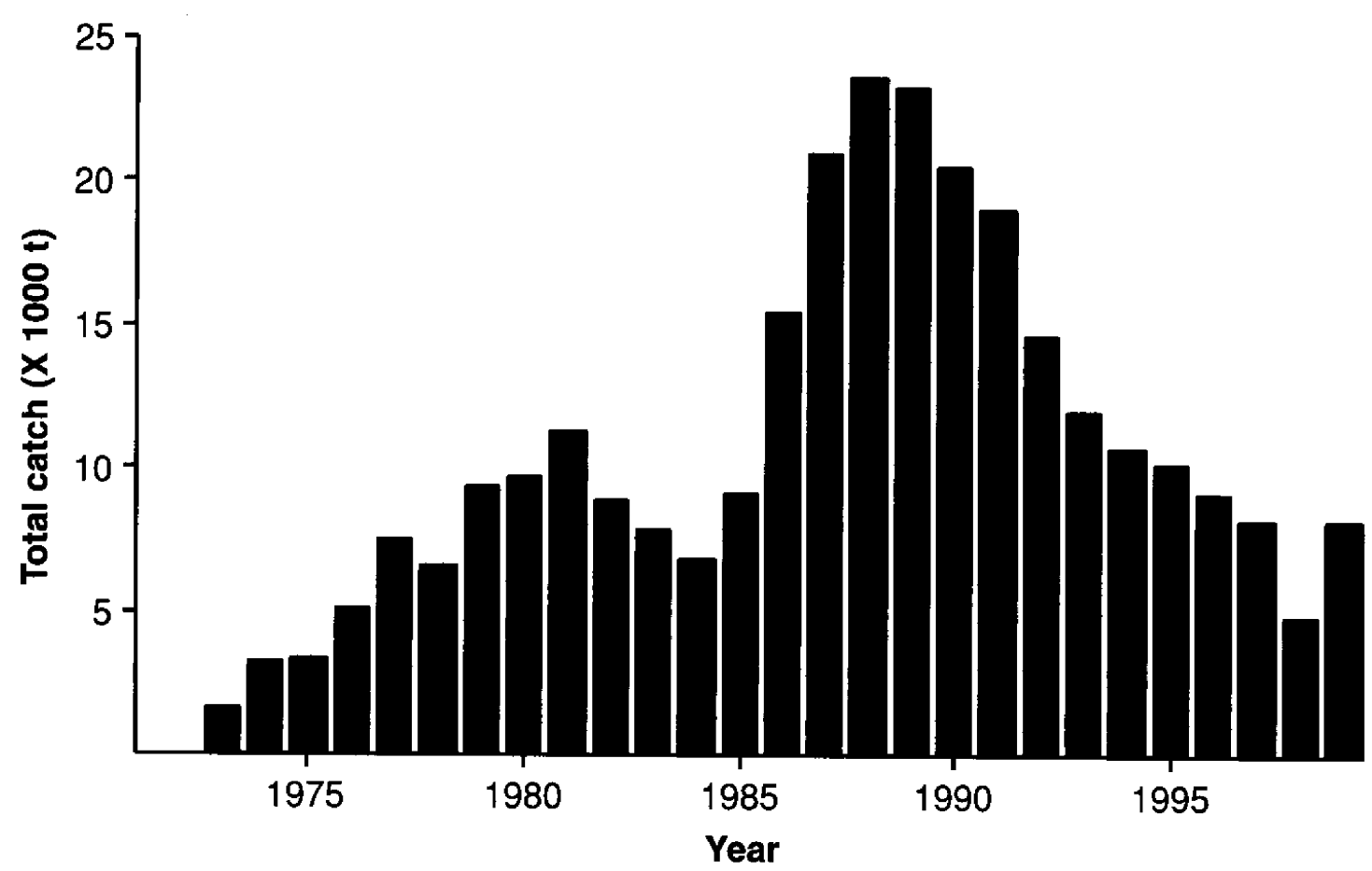

Figure 15 Total catch $(t)$ of red sea urchins in California. 


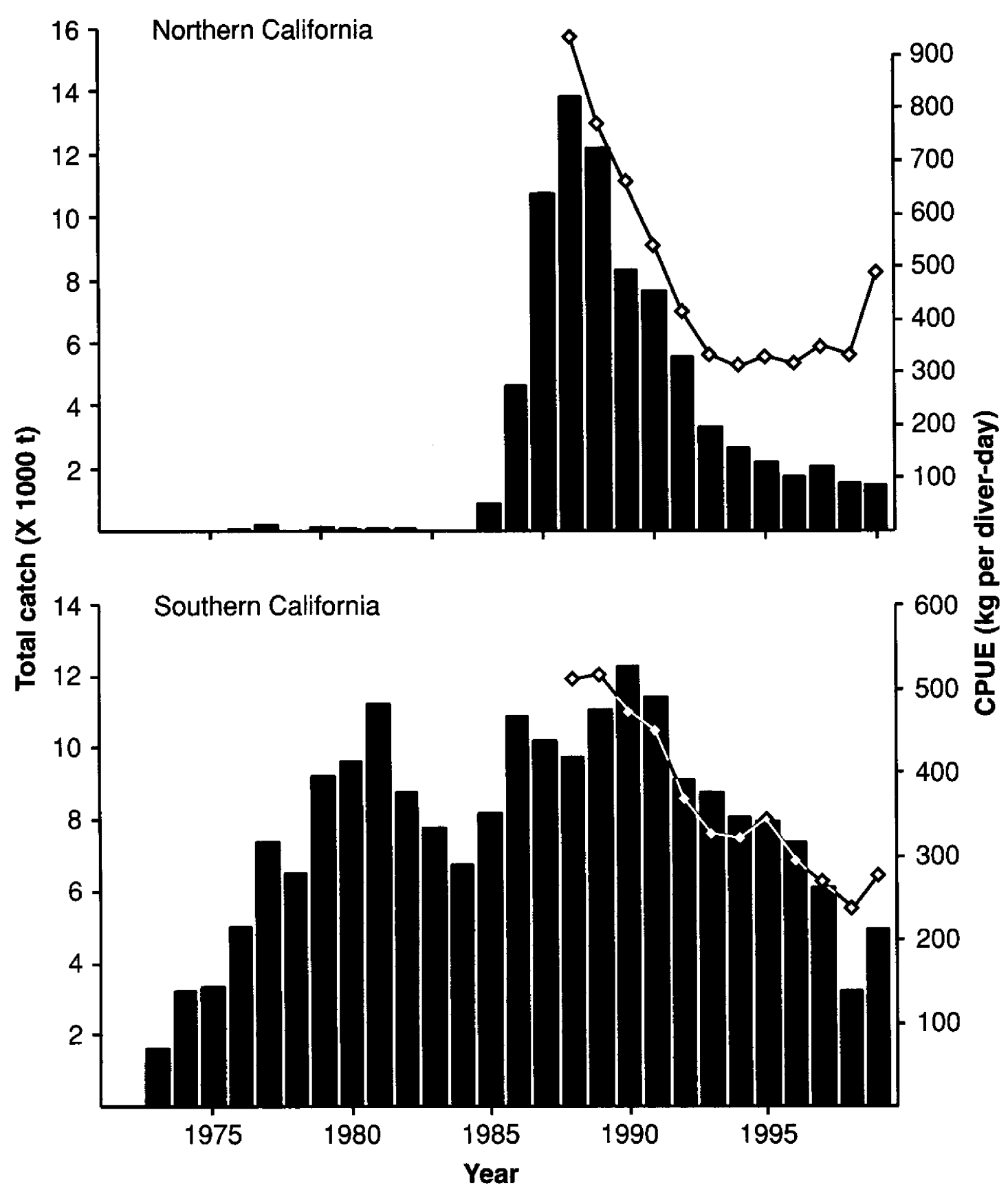

Figure 16 Total catches (t, bars) and catch rates (kg diver-day ${ }^{-1}$, lines) of red sea urchins in the northern and southern regions of California.

El Niño of 1982-83 when warm water weakened or killed kelp (Kato \& Schroeter 1985). In the mid-1980s there were large increases in total catches to a peak in 1988 of $23582 \mathrm{t}$, much of the increase coming from the developing fishery in northern California. At its peak, in $1988,13846 \mathrm{t}$ of sea urchins were landed in the northern region. Since 1988, the total catch has declined by $73 \%$ to approximately $6409 \mathrm{t}$ in 1999 (Fig. 15). Much of this decline occurred in the northern region (in 1999, $1445 \mathrm{t}$ was landed there $-11 \%$ of the 1988 catch). The biggest drop in catch and effort in California occurred after the 1992 season because many divers returned to southern California following the 5-7 yr fishing down of unexploited northern stocks (Kalvass \& Hendrix 1997). 
Although the Californian fishery ranges over a wide area, effort has focused on small "hot spots" that change through time. Before the development of the northern region, and after its equally rapid decline, the northern Channel Islands (San Miguel, Santa Rosa and Santa Cruz) have provided the greatest share of the catch. In 1999, the northern Channel Islands contributed $2640 \mathrm{t}$ of the $4964 \mathrm{t}$ southern California catch (53\%), down $44 \%$ from the $4714 \mathrm{t}$ contribution in 1994. In northern California, $70 \%$ of the $50800 \mathrm{t}$ of red sea urchin harvested between 1988 and 1994 came from about $65 \mathrm{~km}$ of coastline (Kalvass \& Hendrix 1997).

Divers have also moved from shallow $(<10 \mathrm{~m})$ water to working reefs in deeper water. In northern California catch-by-depth changed little between 1988 and 1993, then in 1995 there was a marked shift to deeper ( $>10 \mathrm{~m}$ ) waters (Kalvass \& Hendrix 1997). In southern California the percentage of catch from depths greater than $21 \mathrm{~m}$ increased from $7 \%$ in 1990 to $12 \%$ in 1999. Interpreting these changes in fishing behaviour is difficult because they probably have many causes, including differences in weather (both short-term and longer-term cycles such as ENSO (Kato \& Schroeter 1985, Dayton \& Tegner 1990), the abundance of sea urchins and diver aptitude). In particular, the two relatively strong El Niños during the 1990s may have affected kelp abundance and consequently gonad quality and catches.

\section{Fishing effort and catch rates}

In the early years of the fishery there were few restrictions on the number of permits issued and, by 1988, 938 divers were permitted to harvest sea urchins. Many of these divers joined the fishery in anticipation of a moratorium on new permits. This number fell by natural attrition to 537 in 1992. An effort reduction scheme accelerated the process and 421 divers remained in the fishery in 1999. Despite this scheme, considerable latent effort remains in the California fishery; for example, in $1999,50 \%$ of the catch was caught by $22 \%$ of divers and $10 \%$ of divers fished for less than 10 days $\mathrm{yr}^{-1}$, and only 12 of the top 100 divers in the fishery worked exclusively in the northern zone.

Trends in fishing effort in southern California resemble the serial depletion and decline seen in the Californian abalone fisheries in the mid-1990s (Karpov et al. in press). While the northern Channel Islands have supplied most of the catch over the years, beginning in 1992, catches in the northern islands began to decline as effort and harvests increased from San Nicolas and San Clemente. Recently, fishing effort and catch at San Clemente Island have declined. Whether the harvestable stocks can recover in these heavily fished areas is unknown, particularly in the absence of effective controls on catch.

Catch rates have not been standardised for assessment purposes so trends in raw catch rate must be interpreted with caution. The data are also weakened by ambiguity in effort reporting. Diver-hours, diver-days, vessel-days and receipts (a proxy for diver-days since individual landing requirements were mandated in 1992) have all been used. Catch rates in the southern regions have changed little in the 10 years since the fishery peaked, despite large declines in total catch (see Fig. 16). In the northern region, catch rates fell sharply following the years of greatest landings but have subsequently stabilised and even increased in 1999 (see Fig. 16).

\section{Management}

Although responsibility for managing the sea urchin fishery rests with the California legislature, this was effectively ceded to the Fish and Game Commission in 1973 (CDFG 1989 as 
cited in Kalvass \& Hendrix 1997). In the early years of the fishery, management focused on reducing sea urchin densities as a way to increase kelp abundance and gonad yield (Kato \& Schroeter 1985). It became apparent that this perspective was too narrow and, in 1987, the legislature established the Director's Sea Urchin Advisory Committee consisting of representatives from the fishing industry, California Department of Fish and Game and California Sea Grant. An important role of the committee has been to act as a forum for consensusbased management. This approach has been effective - almost all of the management measures introduced originated from this committee.

California's sea urchin fishery has been subject to relatively passive regulation and operates without a fishery management plan. There was no regulation of the fishery before 1985 and few restrictions on catch or effort until the late 1980s (Kalvass \& Hendrix 1997). Although a permit entitles a diver to harvest sea urchins in both the northern and southern regions, small differences in regulations have evolved in recognition of differences in the oceanography, ecology and fisheries of the two regions. The principal management interventions have been: (a) a moratorium on the issue of new permits since 1987, (b) the introduction of a MLS in 1988 (increased in the northern region in 1990 and in 1992 in the south),

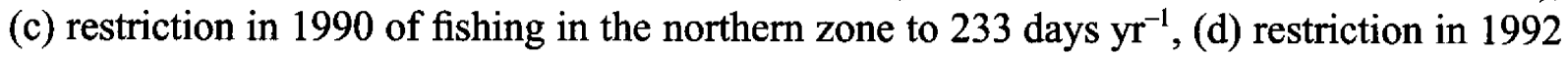
of fishing in the southern zone to 240 days $\mathrm{yr}^{-1}$, and (e) introduction of effort reduction in 1990; this currently requires 10 permits to be retired for each new entrant. All these regulations remain in effect. While the limited entry programme has created a slow but steady decline in the number of permits, it has not significantly reduced potential effort in the fishery (Kalvass \& Hendrix 1997).

Declines in catch and catch rate in the northern region have been the subject of considerable concern (e.g. Kalvass 1992, Botsford et al. 1993, Quinn et al. 1993, Rogers-Bennett et al. 1995). Fishery-dependent modelling of the sea urchin fishery during the period of rapid decline (1985 to 1994) estimated that the $50800 \mathrm{t}$ of red sea urchins harvested from 1988 through 1994 represented about $67 \%$ of the fishable stock available at the start of 1988 . Effort declined during this period as the 126 divers who had worked exclusively in northern California during 1991 had dwindled to 69 by 1995 . Concomitantly, annual catch per permit declined by $57 \%$ from 1990 to 1995 . To test whether this decline was due to fishing down, Botsford and colleagues (Botsford et al. 1998) estimated the decline in abundance expected from fishing down using the changing shape of the size distribution, and compared it with the decline in abundance, as estimated from catch rates. This analysis indicated that three of the four major ports in northern California were over-fished, in the sense that CPUE declined more rapidly than would be expected on the basis of the changing shape of the size distribution. However, only one of the differences was statistically significant. The authors concluded that: (a) most of the decline was due to the fishing down effect, but (b) the fishery seemed to be near the point of affecting recruitment.

In southern California, the red sea urchin resource has remained productive but harvestable stocks (sea urchins larger than the MLS and containing marketable gonads) have apparently been in decline since about 1990 . Although fishing has significantly reduced density in many areas and catch rates have declined, strong but localised recruitment has thus far replenished populations. Consistent recruitment has been noted on artificial settlement substrata and along subtidal transects over the last decade at monitoring stations along the southern California mainland coast and the northern Channel Islands (Ebert et al. 1994, S. Schroeter, unpubl. data). This may be the result of ocean circulation patterns in the Southern California Bight that increase the chances of larval retention and subsequent settlement. 
As the accumulated stocks of large sea urchins are removed, the fishery is increasingly dependent on recruitment to sustain harvests. In northern California, the mode of the size distributions declined from $120 \mathrm{~mm}$ in 1990 to $95 \mathrm{~mm}$ in 1999 (P. Kalvass, unpubl. data; see also Kalvass \& Hendrix 1997). Since 1990, the proportion of sea urchins in the catch within $10 \mathrm{~mm}$ of the MLS has risen from $38 \%$ to $47 \%$. In southern California, mean test diameter declined by $9 \%$, from $102 \mathrm{~mm}$ in 1998 to $93 \mathrm{~mm}$ in 1999. Almost $65 \%$ of the red sea urchins harvested were less than $95 \mathrm{~mm}$ in 1999, compared with $50 \%$ in 1990 . The effect of these changes is 2-fold: more animals are removed from the stock per ton of roe recovered (Kalvass \& Hendrix 1997) and greater reliance is placed on recruitment to sustain the fishery. Currently, there are indications that a pulse of recruitment in the northern region observed in 1992-93 is reaching the fishery (P. Kalvass, pers. obs.).

The abundance of sea urchins has been estimated in California for many years and for many reasons. Surveys have been done by university-based researchers, the National Park Service and the Department of Fish and Game (e.g. Deacon 1973, Tegner \& Dayton 1981, Rowley 1989, Kalvass et al. 1991, Tegner \& Dayton 1991, Ebert \& Russell 1992, Kalvass \& Taniguchi 1993, Pentony 1996, Kalvass \& Hendrix 1997, Morgan et al. 2000a). These studies have provided a wealth of information but had different objectives, little methodological consistency, and geographic coverage that was patchy and inconsistent in time. Surveys in the northern region indicate that densities of harvestable stocks have declined significantly since 1988 (Kalvass \& Hendrix 1997, Botsford et al. 1998, Morgan et al. 2000a, Karpov et al. in press).

There have been several attempts to provide quantitative assessment advice for the fishery. In 1997, Kalvass \& Hendrix used a Leslie depletion model to estimate pre-fishing biomass. This approach assumes that estimates of catch rate regressed on cumulative catch are from a population that is closed except for fishing removals (as the study was done over several years, recruitment is likely to have caused a negative bias in the biomass estimate). Morgan et al. (2000b) used the model-based method of Smith et al. (1998) to estimate natural mortality, fishing mortality and growth rates at 14 sites along the northern California coast. From these they assessed the dependence of yield-per-recruit (YPR) and egg-per-recruit (EPR) on size limits and fishing mortality rates (Morgan et al. 1999, 2000b). The former indicated the current size limit and effort produce a value of YPR near the maximum, and the latter indicates EPR was $<20 \%$ of the unfished value. Because the latter was in the range that can lead to recruitment overfishing (e.g. Mace \& Sissenwine 1993, Mace 1994), they assessed the effects of implementing marine reserves (Botsford et al. 1993, Quinn et al. 1993). Theoretical results on the sustainability of marine reserves indicate the two main uncertainties in their design are the poorly understood larval dispersal patterns and the unknown minimum tolerable lifetime reproduction (Botsford et al. 2001). Botsford et al. (1999) used decision analysis (Hilborn \& Walters 1992) to account for the latter uncertainty, which indicated that placing $15 \%$ of the coastline in reserve led to the greatest long-term yields. Accounting for the possible patterns of larval dispersal is more difficult, but an initial decision analysis approach is described in Morgan et al. (1999).

Prior to the passage of the California Marine Life Management Act in 1998, legislation required that consideration be given to "regulating the catch within the limits of maximum sustainable yields (MSY)" (DFG Code, Sec. 1700). Nevertheless, MSY has not been given an operational definition and there remains no formal assessment to guide management intervention. As a result, management has largely been ad hoc and consensus-driven (Kalvass 1992, Kalvass \& Hendrix 1997). The present management regime is based on size limits and 
restricting fishing effort but is unlikely to prevent any increase in catch and fishing effort that may be caused by perceptions of improved profitability. The Marine Life Management Act has the potential to change the direction of sea urchin fishery management in California because it requires the development of peer reviewed management plans that incorporate the best available science in management measures that ensure the continued viability of the sea urchin fishery and its ecosystem. Another recent law, the Marine Life Protection Act, mandates the implementation of marine reserves, which is now in progress. It remains to be seen whether the implementation of these laws will deliver improved management to California's fishery, particularly in the face of external threats such as an expanding sea otter distribution and large-scale oceanographic events that may affect the dynamics of sea urchin populations (see Tegner 2001 for review).

\section{Baja California (Mexico)}

\section{The fishery}

The Baja California fishery is based on two species: the red sea urchin Strongylocentrotus franciscanus and the purple sea urchin S. purpuratus. Both are at the southern limits of their distributions. These species co-occur with other sea urchins along the Baja coast, (e.g. Centrostephanus coronatus and Lytechinus anamesus), but are the only species of economic significance. The red sea urchin is one of the largest species of sea urchins in the world, growing to about $200 \mathrm{~mm}$ and weighing more than $1 \mathrm{~kg}$. The purple sea urchin is small, growing to about $70 \mathrm{~mm}$.

The fishery is limited to the northern third of the peninsula, from the border with the United States to El Rosario Bay. This $450-\mathrm{km}$ stretch of coastline is divided into four management areas. Of these, the most southern area was the most productive but catches in the neighbouring area were more predictable and, in recent years, that area has assumed greater importance. The fishery for Strongylocentrotus franciscanus began in 1972 and has always supplied the Japanese market. The fishery grew quickly and is characterised by three peaks in catch, in 1979, 1986, and 1990. S. purpuratus has been harvested since 1993 but catches have remained relatively small. Densities of purple sea urchins have risen in the past $10 \mathrm{yr}$, perhaps as a consequence of removing the competitively superior red sea urchin (Schroeter 1978) but inconsistent roe quality has retarded development of the fishery.

Sea urchins are collected by divers using surface-supplied air from depths to $30 \mathrm{~m}$. The divers use short-handled rakes to dislodge sea urchins from the reef and, as they do in other fisheries where they are paid on roe recovered, divers open sea urchins to test roe quality as they work. There is no recreational fishery and the illegal harvest is believed to be small.

The fishery expanded rapidly and by 1979 landings had reached $5800 \mathrm{t} \mathrm{yr}^{-1}$ (Fig. 17). Only $1590 \mathrm{t}$ was landed the following year but this reduction was caused by the combination of El Niño, marketing problems and associated reductions in fishing effort (J. Palliero, pers. obs.). The fishery again expanded quickly, reaching $8493 \mathrm{t}$ in 1981. Regulations introduced in 1987 brought greater stability in the fishery; catches fell through the 1990s as increasingly restrictive management measures were introduced and were at their lowest levels in 199899. Landings in the last fishing year, 1999-2000, rose sharply again, to $2153 \mathrm{t}$ (Fig. 17).

The number of divers has remained relatively constant since the introduction of management (300 in 1987 and 291 in 1999-2000). About 40\% of divers in 1999-2000 worked in 


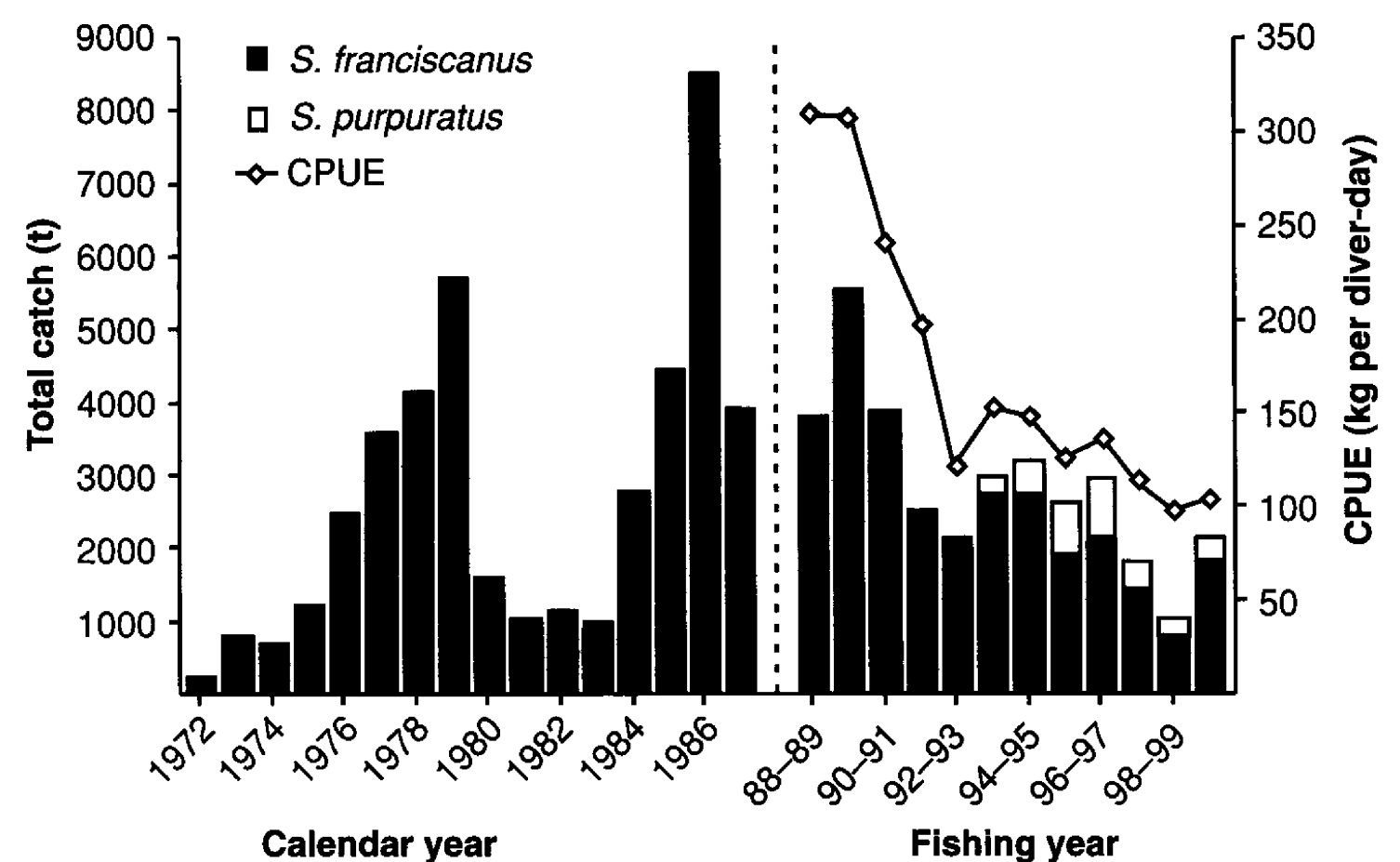

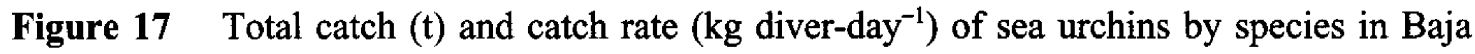
California. Note the change in reporting from calendar to fishing year in 1987.

the most southern management area in the fishery, the rest divided roughly equally among the other three areas. Catch rates for $S$. franciscanus have declined significantly from a mean rate of $309 \mathrm{~kg} \mathrm{day}^{-1}$ in 1989 to $104 \mathrm{~kg} \mathrm{day}^{-1}$ in 1999-2000 (Fig. 17). The declines were greatest in Area 4 where catch rates fell from $390 \mathrm{~kg} \mathrm{day}^{-1}$ to $138 \mathrm{~kg} \mathrm{day}^{-1}$ in 1995 (Cota et al. 1996).

\section{Management}

The red sea urchin fishery was unregulated until 1987 when it was transformed from an open-access competitive model to one in which permit holders were given exclusive access to areas or "territories". Before 1987, divers could fish anywhere and many areas were severely depleted. In 1994, the Federal Government gave permit holders (these may be individuals, co-operatives or other social institutions) two-year leases (and on application 20 -yr leases) for exclusive access to areas. Permits are tradable and these changes provide investment security and promote greater commitment to long-term sustainable use. In 2000, there were 48 permit holders, each with an exclusive right to an area of sea bed; a total of 291 divers were employed to harvest sea urchins within these 48 areas.

Other management measures introduced in 1987 included a MLS of $80 \mathrm{~mm}$ (red sea urchins on the Baja California coast are sexually mature at $41-50 \mathrm{~mm}$ (Palliero et al. 1992)), a closed season between April and June (later extended to March-June), and a TAC for the whole fishery. In addition, catch and effort reporting was required. In 1996, industry and government placed a moratorium on new permits and limited divers to $150 \mathrm{~kg} \mathrm{day}^{-1}$ and fishing to five days per week.

The TAC is used as a precautionary instrument only; each year it is set by government based on an analysis of survey and catch and effort information (e.g. Cota et al. 1996). If the quota is caught within the fishing year (this has happened twice) then further quota may be 
approved. The total catch depends to a greater degree on the roe recovery rates, beach price and abundance. For example, in the 1998-99 fishing year, Macrocystis forests were severely depleted as a result of an El Niño event (CALCOFI 1999) and roe were poor. This, along with a depressed market in Japan, meant that the TAC was not caught.

Assessments of the red sea urchin fishery are based on annual analyses of fishery-derived information such as catch rate and mean size in the landed catch, and fishery-independent surveys (e.g. Palliero et al. 1992, Cota et al. 1996). About half the standing stock of legalsized red sea urchins is caught each year (Cota et al. 1996). Since assessments began there have been declines in catch rates and the mean size of sea urchins (from $93 \mathrm{~mm}$ in 1991 to $78 \mathrm{~mm}$ in 1996 (Cota et al. 1996) ). Video surveys of reefs also indicate declines in densities of red sea urchins, particularly within Macrocystis forests. Densities of juvenile red sea urchins are greatest on the margins of the forests. There is evidence that purple sea urchins have increased in density and have replaced red sea urchins in deeper water (Cota et al. 1996).

\section{New Brunswick (Canada)}

The green sea urchin, $S$. droebachiensis, forms the basis of the New Brunswick fishery. Sea urchins are most abundant in waters less than $10 \mathrm{~m}$ deep (Robinson \& MacIntyre 1993, 1995), and are harvested by dragging or diver-based techniques (either hand gathering or suction harvesting). The fishery initially developed to supplement fisheries in the United States; small landings $(<50 \mathrm{t})$ were reported until the early 1990 s when catches increased dramatically (DFO 2000a). Landings peaked in 1996 at $1900 \mathrm{t}$ and have fallen slightly since then, partly because of the introduction of quotas (Fig. 18).

The fishery is divided into three management zones, two of which (Grand Manan Island and the mainland and coastal islands) account for almost all the catch. Fishers are permitted to fish in only one of these two zones, plus the third zone. A MLS of $50 \mathrm{~mm}$ applies to the

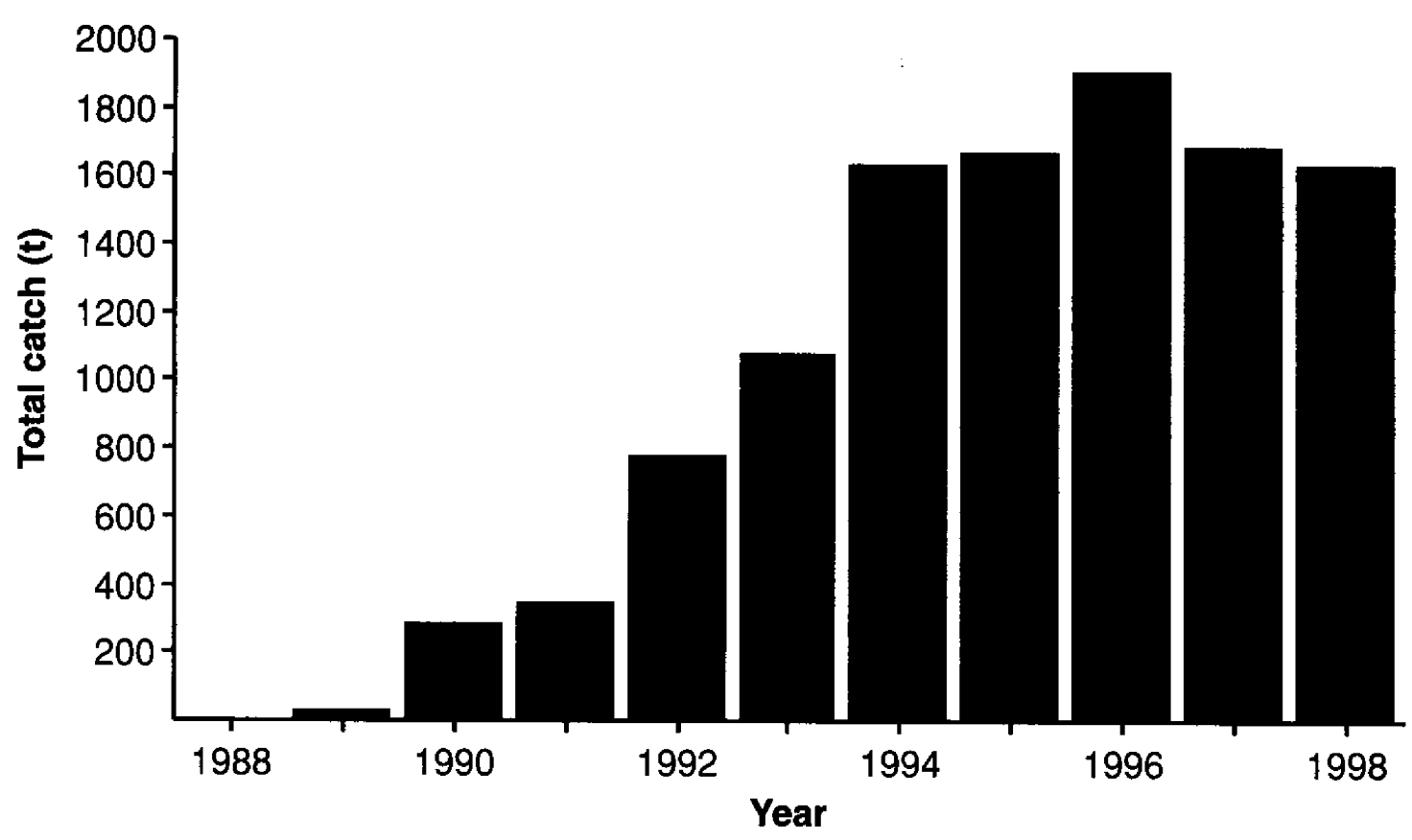

Figure 18 Total catch (t) of sea urchins in New Brunswick. The reported year refers to the fishing year completed in that calendar year. 
whole fishery. Fishing is restricted to a 6-month (Grand Manan) or 8-month (mainland and coastal islands) season and harvesting is limited to daylight hours. Since 1995, dragging has been the only method permitted in the Grand Manan fishery; both dragging and diving are allowed on the mainland and coastal islands.

In addition to these input controls a TAC provides a theoretical limit to catch in both management areas. These TACs were implemented in 1996 and are derived from biomass estimates from a dive survey in 1992-94 and ageing studies (Robinson \& MacIntyre 1997, DFO 2000b). For Grand Manan Island, the $900 \mathrm{t}$ TAC was $6.8 \%$ of the estimated exploitable biomass of $13245 \mathrm{t}$. The TAC for the mainland and coastal islands was set at $979 \mathrm{t}, 3.3 \%$ of an estimated biomass of $29879 \mathrm{t}$. The differences in exploitation rate are based on perceived differences in productivity between areas; juveniles were present in greater numbers in surveys from Grand Manan (DFO 2000a). The TAC is divided among permit holders as individual transferable quotas in Grand Manan but not the mainland management area. Neither TAC has been caught since they were introduced.

Stock status is determined annually from catch rates from mandatory logbooks (DFO $2000 \mathrm{~b}$ ). Catch rates in the drag-only fishery at Grand Manan Island have declined from a peak of nearly $1600 \mathrm{~kg} \mathrm{day}^{-1}$ in 1994 to $824 \mathrm{~kg}$ day $^{-1}$ in 1999 despite a shift in fishing grounds towards the south of the island in an attempt to maintain catch rates. The mean size of sea urchins in the landed catch declined over this period. There are no consistent trends in catch rate or the size of sea urchins in the catch from either dragging or diving in the mainland and coastal islands (DFO 2000a). Current assessments are considered inadequate (DFO 2000a) and there has been no management intervention in either fishery since the imposition of TACs in 1996.

\section{Russia and the former USSR}

Sea urchin fisheries in Russia are now found only in the far east, although harvesting has been reported from the Barents Sea (Keesing \& Hall 1998). Sea urchin fisheries are centred on the Japan Sea, the Kamchatka Peninsula and the Kuril Islands (Bazhin 1998, Keesing \& Hall 1998). Russian landings are dominated by the fishery for Strongylocentrotus intermedius in the Japan Sea and Sakhalin Island. Little is known of this fishery although small amounts of $S$. nudus were landed in 1998 (V. Levin, as cited in Keesing \& Hall 1998). Further north, on the Kamchatka Peninsula, from Cape Lopatka to the Commander Islands, only $S$. polyacanthus is harvested. Remoteness and heavy ice for much of the year has impeded development of these fisheries. A fishery in the Kuril Islands targets $S$. intermedius and in 2000, Japan imported $3300 \mathrm{t}$ of sea urchins from the Kiril Islands, most of which was processed in Hokkaido (Y. Agatsuma, pers. obs.). Although S. droebachiensis and S. pallidus may be abundant and are considered to be potential fisheries (Bazhin 1998), few have been harvested in recent years. Most sea urchins landed in Russia are shipped live to processing plants in Hokkaido. There are no recreational or customary fisheries for sea urchins and illegal harvesting is believed to be small.

FAO catch statistics for USSR/Russia for all echinoderms appear to be incomplete and are considered unreliable by some authors (e.g. Reid \& Ovichinnikov 1995, as cited in Keesing \& Hall 1998). Catches from the Soviet Union before 1986 are small and sporadic (Fig. 19) but jumped to $6328 \mathrm{t}$ in that year, the highest reported catch. Catches from Russia in 1992 fell to less than half that before the break-up of the Soviet Union in 1992. 


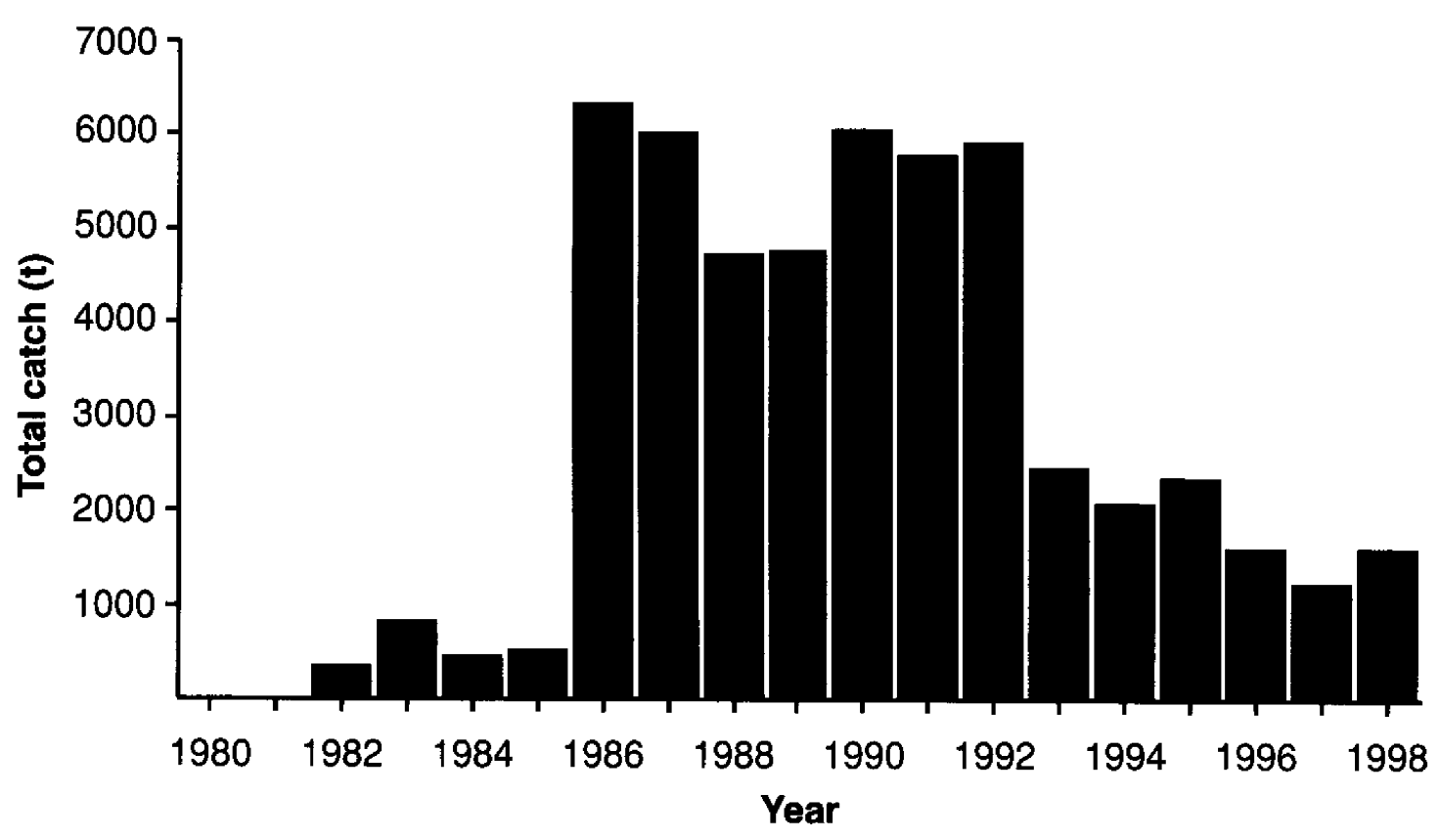

Figure 19 Total catch (t) of sea urchins in the USSR (pre-1986) and Russia thereafter.

Each year since 1992, catches of $S$. polyacanthus have been less than $90 \mathrm{t}(<6 \%$ of the total reported catch in Russia) and less than a quarter of the allocated TAC of between $280 \mathrm{t}$ and $540 \mathrm{t}$. Fishing has caused measurable changes in the population structure at many locations, particularly in the southeast (Bazhin 1998), but there are no consistent indications that fishing has significantly diminished stocks. Densities have increased on some fishing grounds (A. Bazhin unpubl. data) and there is evidence that large animals lost to the fishery are replaced by smaller sea urchins migrating inshore from deeper water, often from areas of barrens habitat (Bazhin 1998, A. Bazhin, unpubl. data).

All Russian sea urchin fisheries are managed by a mixture of input and output controls (see Ivanov 1998 for review). The TAC for regional fisheries is set by the Ministry of Fisheries and other central agencies in Moscow, following advice from the regional fisheries laboratories. For sea urchin fisheries on the Kamchatka Peninsula this advice is based on fishery-independent surveys and information derived from the fishery. A portion of the TAC is caught under supervision from scientific observers and is allocated to the regional fisheries research institutions as a quota. This quota is purchased by fishers at a discount and distribution and size structure of the catch is well-documented. Companies fishing the "scientific quota" are permitted to fish during the closed season. The remainder of the TAC is caught by fishers who are required to provide daily reports of catch and location. Initially this was intended to provide a mechanism for within-season adjustment of the TAC, but in practice the centralised control of quota-setting allows little flexibility. A MLS of $50 \mathrm{~mm}$ is in place and a closure between 15 September and the end of December ostensibly protects spawning sea urchins.

\section{Alaska (USA)}

The sea urchin fishery in Alaska targets primarily red sea urchins ( $S$. franciscanus) in the state's southeastern panhandle and green sea urchins ( $S$. droebachiensis) in the northern 


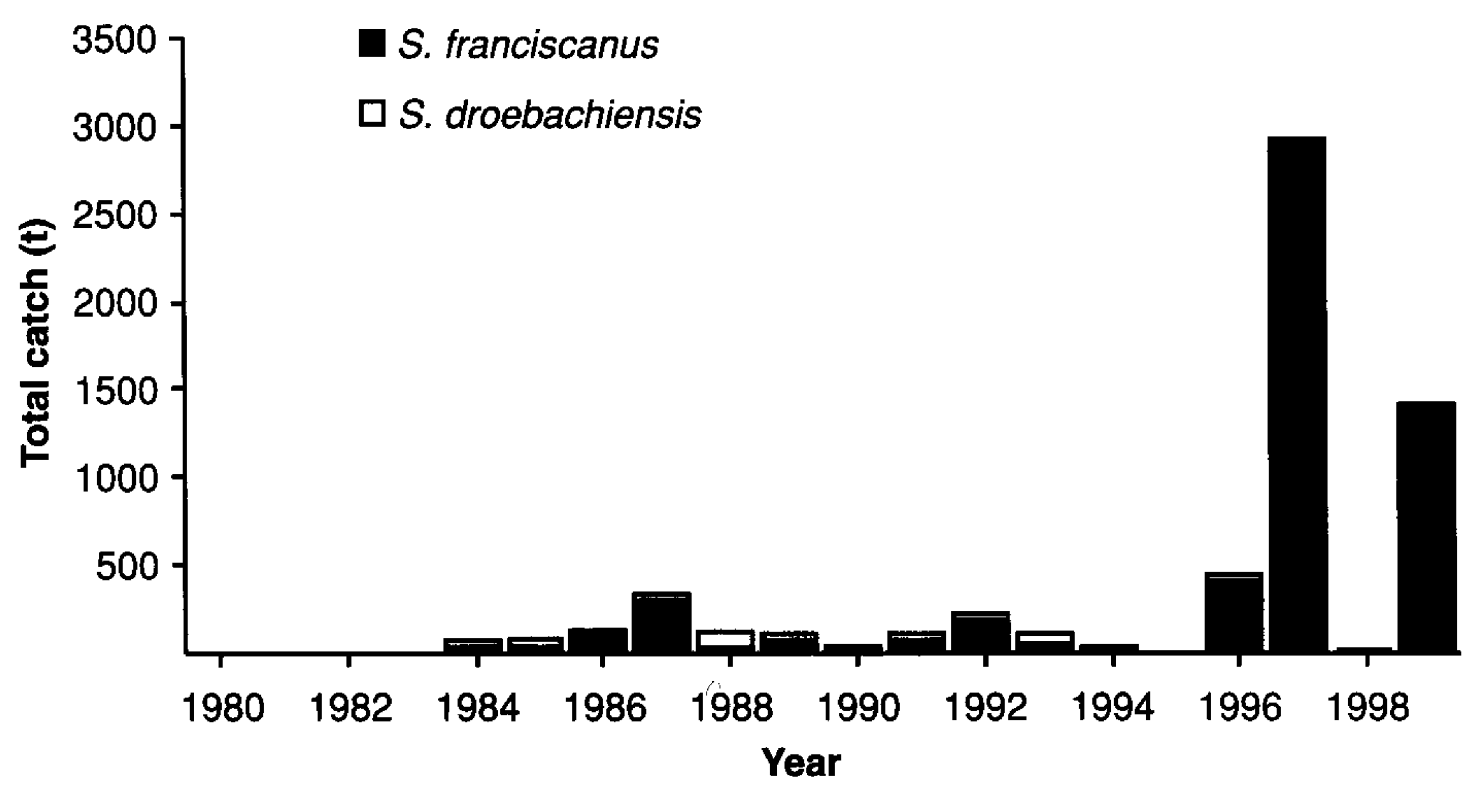

Figure 20 Total catch (t) by species of sea urchins in Alaska.

Gulf of Alaska. Commercial harvests began in 1980, but early catches were sporadic and small (peaking at $343 \mathrm{t}$ in 1987, Fig. 20) and the fishery was limited by marketing problems. Prior to 1990 , in the early development of the fishery, harvesting was restricted to permitted divers but there were few other restrictions.

A second attempt to develop the fishery began in the Sitka area in 1990. Total catch was limited to $2 \%$ of the biomass estimated from stock assessment surveys. Catches remained small (<200 t, Fig. 20) and this fishery ended in 1993 after sea otters expanded their range into the fishing area. The sea otters removed an estimated $64 \%$ of the sea urchin population in one winter, with depredations continuing at unknown levels in subsequent years (see below). The third and current attempt to develop the fishery began in 1994 in southeast Alaska near Ketchikan in areas free of sea otters. Catches expanded rapidly and, in 1997, $2921 \mathrm{t}$ was landed (Fig. 20). In 1999, approximately $1420 \mathrm{t}$ was landed.

Commercial harvest levels are now based on biomass estimates derived from population surveys. In 1997 a management plan and regulations established an open competitive commercial fishery in nearly all of the viable commercial fishing grounds of southern southeast Alaska. The plan is based on an agreed exploitation rate calculated from a surplus production approach similar to that used for the sea cucumber fishery in southeast Alaska (Woodby et al. 1993, see also British Columbia, p. 363). Total allowable catches for each of the 24 areas in the fishery are calculated as a small fraction of biomass (Gulland 1971, Caddy 1986): TAC $=\mathrm{XMB}$, where: $\mathrm{X}(=0.4)$ is a scaling factor, $M$ is the estimated instantaneous natural mortality rate (estimated to be 0.16 near Sitka, Woodby, 1991), and B is the lower bound of the $90 \%$ confidence interval of triennial biomass estimates from fishery independent surveys (Woodby 1998). Densities are usually estimated as the number of sea urchins per metre of shoreline, and biomass is calculated from mean weights and the shoreline length of surveyed habitat. Density estimates based on benthic area are used only for a few offshore reefs.

Surplus production models are commonly used in data-limited situations (Caddy 1986), but are simplistic and risky if not applied cautiously (e.g. Garcia et al. 1989). The main safeguards in their application to the Alaskan fishery are conservative estimates of biomass used. Continued collection of survey information and completion of research on growth and 
mortality may soon allow better estimates of sustainable yield. In two experimental harvest areas, the exploitation rate has been allowed to reach $20 \%$ per year. The purpose of this experiment was to harvest at a rate high enough to elicit a detectable population response, such as increased recruitment or changes in growth rates. Unfortunately demand for sea urchins has been too weak to achieve those high rates and the exploitation rate has ranged from less than $1 \%$ to $17 \%$ in each of the past two years in the two areas.

The fishery opens on October 1 each year and each area is closed when the TAC is taken. There are no rotational closures. The TAC has not been caught in any of the four years since the current management plan was adopted so some areas have remained open all year. There are currently 95 transferable permits in the fishery. There are no size limits in the fishery and harvest methods are limited to picking sea urchins by hand using a rake or an abalone iron. One fishing area and a portion of another have been set aside as control areas which are surveyed every year to follow trends in unfished populations. Fishing is prohibited within 3 nautical miles of four islands with Steller sea lion (Eumetopias jubatus) colonies.

\section{South Korea}

Sea urchin harvesting has a long history in South Korea but accounts for only a small proportion of the total seafood harvest (Korean Fishery Association 2000). About 40\% of the total sea urchin harvest is exported to Japan. Of the four species of sea urchin commercially harvested, Anthocidaris crassispina, Hemicentrotus pulcherrimus, Pseudocentrotus depressus and Strongylocentrotus intermedius, the last is the most valuable. Its current price is about US\$45 $\mathrm{kg}^{-1}$ of roe. The prices of Hemicentrotus pulcherrimus and Anthocidaris crassispina roe are approximately US\$35 $\mathrm{kg}^{-1}$ and US\$25 $\mathrm{kg}^{-1}$, respectively. Fishing seasons differ among species and areas but harvesting for each is concentrated in the month prior to spawning. During the spawning season, the roes have a bitter taste and become soft, making them less valuable. In general, A. crassispina and Hemicentrotus pulcherrimus spawn at Jeju Island in July, during August on the south coast and during September on the east coast (Yoo et al. 1982).

Anthocidaris crassispina is widely distributed on all coasts of South Korea but the fishery is concentrated on the rocky reefs of the east coast, facing the Sea of Japan (Hur et al. 1985, Yoo 2000). Similarly, fisheries for Hemicentrotus pulcherrimus and Strongylocentrotus intermedius are concentrated on the east coast, in Kyungnam province and in Kyongbook province (Hur et al. 1985). S. intermedius is found in deeper waters in the north of the province where the water temperature at $10 \mathrm{~m}$ falls below $20^{\circ} \mathrm{C}$. All species except $S$. intermedius are harvested from the subtropical waters of Jeju Island, to the south of the Korean peninsula; small catches of Pseudocentrotus depressus are taken from Jeju Island but these are not differentiated from Anthocidaris crassispina. Sea urchins are relatively rare on the muddy intertidal and shallow subtidal shores of the west coast; small numbers of A. crassispina and Hemicentrotus pulcherrimus are found on isolated rocky islands.

In 1999 nearly $90 \%$ of sea urchins harvested in South Korea were caught by women (known as "Hae-nyeo" or "women of the sea") who breath-hold dive. In addition to sea urchins these women harvest abalone, topshells, sea cucumbers and other benthic invertebrates. Skilled divers catch mainly Anthocidaris crassispina at depths near $10 \mathrm{~m}$. Sea urchins are also caught by divers working from boats using surface-supplied air. Sea urchins are only a minor component of the catch of these latter divers, who target large clams such as $M y a$ 


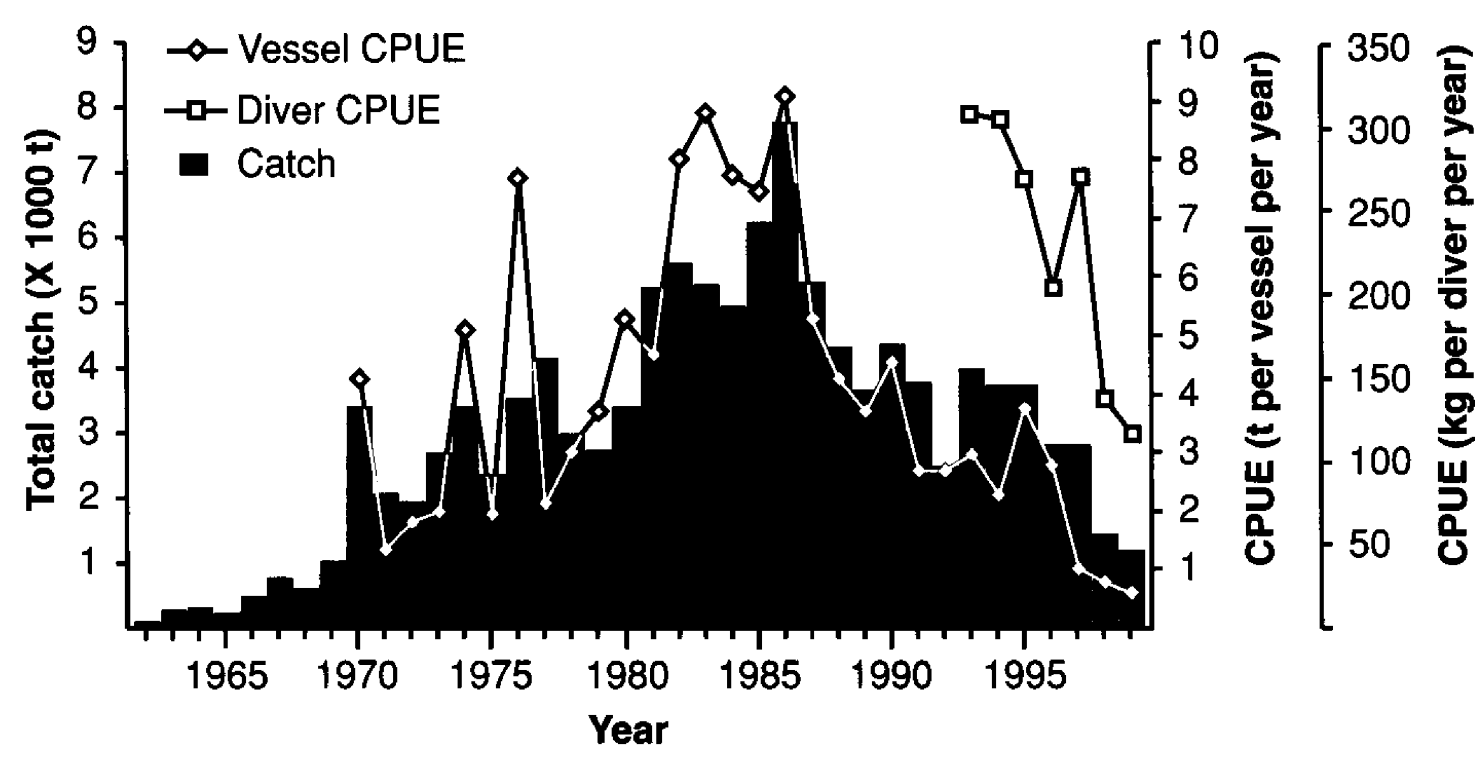

Figure 21 Total catch (t) and catch rates for divers and vessels in the sea urchin fishery in South Korea.

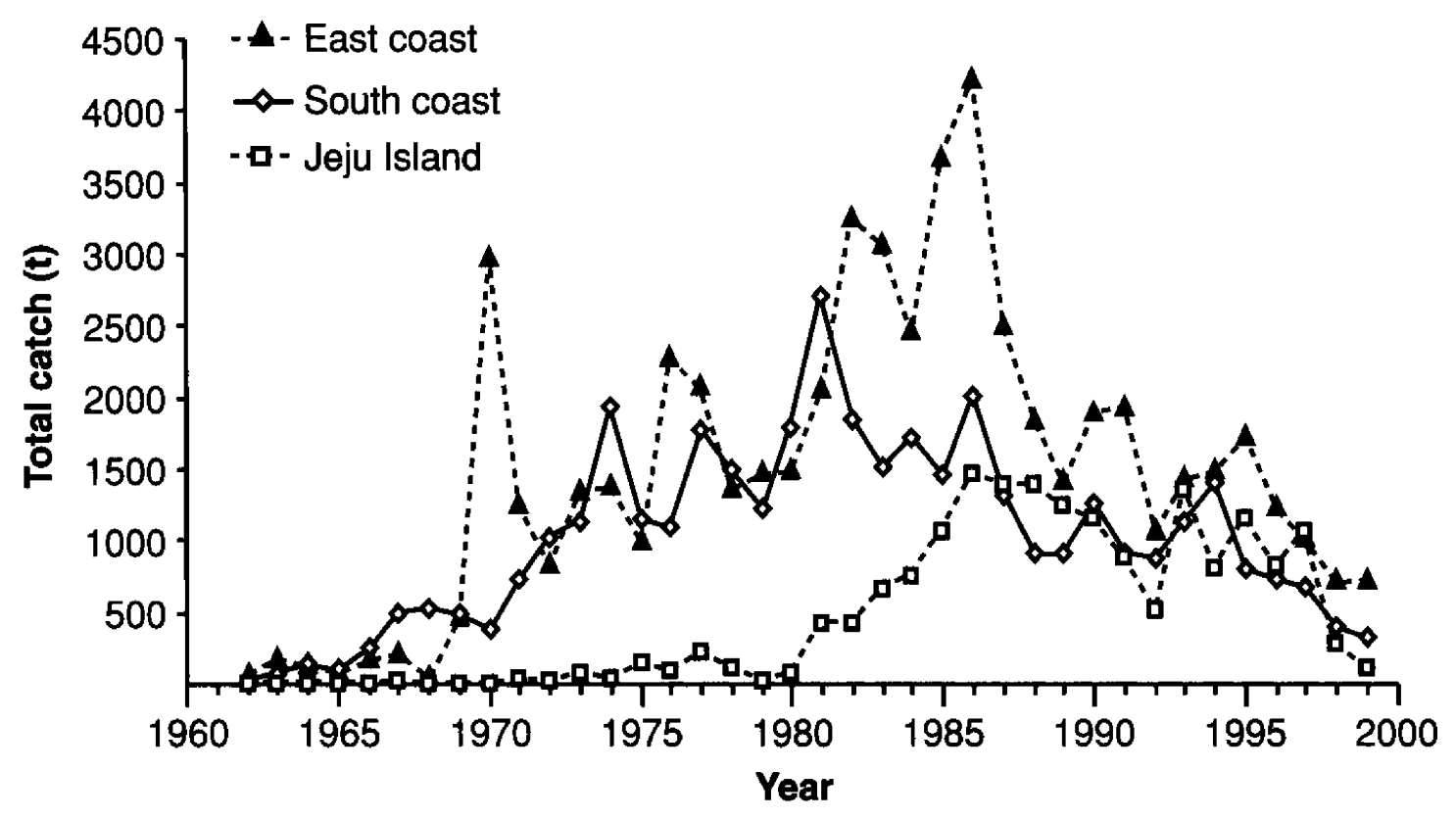

Figure 22 Total catch $(\mathrm{t})$ of sea urchins by region in South Korea.

arenaria oonogai and Tresus keenae, cockles (Anadara broughtonii) and sea pens (Atrina pectinata) at depths below $10 \mathrm{~m}$. Historically, catches using this method were more important but have declined from nearly $50 \%$ of the commercial catch in the 1970 s (Ministry of Maritime Affairs and Fisheries 1999).

Large-scale commercial harvests began in the 1960s and peaked at $7751 \mathrm{t}$ in 1986 (Fig. 21). After 1986 catches sharply declined, were relatively stable through most of the 1990s before again falling. In 1999 only $1182 \mathrm{t}$ of sea urchins were landed (Fig. 21). In 1999 , the production of sea urchins from the east coast (Kangwon and Kyoungbook provinces) accounted for $62 \%$ of total production, and that from the south coast and Jeju Island $28 \%$ and $10 \%$, respectively. Production from the east coast and Jeju Island peaked in 1986 and in 1981 on the south coast (Fig. 22). There are no production statistics by species. Approximate 
species proportions may be estimated based on interviews with divers and season of harvest. In 1999, Anthocidaris crassispina and Hemicentrotus pulcherrimus each accounted for 40$45 \%$ of the total harvest (S. Hur, unpubl. data). Of the remainder, Pseudocentrotus depressus and Hemicentrotus pulcherrimus accounted for nearly $10 \%$ and Strongylocentrotus intermedius the remainder (about $30 \mathrm{t}$ in 1999).

The dive fisheries, in waters less than $10 \mathrm{~m}$ deep, are owned and managed by local fishing villages. These fisheries are required to report statistics to the government (Ministry of Maritime Affairs and Fisheries 1996). Fishing is restricted to women living in each village. In general, there are no MLS or other limits on catch but the village decides how many divers can work and when. In 1996, 10414 divers harvested sea urchins; this declined to 8976 in 1999. The mean catch rate of divers has fallen, from $308 \mathrm{~kg} \mathrm{yr}^{-1}$ in 1993 to $115 \mathrm{~kg}$ in 1999 .

Fishing in water deeper than $10 \mathrm{~m}$ is managed by the Provincial Government and is restricted to licensed vessels. The number of vessels is limited by a moratorium and has declined from a peak of 681 in 1970 to 236 in 1997. Catch rates in this fishery peaked at a mean of $9.0 \mathrm{t} \mathrm{vessel-yr}^{-1}$ in 1986, but have declined each year since and, in 1999 a mean of only $0.6 \mathrm{t}$ was caught vessel-yr ${ }^{-1}$ (Fig. 21). Most species are widely distributed to depths beyond the breath-hold capacity of divers. Consequently, the decline of sea urchin stock may not be due to over-fishing, at least in this sector. The decline may have been promoted by environmental factors, particularly pollution and macroalgae resources (see p. 401) but this conclusion cannot be considered robust in the absence of stock assessments.

\section{Nova Scotia (Canada)}

The green sea urchin, $S$. droebachiensis, is common on shallow rocky reefs around Nova Scotia (see Scheibling \& Hatcher 2001 for a recent review) but is harvested mostly from counties on the Atlantic coast. A largely unexploited resource is thought to exist around Cape Breton Island. The fishery is dive-only and operates to depths of $15 \mathrm{~m}$. It began in 1989 although the catch remained at less than $100 \mathrm{t}$ per annum until the 1993-94 fishing season when there was an explosive increase in fishing effort, largely brought about by rises in the beach price (Fig. 23a). Almost all the catch is exported to Japan in some form. Most of the best quality sea urchins are shipped directly as whole animals, about $20 \%$ are processed in Nova Scotia and the remainder in Maine, before export to Japan. Most landings have come from Guysborough and Shelburne counties, but in 1998-99 and 1999-2000, Digby county accounted for $19 \%$ and $43 \%$ of the total catch, respectively. There is no recreational fishery for sea urchins in Nova Scotia and the illegal harvest is small.

The fishery is managed by the Department of Fisheries and Oceans (DFO). Until recently, DFO limited the number of licenses per section of coastline, usually a county, based on an assessment of the number of licenses that might be supported (DFO 2000a). Fishers competed for catch but there is no limit on total catch within each area. New entrants were required to land at least $4 \mathrm{t}$ per year to retain their license. There are no fishing seasons or Marine Reserves in Nova Scotia but a 50-mm MLS is observed.

Thirty per cent of the licenses have been given to First Nation fishers as communal licenses. They have not been required to meet participation requirements, but otherwise abide by the same rules as commercial licensees under the Fisheries Act. In a 1992 decision of the Supreme Court of Canada, First Nation people were granted the right to take a small amount of any commercial species for food and ceremonial purposes, but they have rarely 

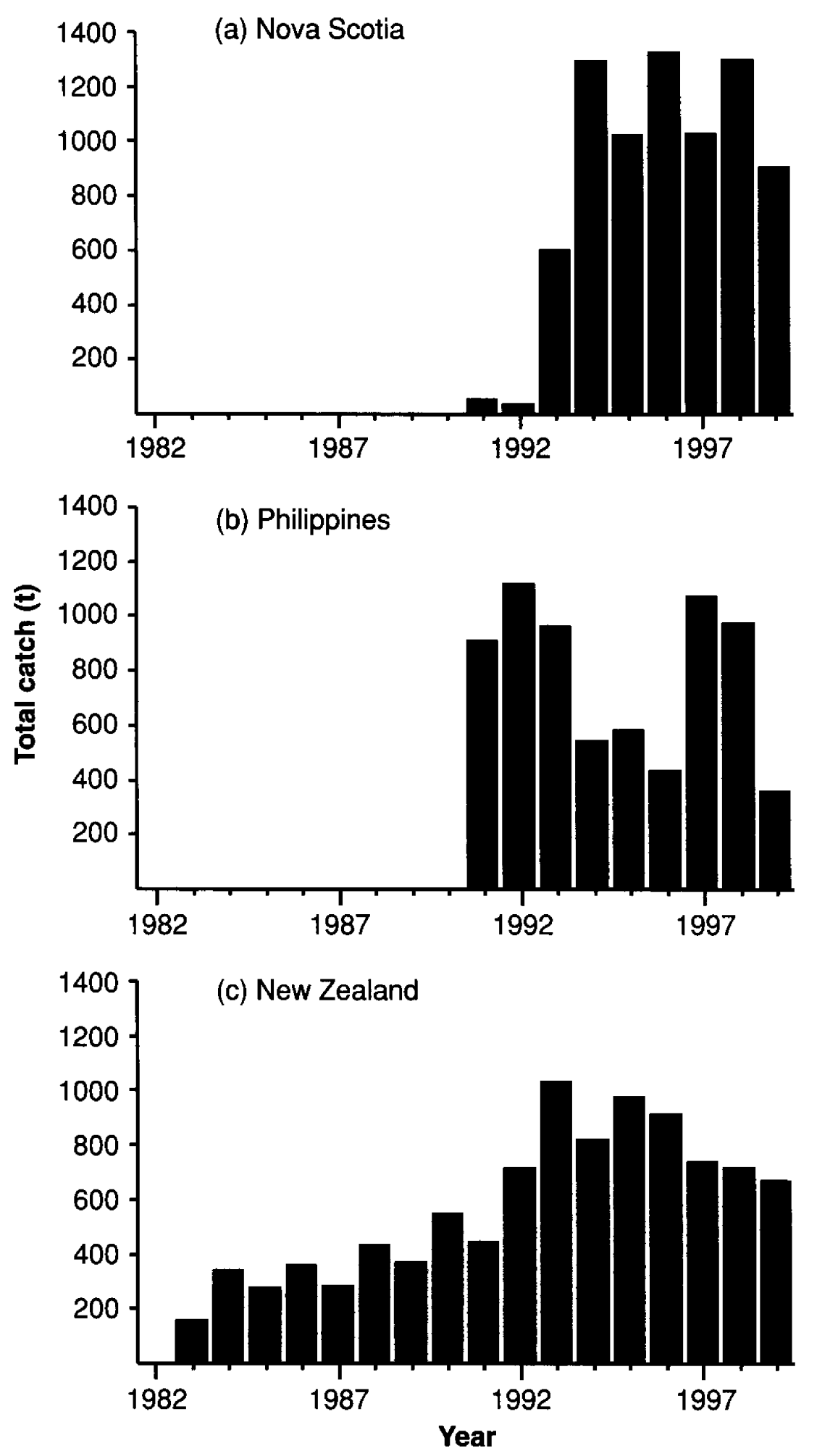

Figure 23 Total catch ( $t$ ) of sea urchins from (a) Nova Scotia, (b) the Philippines, and (c) New Zealand.

exercised that right. In a 1999 decision by the Supreme Court, First Nation fishers were furthermore allowed to take and sell enough fish to make a "moderate livelihood" under regulation by the management agency. Arrangements to comply with the second ruling are at present being negotiated. 
Management is evolving away from this competitive form of fishing to a unique system of area-based management in which individual licensees (or permit holders) have exclusive access to stretches of coastline (Miller \& Nolan 2000). So far as we are aware, in all other area-based systems of management, "ownership" is vested in groups or communities rather than individuals (but see pp. 393-405). Fishers may apply for a "restricted zone" after meeting specified guidelines: demonstrating a history of fishing sea urchins, providing a map of kelp and sea urchin distribution in the proposed zone (see below), promising to increase the habitat carrying capacity for marketable sea urchins, and promising to detail catches and fishing locations. The area requested is then surveyed by DFO and either the zone is granted or new borders are negotiated. After a four-year trial period the zone is surveyed again by DFO which then decides whether the zone has been fully used. If a significant portion of the beds has not been fished then a reduced zone size is negotiated. This form of management was initiated in 1995 and continues to develop, despite fisher resistance to changes in the size of zones. The MLS of $50 \mathrm{~mm}$ is still in force in the restricted zones. Exclusive access has many advantages, including the ability to harvest sea urchins at times and places that maximise roe recovery without competition. Furthermore, the benefits of enhancement, such as moving sea urchins to areas with more algae, accrue to the individual who invests time and money in the work.

The core of this management is the requirement for fishers to maintain a dynamic balance between sea urchin densities and kelp (Miller \& Nolan 2000). On the Atlantic coast of Nova Scotia sea urchins are most abundant in dense aggregations or "feeding fronts" that occur as bands at between $1 \mathrm{~m}$ and $15 \mathrm{~m}$ depth. Above this band there are dense kelp forests; below it sea urchins are less dense but sufficiently abundant to maintain the barrens habitat (Chapman 1981; see Scheibling \& Hatcher 2001 for the most recent review of the extensive ecological literature). The location of the feeding front along this depth gradient is determined by exposure to wave action, the time of year, and sea urchin density. As the sea urchins consume the algae, the aggregations move shoreward at a rate of 1-4 m per month (Breen \& Mann 1976, R. E. Scheibling, unpubl. data as cited in Scheibling \& Hennigar 1997). Fishers target the feeding fronts because roe recoveries are greatest there and fisheries managers use this relatively simple one-dimensional resource to simplify assessments. Within the restricted zones, assessments are based on the depth at which these bands are found as an index of exploitation and the length of the band along the shore is used as an index of the size of the resource (DFO 2000b, Miller \& Nolan 2000).

A series of species invasions in recent years has disrupted the dynamics of interactions between kelp and sea urchins (see Scheibling 2000, Scheibling \& Hatcher 2001 for review), and these changed dynamics pose a major threat to the fishery. The first and best documented invasion was that of a parasitic amoeba Paramoeba invadens (see Scheibling \& Hatcher 2001 for review). In the early 1980s more than $270000 \mathrm{t}$ of sea urchins were killed by the parasite (Miller 1985, Moore et al. 1986). Since its re-appearance in 1994, the parasite is thought to be responsible for the death of more than $100000 \mathrm{t}$ of sea urchins (R. J. Miller, unpubl. data). In Halifax, Lunenburg, Queens and Shelburne counties, mass mortalities from disease have reduced sea urchin densities below economically viable levels. In Guysborough county, at least $60 \%$ of the stock was lost to disease in 1999-2000 (Miller \& Nolan 2000). Most other counties have not experienced significant disease related mortality, and there remains a substantial sea urchin resource, much of which is currently unexploited. Sea urchins below the seasonal thermocline are believed to escape the disease and these sea urchins re-establish populations in shallow water, a process taking up to a decade (Scheibling 
2000). There is a need to develop a predictive model for the spread and effects of disease on the sea urchin and other nearshore fisheries.

A bryozoan, Membranipora membranacea, has colonised kelp forests in some areas (Scheibling et al. 1999). The appearance of the bryozoan, first observed in 1992, may accelerate the demise of kelp forests by reducing biomass (Dixon et al. 1981) and increasing the rate at which the feeding fronts move inshore (Scheibling et al. 1999). Coincident with the appearance of the bryozoan, the green alga Codium fragile has also appeared on the Nova Scotia coast (Chapman 1999). This species recruits to areas of what were barrens habitat following mortality of sea urchins and into kelp forests whose canopy has been disrupted by the bryozoan. C. fragile can out-compete kelp and thus has the potential to change the cyclic nature of habitat structure in Nova Scotia (Scheibling 2000). Although sea urchins will consume $C$. fragile, their roe is of a poorer quality (Prince \& LeBlanc 1992, Scheibling 2000).

The Nova Scotian sea urchin fishery has one of the most innovative management strategies anywhere. The exclusive access in restricted zones offers the potential to maximise the economic return from the resource while satisfying the management agency's responsibilities for sustainable harvest. Refuges are provided by barrens habitat too deep for divers to harvest and in areas where sea urchins are too few or have roe recovery too small to harvest economically. Spawning is protected by the MLS: green sea urchins become reproductive at about $25 \mathrm{~mm}$ (Miller \& Mann 1973, Wahle \& Peckham 1999), well below the MLS of $50 \mathrm{~mm}$. Perversely, however, the re-emergence of disease (Scheibling \& Hennigar 1997) and the complicating effects of other invading species makes long-term sustainable harvest a difficult management objective. The effects of these invaders and the timescale over which they operate makes predictions highly uncertain. Under these circumstances, the explicitly experimental nature of the restricted zones offer possibly the best chance of maximising yield and increasing understanding of these complex dynamics.

\section{Philippines}

Sea urchins are a common part of the diet of many coastal communities and are harvested by shore-collecting and diving on reefs where seagrass and algae (e.g. Sargassum) are abundant. The most commercially important sea urchin species is Tripneustes gratilla although other species, such as Diadema setosum are also harvested for local consumption (JuinioMeñez et al. 1995, 1998, Talaue-McManus \& Kesner 1995). One of the most important regional fisheries in the Philippines is in northwestern Luzon. There is a large domestic market centred on Manila and most of the exported product goes to Japan as fresh whole sea urchins or processed roe products (unpubl. data from the Bureau of Agricultural Statistics).

As with other invertebrate stocks in the Philippines (Ross 1984, Juinio et al. 1989), few reliable statistics are available on sea urchin fisheries. FAO catch data are confounded by the large fishery for holothurians (Trinidad-Roa 1988, Conand \& Byrne 1993). FAO reports catches of echinoderms of between $1487 \mathrm{t}$ and $4071 \mathrm{t}$ since 1985 but most of this appears to be holothurians (Conand \& Byrne 1993). Nevertheless, catches of sea urchins in the Philippines appear to be substantial; minimum estimates of catches since 1991 may be reconstructed from recorded exports of sea urchin products using unpublished data kept by the Bureau of Agricultural Statistics. Assuming a roe recovery rate of $15.8 \%$ (M. A. JuinioMeñez, unpubl. data), a time series of exports from the Philippines since 1991 in whole 
animal wet weight may be derived (Fig. 23b). Exports fell sharply between 1994 and 1996 but recovered in the late 1990s before declining again in 1999 to be at their lowest level since 1991 (Fig. 23b).

The pattern of development and collapse in the commercial fishery for Tripneustes gratilla in Bolinao is typical of other sea urchin fisheries in the Philippines (Talaue-McManus \& Kesner 1995). In Bolinao harvesting for export began in the 1970s and developed through the 1980 s as an unregulated open access fishery. In 1988, a seasonal closure was implemented but this was enforced for only two years and did little to slow the decline in catch (Juinio-Meñez et al. 1998) and the fishery collapsed in 1992. Ironically, the Municipal Government prohibited commercial harvesting of sea urchins in Bolinao in 1993, after the fishery collapsed. This prohibition remains in force but commercial harvesting of sea urchins resumed in 1998 after good recruitment occurred for the first time since 1992. The total landed catch in 1999 was approximately half of that in 1992 (A. Juinio-Meñez, unpubl. data). Catch rates in 1999 ranged between 0.7 and $2.8 \mathrm{~kg}$ roe person-day ${ }^{-1}$ and are comparable with those reported in 1991 and 1992 (Talaue-McManus \& Kesner 1995), prior to the collapse of the fishery. In the wake of this collapse, research on the culture and grow-out of sea urchins was undertaken to rehabilitate the fishery. The grow-out was based partially on the experience of fishers nearby who used grow-out cages on a small-scale to produce high quality sea urchins for the local market (Juinio-Meñez et al. 1998). This system is discussed in more detail in the section on enhancement (pp. 393-397).

\section{New Zealand}

In New Zealand, sea urchins are harvested in most regions by commercial, recreational and Maori customary fishers (McShane 1992). Although as many as 10 species of sea urchin are caught in commercial fisheries, Evechinus chloroticus is the only species targeted, and it accounts for more than $99 \%$ of the recorded catch and is the only species considered here. Most $E$. chloroticus are found in waters less than $10 \mathrm{~m}$ deep and are harvested by breathhold diving although about $10 \%$ of the total catch in the 1998-99 fishing year was taken by dredge. Almost all of the roe harvested in this fishery is consumed on the domestic market.

Customary Maori catches are poorly described but the total non-commercial harvest may be as much as $50 \%$ of the commercial catch. Commercial harvesting is concentrated in five of the ten fish-stocks. Commercial catch peaked in 1992-93 when $1032 \mathrm{t}$ was landed (Fig. 23c). Commercial harvest has declined each year for the last five years and a total of $663 \mathrm{t}$ was reported in 1998-99. No catch statistics are available before 1983.

Participation in the commercial fishery declined through the $1980 \mathrm{~s}$, rose to a peak of 138 fishers in 1991-92, then fell to 71 in 1999. There is considerable latent effort in the major fisheries: in 1998-99 more than $83 \%$ of the total catch was landed by $20 \%$ of the permit holders. These patterns, along with the overall decline in catch since 1993 is consistent with a "race for property rights" prior to imposition of the permit moratorium and in anticipation of the allocation of commercial individual transferable quota, in 2002. Catch rates from compulsory logbooks form the only time series of relative abundance data. Patterns are erratic in all major fisheries and probably do not reflect trends in stock size.

Commercial fishing is managed by a range of regulatory measures, including: (a) a moratorium on new permit holders since 1992, (b) limits on fishing methods (currently dredging and breath-hold diving only), (c) competitive TACs and daily catch limits in some 
fisheries, and (d) area closures. There are no seasonal closures or size limits in any fishery. The competitive TACs were set "administratively" in 1988 and were not based on an assessment of sustainable yield. Where present, competitive TACs are either not caught or exceeded, both by wide margins. Annual catches have varied erratically in most areas and there have been major declines in catch and effort in several since their peaks in the early 1990s. There is considerable latent effort in all the major fisheries; the catch landed in 1998-99 was taken by a small proportion of permit holders.

Although there is a wealth of information on the biology and ecology of this species (see Andrew 1988, Barker 2001 for reviews), there are no estimates of biomass, trends in relative abundance or assessments of sustainable yield for any fishery. An experimental fishery in Dusky Sound was established in the early 1990s to estimate productivity and the effect of fishing on associated biota (McShane 1992). Stock size was to be estimated by depletion methods but this was unsuccessful because only $133 \mathrm{t}$ of the projected $1000 \mathrm{t}$ was caught (McShane et al. 1994). This catch was insufficient to cause a measurable change in estimated biomass. This fishery failed, in part because it could not reliably produce roe of acceptable quality for the Japanese market. No other attempts to develop export markets have succeeded (McShane et al. 1994).

Little is known of the ecological effects of $E$. chloroticus fisheries. The species removes all large brown algae from areas of reef in some parts of the country but not others (Barker 2001). It is likely that large-scale commercial fisheries will have complex effects that need to be managed. Nevertheless, management of New Zealand's sea urchin fisheries retains a single-species focus.

\section{Spain}

Information on the fishery in Spain is difficult to obtain: FAO reports catches only since 1996 with a maximum catch of $595 \mathrm{t}$ in 1997 . Most of this catch comes from the northern Atlantic regions of Galicia and Asturias, where Paracentrotus lividus is harvested. Sea urchins are collected both in the intertidal zone and from subtidal reefs (Haya 1988) and the majority of the harvest is canned and sold domestically (E. Ballesteros, unpubl. data). Sea urchins are also harvested from the south of Spain, mainly for festivals but little is known of this fishery.

On the Mediterranean coast of Spain, sea urchins ( $P$. lividus) are harvested mostly in northern Catalonia (Ballesteros \& Garcia 1987, Le Direac'h et al. 1987) and catches have increased in the last two last decades as consumption of sea urchin roe has become more popular. Breathhold diving has become the prescribed method of harvest in Catalonia, where commercial divers must have a licence to harvest shellfish, including sea urchins. The fishery is not capped by a TAC. SCUBA is allowed in other regions in Spain, such as the Balearic Islands. There are no size limits or closed seasons in place in Spanish sea urchin fisheries.

The sea urchin resource in Catalonia is considered to be large (Lozano et al. 1995, Turon et al. 1995, Palacín et al. 1998a), largely due to the lack of disease (Boudouresque et al. 1980) and the cascading effects of intense fishing for predators of sea urchins (Sala \& Zabala 1996). The estimated abundance of sea urchins $>20 \mathrm{~mm}$ on reefs in depths $<10 \mathrm{~m}$ is roughly 280 million individuals for the whole coast of Catalonia (Palacín et al. 1998a). Commercial landings in Catalonia are recorded from 1992, and according to data supplied 
by the Fisheries Department they range between $0.5 \mathrm{t} \mathrm{yr}^{-1}$ and $9 \mathrm{t} \mathrm{yr}^{-1}$ (mean $=5 \mathrm{t} \mathrm{yr}^{-1}$ in the last four years). These estimates are considered to significantly underestimate the commercial catch because a large proportion of the harvest is sold directly to retailers or otherwise processed and does not pass through the wholesale channels. The true landings in Catalonia, including those from the recreational sector are likely to be between $30 \mathrm{t} \mathrm{yr}^{-1}$ and $40 \mathrm{t} \mathrm{yr}^{-1}$ (E. Ballesteros, unpubl. data) or $1 \%$ of the total harvestable population on reefs in $<10 \mathrm{~m}$ depth (Palacín et al. 1998a). There is growing evidence that densities of sea urchins are increasing in northern Catalonia, and threatening populations of large brown algae (Verlaque 1984, Palacín et al. 1998b).

\section{Washington (USA)}

\section{The fishery}

Washington's commercial fishery for red sea urchins (Strongylocentrotus franciscanus) began in 1971 and quickly developed into a $700 \mathrm{t} \mathrm{yr}^{-1}$ fishery (Fig. 24). The fishery extends from the San Juan Islands to Cape Flattery, at the mouth of the Strait of Juan de Fuca. Catches in the early 1980s slumped because poor roe quality disrupted market confidence but they rebounded to a peak of $4024 \mathrm{t}$ in 1988. Landings fluctuated for the next four years before declining sharply in 1993 to $503 \mathrm{t}$ and have slowly declined since to a low of $217 \mathrm{t}$ in 1999 (Fig. 24). Beginning in 1986, a small fishery developed for green urchins, S. droebachiensis. This fishery also peaked in 1988, when $464 \mathrm{t}$ was landed (Fig. 24). Since then catches have ranged between $442 \mathrm{t}$ in 1992 and $91 \mathrm{t}$ in 1998 with no consistent pattern. Because quotas have remained stable for green sea urchins since 1995, market quality and the timing of the spawning season are the primary influences on catch.

Catch rates of red sea urchins increased through the 1970s as the fishery developed and peaked in 1985 at $2536 \mathrm{~kg}$ vessel-day ${ }^{-1}$ (Fig. 24). Catch rates plummeted the following year

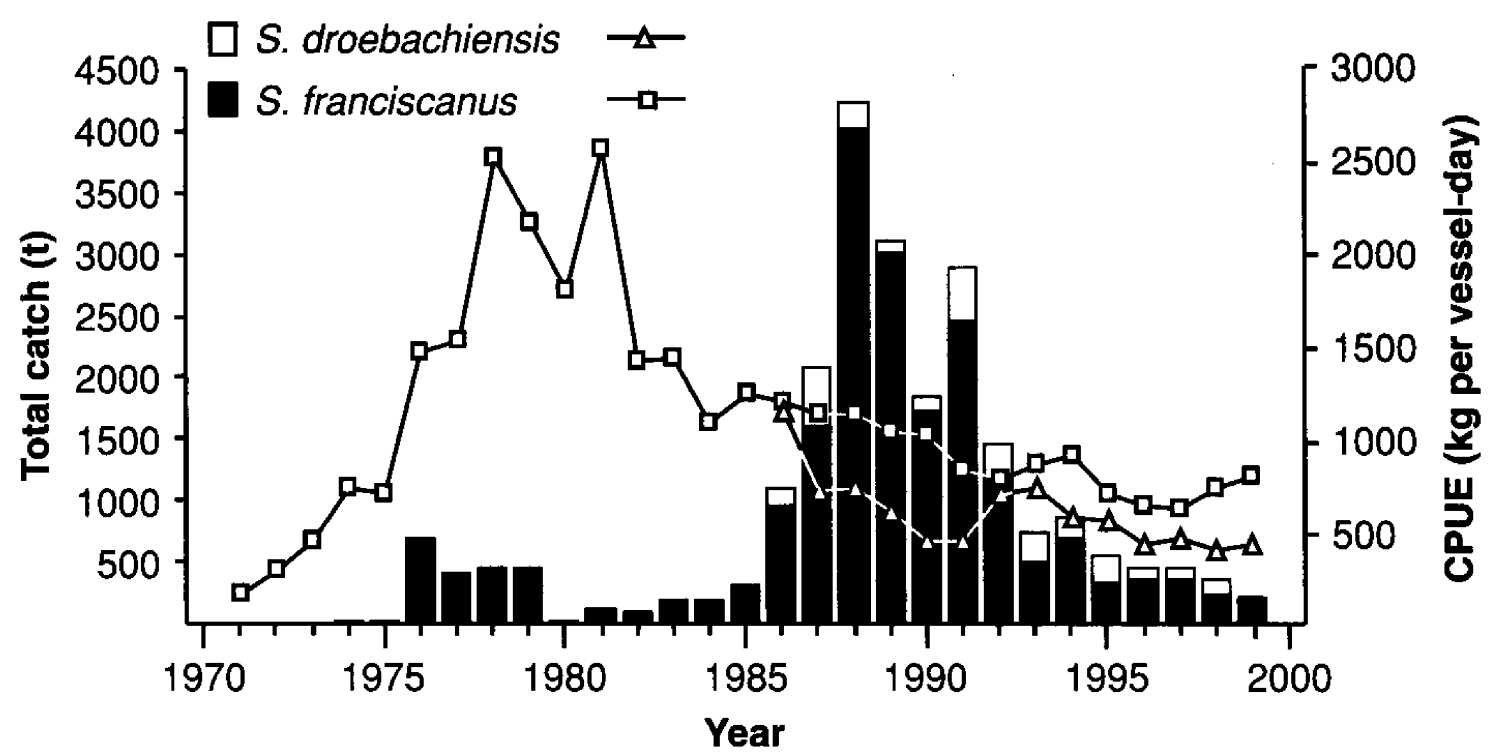

Figure 24 Total catch ( $\mathrm{t}$, bars) and catch rate $\left(\mathrm{kg}\right.$ vessel-day ${ }^{-1}$, lines) of sea urchins from Washington (USA). 
to only $1412 \mathrm{~kg}$ vessel-day $^{-1}$ and steadily declined through most of the 1990 s (Fig. 24). A sharp drop in catch rate in 1995 may be attributed to the entry of large numbers of new divers following the advent of the tribal fisheries (see below). In 1999 catch rates were slightly over half those in 1986. Catch rates of green sea urchins have also declined over the life of the fishery but the changes are both less extreme and less consistent. Catch rates for red sea urchins have risen in the last few years and preliminary estimates for the year 2000 suggest they may be as high as $1085 \mathrm{~kg}$ vessel-day ${ }^{-1}$ (A. Bradbury, unpubl. data). Catch rates for green sea urchins have remained relatively consistent since 1996 (Fig. 24).

\section{Management}

The red sea urchin fishery was regulated only by licensing and catch reporting requirements before 1977 , when a range of measures was introduced. Of these, the most significant was a rotational fishing scheme in which harvesting was limited to two of five zones that were rotated every three years (in the third year of rotation only one of the five zones was fished). In 1977 fishing was restricted to winter and size limits were introduced to protect the smallest $20 \%$ and largest $20 \%$ of the population. At the San Juan Islands, sea urchins between $102 \mathrm{~mm}$ and $140 \mathrm{~mm}$ were vulnerable to the fishery and those in the range 83$114 \mathrm{~mm}$ could be harvested in the remaining three zones in the Strait of Juan de Fuca. The introduction of a MxLS was based on the observation that juvenile red urchins were abundant under the spine canopy of adults (Bernard \& Miller 1973, Tegner \& Dayton 1977, and see Cameron \& Schroeter 1980, Breen et al. 1985). The MxLS was not well-observed by the fleet and over-legal-sized sea urchins constituted a significant proportion of the catch (Pfister \& Bradbury 1996).

In 1977 there were 12 boats in the fleet and this increased only slowly until 1986 when the fleet approximately doubled each year until 1989, when there were 189 boats. The explosive growth of the fleet prompted an emergency closure of the fishery in 1988, when mid-season surveys in one zone suggested that legal-sized sea urchin density had declined by $63 \%$. Following the peak season in 1988 , the fishing season was further restricted and a limited entry scheme reduced the fleet by $67 \%$. From 1988 until 1993, when a model-based quota system was established, managers made ad hoc adjustments to season length based on the observed trends in sea urchin density and size at index stations.

In 1994, the U.S. Federal District Court granted 16 First Nation tribes access to half the annual sea urchin quota, but tribal fishers did not enter the fishery until 1996. Each of the 16 tribes was legally constrained to fish within "usual and accustomed" fishing areas, preventing them from participating in the large-scale rotational fishing system. As a consequence, the rotational fishing scheme introduced in 1977 was abandoned.

The green sea urchin fishery was regulated from its beginning with ad hoc annual quotas. These ranged from a high of $455 \mathrm{t}$ in 1987 to $227-272 \mathrm{t}$ since 1992. A MLS of $57 \mathrm{~mm}$ was also imposed in 1987, based on an assumed size-at-maturity of $50 \mathrm{~mm}$. Harvesting typically has been allowed earlier in the year than red sea urchin fishing because of earlier maturation of green sea urchin gonads. During December and January both fisheries are open.

\section{Assessment and Status}

The most important data for the fishery for red sea urchins is a time series of relative abundance indices (Pfister \& Bradbury 1996, Lai \& Bradbury 1998). Biomass at index 
stations was estimated using either a change-in-ratio estimator or an adaptive cluster sampling design. Surveys began in 1984 but the programme was reduced in 1995 and terminated in 1997 (Lai \& Bradbury 1998). In 1993 and 1994, underwater video was used in the San Juan Islands to estimate the density of red sea urchins and sea cucumbers (Parastichopus californicus), using a stratified systematic sampling design (Bradbury et al. 1998). These surveys provided estimates of the relative abundance of sea urchins in three size classes (undersize, size and oversize with respect to the size limits). At the San Juan Islands, densities of legal-sized red sea urchins halved between 1988 and 1989; catch rates in the same area declined only about $10 \%$. Changing diver behaviour, such as increasing depths for harvesting, and fishing in new areas (Pfister \& Bradbury 1996) make interpretation of these trends in catch rate difficult. Nevertheless, the overall decline in catch rate suggests an overall reduction in abundance.

The Washington fishery has been assessed using a size-structured model that evolved from a relatively simple simulation model to an assessment model designed to provide management advice (Pfister \& Bradbury 1996, Lai \& Bradbury 1998). Pfister \& Bradbury (1996) used a relatively simple size-structured model to explore the effects of assumptions about population processes such as constant recruitment and positive density dependence caused by fertilisation success and canopy sheltering behaviour noted above. The impacts of these assumptions were compared under deterministic projections of up to $100 \mathrm{yr}$. Including positive density-dependence in population processes caused significantly greater declines in the modelled population under fishing. Variable recruitment increased uncertainty considerably and only relatively light fishing was sustainable. Under variable recruitment the period of rotation had to be longer than two years to maintain the population at greater than $50 \%$ of pre-fishing biomass. Ebert (1998), however, subsequently disputed the importance of positive density-dependence in sea urchin population models, based on tagging studies in Washington and Oregon.

Beginning in 1993, a size-structured model fitted to survey data and population sizefrequency distributions has been used to recommend harvest rates in the five management areas (Lai \& Bradbury 1998). The model results supported the earlier finding of Pfister \& Bradbury (1996) that periodic rotation reduced yields but lowered the risk of stock collapse and year-to-year variability in yield. The model predicted that yields would be maximised for a three-year rotational system with a $20 \%$ harvest rate, and for an every-year fishery with a $10 \%$ harvest rate. When Washington switched to an every-year fishery, annual harvest rates ranged from $3-9 \%$ of the estimated harvestable biomass. These rates varied by zone based on the estimated proportion of the unfished biomass remaining in a zone. In 1998, red sea urchin TACs were reduced by $15 \%$ from the 1997 levels as an arbitrary precaution in the absence of survey data. There have been no formal assessments of the green sea urchin fishery. Although surveys done in 1993-94 to estimate the density of red sea urchins also counted green sea urchins, these estimates were believed to be unreliable for green sea urchins.

\section{China}

Sea urchin fisheries in China are concentrated in the Yellow Sea and, to a lesser extent, the South China Sea. Four species are harvested: Hemicentrotus pulcherrimus, Strongylocentrotus nudus, Anthocidaris crassispina and Glyptocidaris crenulatus. Of these, the second and fourth are the most important. The fishery for $G$. crenulatus is restricted to the northern 
Yellow Sea where it is caught by dredge at depths between $20 \mathrm{~m}$ and $30 \mathrm{~m}$. The remaining species are collected by hand in the intertidal zone, by diving, and in the shallow subtidal zone from small boats using rakes and spy-glasses. The fishing season for $G$. crenulatus and Strongylocentrotus nudus is between November and June, and Hemicentrotus pulcherrimus are caught between October and December. There are MLS restrictions for $H$. pulcherrimus $(30 \mathrm{~mm})$ and for Strongylocentrotus nudus $(50 \mathrm{~mm})$.

Few formal statistics are available for Chinese sea urchin fisheries. FAO statistics report small catches of less than $300 \mathrm{t} \mathrm{yr}^{-1}$ for all echinoderms combined, but these are almost certainly underestimates of actual harvest. Japanese import statistics suggest there is a much larger fishery. In 1999, for example, $382 \mathrm{t}$ of roe was imported to Japan (see Table 1, p. 345). Since 1986, up to $50 \mathrm{t}$ of Hemicentrotus pulcherrimus has been exported to Japan from Qingdao each year but, since 1989, there appears to have been a mass mortality of this species and catches have ceased. The combined catch of Strongylocentrotus nudus and Glyptocidaris crenulatus from the Yellow Sea reached $1200 \mathrm{t}$ in 1995 with G. crenulatus accounting for $60 \%$ of this catch. Landings have subsequently declined, possibly because of over-fishing and less than $50 \mathrm{t}$ was reported landed in 2000.

\section{Oregon (USA)}

The fishery for red sea urchins (Strongylocentrotus franciscanus) began at Port Orford in 1986. Landings in 1988 were less than $26 \mathrm{t}$, but rose rapidly, reaching a peak of $4222 \mathrm{t}$ in 1990. Since then landings declined rapidly to their 1999 level of $112 \mathrm{t}$ (J. Schaefer, Oregon Department of Fish and Wildlife, pers. comm, Fig. 25). The high catch rates in the early years of the fishery were maintained by divers moving to new grounds once the accumulated stocks had been harvested. The fishery is now believed to be reliant on annual recruitment (Richmond et al. 1997).

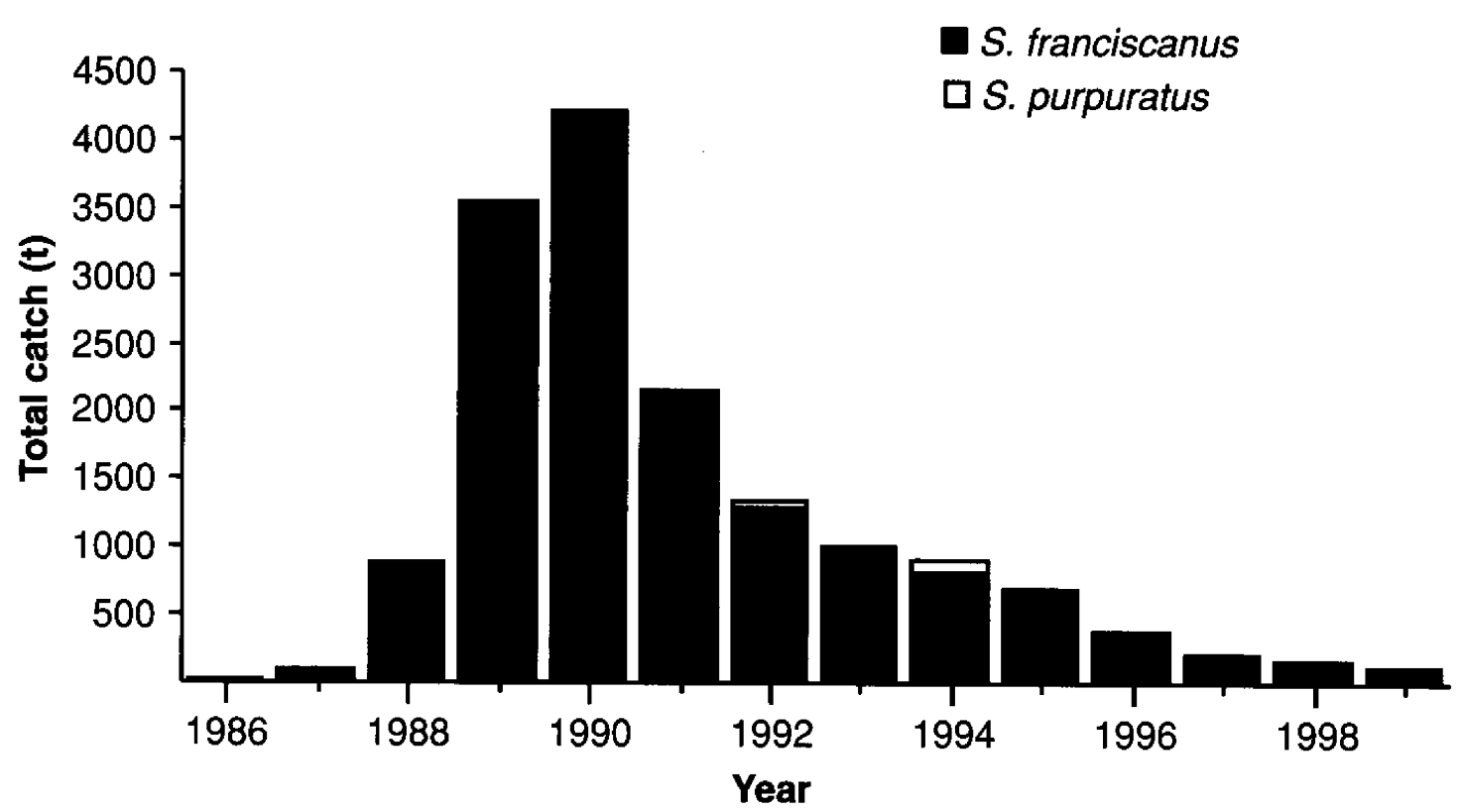

Figure 25 Total catch $(\mathrm{t})$ of sea urchins by species in Oregon. 
The fishery currently operates from six main ports from Bookings to Depoe Bay, but is concentrated in the far south of the state, and Port Orford in particular. The fishery is exclusively a dive fishery - divers typically work from boats less than about $12 \mathrm{~m}$ in length using surface-supplied air. The fishery was unregulated for the first two years but participation was then limited to 92 divers, each with a non-transferable license. In 1988, a MLS of 3 in $(76 \mathrm{~mm})$ and mandatory logbooks were introduced. In 1991 the MLS was increased to 3.5 in $(89 \mathrm{~mm}$ ) following per-recruit modelling (Golden et al. 1991, as cited in Richmond et al. 1997). In subsequent years several closures were implemented, notably around colonies of Northern (Steller) sea lions, and fishing was banned in very shallow waters ( $<10 \mathrm{ft}$ deep). In 1995 an effort reduction scheme was implemented to reduce participation to 30 divers. Under this scheme three permits have to be cancelled for each new entrant.

Catch rates declined from a peak in 1989 but have remained relatively stable since 1992 despite falling catches (Richmond et al. 1997). Similarly, the mean size of red urchins landed has declined and the proportion of large sea urchins has fallen sharply. Since 1994 poor gonad quality has changed patterns in fishing effort, confounding interpretation of trends in catch and effort. Although it currently produces only a little over $100 \mathrm{t} \mathrm{yr}^{-1}$, the fishery is believed to be stable. The management goal of 30 permits is believed to be sufficient to ensure sustainable catches (Richmond et al. 1997).

In 1991, the harvest of purple sea urchins (S. purpuratus) was allowed under a special permit. A MLS and other conditions governed harvesting. Area based quotas were set and areas were closed to fishing when densities dropped to $30 \%$ of their pre-fishing level (Richmond et al. 1997). Catches have always been small - they peaked in 1994 at $99 \mathrm{t}$ or $11 \%$ of the total harvest but have since fallen to less than $2 \%$ of a declining total harvest. Several sea urchin reserves have been established as unfished controls.

\section{Australia}

A small commercial fishery in Tasmania for the sea urchin Heliocidaris erythrogramma exports processed roe to the Japanese market (Dix 1977a,b, Sanderson et al. 1996, Keesing 2001). Harvesting is by diving only and the recreational and illegal fisheries are thought to be negligible. Annual landings have been less than $260 \mathrm{t}$ since the fishery's inception in 1986. Catch statistics are available only since 1990 and indicate few clear trends in either catch or catch rate over the last decade. Catches have increased in recent years, partially in anticipation of a management plan and further restrictions on participation. Roe recovery rates are low compared with other sea urchin fisheries. For the $10 \mathrm{yr}$ for which data are available, roe recovery averaged $4.3 \%$ (S.D. $=0.74$ ) but has increased for each of the last seven years. It is unclear whether this trend is caused by reductions in the density of sea urchins, increased diver experience or processes unrelated to the fishery. The only management in place in the fishery has been a moratorium on the issue of permits, possession of which entitles a diver to harvest without restriction. In 1998, only 15 of the 60 permitted divers participated in the fishery, so latent effort is of some concern. There have been no assessments of the status of stocks and there is little contrast in time series of catch rate (C. Johnson, unpubl. data). Trends in catch and effort are further confounded by poor data quality. A draft management plan proposes a MLS (Dix 1977b), closed areas and seasons, and effort controls. 
In New South Wales, two species are harvested in small but developing fisheries (King et al. 1994, Andrew et al. 1998, Byrne et al. 1998). The large, fast growing sea urchin Centrostephanus rodgersii is abundant and an important herbivore on shallow subtidal reefs (Andrew \& Underwood 1993, Andrew \& O’Neill 2000, see Andrew \& Byrne 2001 for review). Until recently there was an exploratory fishery only for this species and catches were less than $5 \mathrm{t} \mathrm{yr}^{-1}$ (Andrew et al. 1998) but, in 2000, $23 \mathrm{t}$ was harvested (C. Blount, New South Wales Fisheries, pers. comm.). Since 1998, a second species, Heliocidaris tuberculata, has been harvested, with more than $83 \mathrm{t}$ landed in 2000 (C. Blount, pers. comm.). Sea urchin harvesting is limited to 37 divers who own transferable licences to catch sea urchins by diving. Harvesting is restricted to approximately half the coastline of New South Wales. There have been no stock assessments of either species.

\section{France}

Sea urchin fisheries in France are some of the oldest in the world (Allain 1972, Le Direac'h 1987, Le Gall 1987). In their modern form they principally supply markets in Paris and Marsielle (Le Gall 1987, Boudouresque \& Verlaque 2001). The violet sea urchin, Paracentrotus lividus, dominates these fisheries and has traditionally been harvested in Brittany as well as in the Mediterranean (Le Gall 1987, Le Direac'h 1987, Le Direac'h et al. 1987). Sphaerechinus granularis and Psammechinus miliaris are also harvested for human consumption in Brittany and in the Mediterranean (Le Gall 1987, Guillou \& Michel 1993). Other species, such as Arbacia lixula and Echinus spp., are harvested to make curios for tourists (Sloan 1985, Le Direac'h 1987).

Sea urchins have been harvested in France using a variety of methods, such as hooks, grapples, and hand-held drags, but diving is now the predominant method (Le Gall 1987, Le Direac'h 1987). In the Breton fishery, a unique entanglement device, known as "le faubert" has been used to catch sea urchins since at least 1935 (Le Gall 1987). This method is considered to cause considerable incidental mortality of sea urchins as well as damage to the sea floor (Sloan 1985). A wide variety of management tools are used in French fisheries, including size limits, closed seasons, gear restrictions and marine reserves.

Reported landings in France peaked in 1945, when $1131 \mathrm{t}$ was landed, almost all of it from the Mediterranean fishery (Le Direac'h 1987). Catches have since declined considerably, and in 1998, only $59 \mathrm{t}$ was recorded in the FAO summaries for these fisheries (Fig. 26). For most of the 1950s and early 1960s the fishery in Brittany accounted for 30-60\% of national production before it collapsed in the late 1960s (Southward \& Southward 1975, Sloan 1985, Le Gall 1987). During this time catches in northern Brittany fell from more than $300 \mathrm{t} \mathrm{yr}^{-1}$ in 1962 to less than $60 \mathrm{t}$ in 1970, and subsequently to less than $30 \mathrm{t}$ (Fig. 26). Guillou \& Michel (1993) reported landings of $250 \mathrm{t}$ of Sphaerechinus granularis from the Glénan Islands in southern Brittany but these do not appear in the FAO summaries. Reported landings from the Mediterranean have declined over a longer time period from a peak of $1106 \mathrm{t}$ in 1945 to less than $60 \mathrm{t}$ in 1998 (Le Direac'h 1987) (Fig. 26). The abundance of sea urchins in the western Mediterranean, particularly around Marseille, appears to have fluctuated widely in response to fishing (both of sea urchins and, conversely, their predators), disease, and pollution (see papers in Boudouresque 1987 and Boudouresque \& Verlaque 2001 for review). The complexity of these processes and the absence of stock assessments make inferences about the current status of stocks difficult (Sala et al. 1998a, Boudouresque \& Verlaque 2001). 


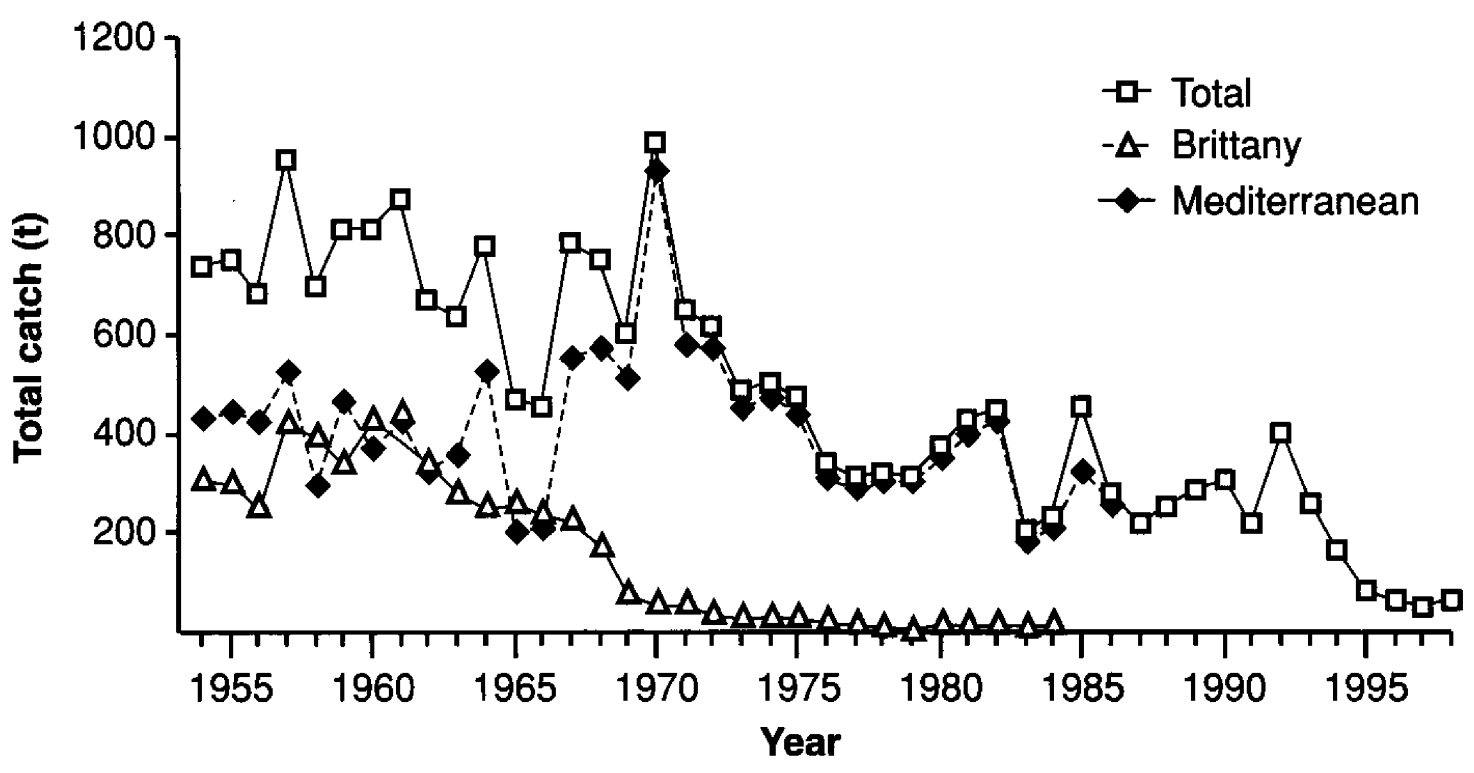

Figure 26 Total catch $(t)$ of sea urchins by region in France.

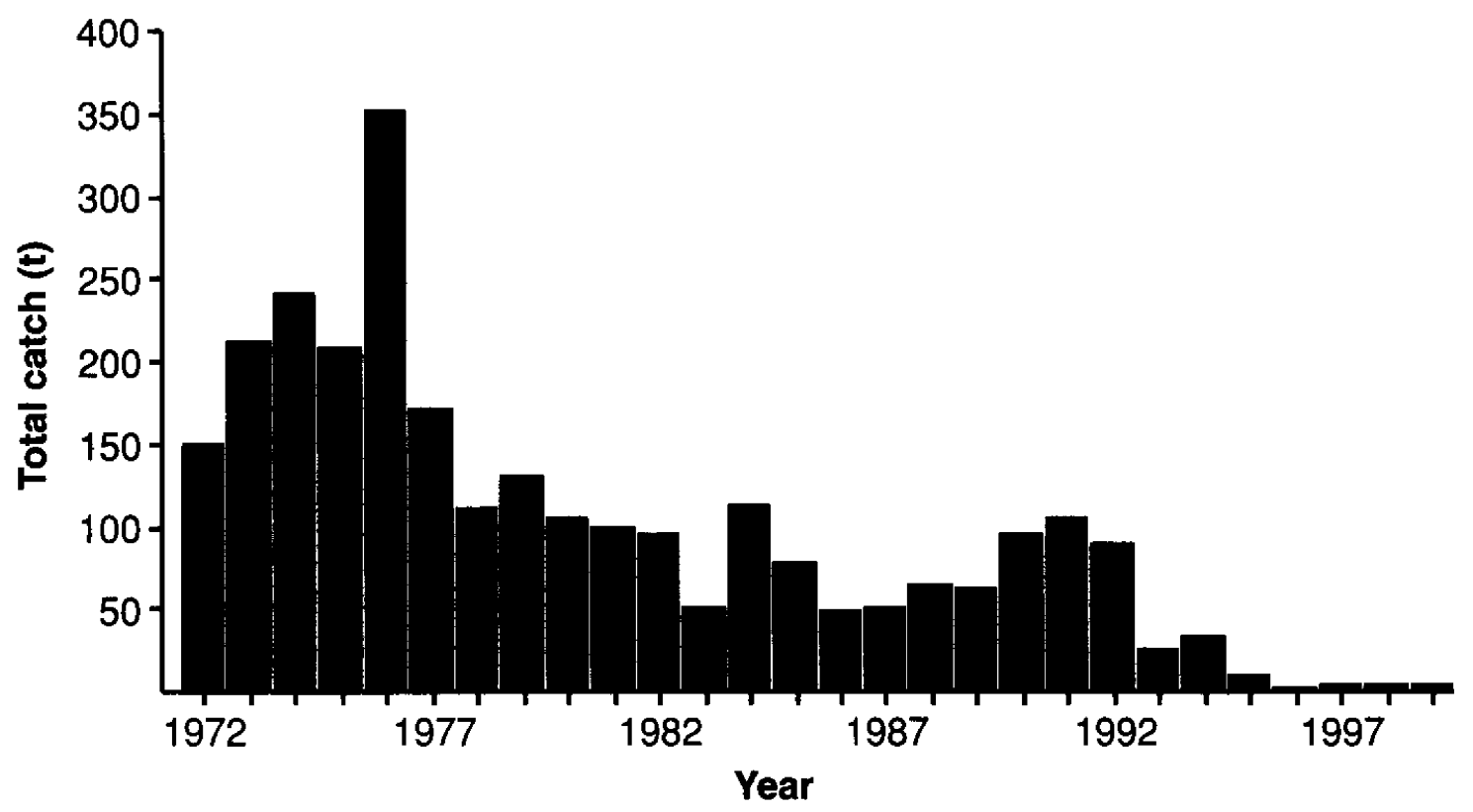

Figure 27 Total catch $(\mathrm{t})$ of sea urchins in Ireland.

\section{Ireland}

Paracentrotus lividus is common throughout rocky intertidal and shallow subtidal zones of southern Ireland and has been exported to France since at least 1948 but catches were relatively small until the Breton fishery collapsed (Southward \& Southward 1975, Sloan 1985). Recorded landings peaked in 1976 at just over $350 \mathrm{t}$ (Fig. 27) but landings were probably substantially under-reported (Moylan 1997). Landings have subsequently declined and in 1999 only $3.4 \mathrm{t}$ was reported (Fig. 27 and Barnes et al. 1999). Populations of $P$. lividus have been severely depleted in many areas of southern Ireland (Byrne 1990, Moylan 1997).

Many factors may have contributed to the demise of the Irish fishery, including long-term variation in recruitment, but the most likely and predominant cause is over-fishing. Through 
the $30 \mathrm{yr}$ that the fishery expanded, peaked and declined there were no government imposed constraints on catch or effort (Moylan 1997), there were no formal assessments of stock status and no assessments of the recovery of populations depleted by fishing (Moylan 1997). Market demand for sea urchins larger than $50 \mathrm{~mm}$ provided the only apparent constraint on harvesting (Sloan 1985, Moylan 1997).

\section{Iceland}

A fishery for the green sea urchin Strongylocentrotus droebachiensis, developed in Iceland in the early 1990s, primarily for the Japanese market (Einarsson 1994). The fishery had an explosive development, increasing from negligible amounts in 1992 to a peak of $1500 \mathrm{t}$ in 1994. In the two following years total catch declined to $500 \mathrm{t}$ in 1996 and $20 \mathrm{t}$ in 1997, with negligible catches since (Einarsson 1994, S. E. Einarsson, unpubl. data). The fishery began as a dive fishery but quickly changed to using a modified scallop dredge. The fishery declined precipitously, not because of over-exploitation but because of poor demand (Einarsson 1994). During the brief life of the fishery there were no management restrictions on effort or catch. The sustainable annual harvest of sea urchins is thought to be $1600 \mathrm{t}$ (Einarsson 1994).

\section{Other fisheries}

In addition to those described above, small fisheries exist in Barbados, Fiji, Peru, and North Korea, among other places. Information on these fisheries comes predominantly from FAO statistics. Based on 1998 FAO data these fisheries collectively account for less than $2 \%$ of world production. It is likely that much of the production of echinoderms in Fiji (503 $\mathrm{t}$ in 1998) was holothurians (Conand 2001) but there is insufficient information available to separate these taxa. Sloan (1985) reported a substantial fishery for Anthocidaris crassispina in Hong Kong (2000 $t$ in 1980) but there is little information available on this fishery and it is not included in estimates of world production.

Paracentrotus lividus has been harvested from Portugal, Morocco, and in the Mediterranean Sea for many centuries (Sloan 1985, Le Direac'h et al. 1987, Le Gall 1987, Boudouresque \& Verlaque 2001) but there is little published information on the current status of these fisheries. There are also small artisanal fisheries, particularly in the tropics, that remain poorly described in the international literature. In Barbados there is a fishery for Tripneustes esculentus with large fluctuations in catch (Lewis 1958). Scheibling \& Mladenov (1987) reported that the fishery had collapsed but more recent reports suggest it has recovered (Vermeer et al. 1994). At the Galapagos Islands an artisanal fishery takes $T$. depressus and there is considerable pressure to develop this into a commercial fishery as other near-shore fisheries, particularly those for holothurians, decline (P. Guarderas, pers. comm.). In North Korea, FAO reports only a small fishery that began in 1986 and peaked a year later at $250 \mathrm{t}$.

There are also developing fisheries in several eastern provinces in Canada, all for Strongylocentrotus droebachiensis. There are large resources of, but small fisheries for, sea urchins in Labrador and Newfoundland (R. Hooper, Memorial University, pers. comm.). The fishery in Newfoundland is at present expanding quickly and may develop into a major fishery (R. Hooper, pers. comm.). Largely unexploited resources also exist in Quebec 
(Himmelman et al. 1983, Bonardelli 1997, J. Himmelman, pers. comm.), Norway (Hagen 1987), and the Gulf of Mexico (Watts et al. 2001) among other places.

\section{Enhancement}

Enhancement of sea urchin fisheries may be divided into three categories: (a) reseeding, (b) habitat enhancement, and (c) transplantation in wild populations. We define "reseeding" as the release of hatchery-reared juveniles to augment natural recruitment. The term "sea ranching" is commonly used in the Japanese context to refer to such reseeding (e.g. Imamura 1999) but we reserve that term for husbandry of animals under semi-controlled conditions in the wild. Partially in anticipation of the demise of wild fisheries, aquaculture and sea ranching have become active fields of research (see the papers in Journal of Shellfish Research 17 (8) for a recent collection). Roe enhancement in wild populations involves transplanting wild juveniles or adults from habitats where somatic and gonadal growth are low to other habitats where they are higher. Adult sea urchins may also be transplanted to establish populations of sea urchins in areas that have been denuded. Although we briefly review the enhancement of wild populations by transplantation, sea ranching and land-based aquaculture are beyond the scope of this review.

\section{Reseeding}

The theoretical basis of stock enhancement by reseeding is the belief that populations are recruitment limited (Doherty 1999) (i.e. abundance is limited by processes acting on sea urchins before they settle and grow large enough to be sampled in the field). Such processes may include fertilisation success, food limitation, predation of larvae before and during settlement, and dispersal. Circumventing mortality in these early life-history stages by outplanting hatchery-reared juveniles holds the potential to improve on nature. Travis et al. (1998) put the argument neatly:

The appeal of stock enhancement rests in its simple premise and its bold promise. The premise is that we can raise large numbers of larvae or juveniles and, by releasing them successfully into the marine environment, compensate for the enormous natural mortality in these stages and thereby increase stock size in the late juvenile and early adult stages. The promise is that this intervention will compensate for the fishing mortality that created the problem in the first place.

Successful reseeding rests on the further assumption that the population receiving the out-planted animals is not near the carrying capacity of the environment. Theory contends that density-dependent processes, particularly food limitation, get stronger as a population approaches the carrying capacity. For reseeding to make sense, mortality of juveniles has to be relatively independent of density, at least within the range observed in the population receiving reseeded juveniles. If this were not the case then the reseeded sea urchins would simply "replace" those already in the wild population. There is relatively little evidence of density-dependent mortality in edible sea urchins (Lawrence 2001) and consequently the notion 


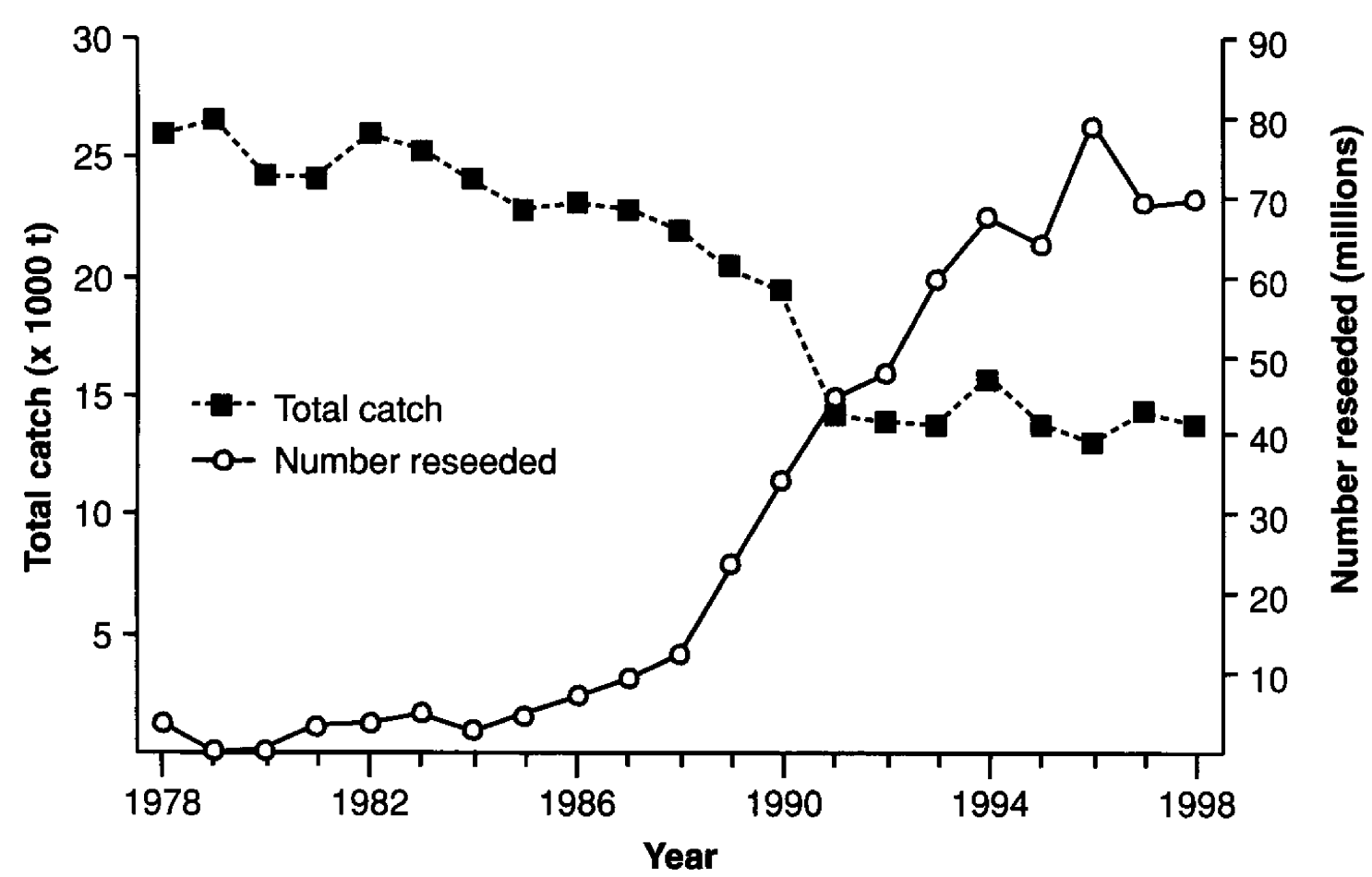

Figure 28 Total catch $(t)$ of sea urchins and number of sea urchins reseeded in Japan.

of an environmental carrying capacity for sea urchins is a little elusive. Sea urchins share attributes with other echinoderms (e.g. the lack of a large muscle mass) that buffer individuals from density-dependent mortality (Johnson \& Mann 1982, Andrew 1989). These generalisations suggest that sea urchins may be appropriate candidates for enhancement by reseeding.

Enhancement of sea urchin fisheries, particularly through reseeding, has reached its fullest expression in Japan where it has been a major management tool for more than a decade (Saito 1992, Imamura 1999). The number of sea urchins reseeded in Japan increased sharply in the late 1980s and has plateaued since 1994 (Fig. 28). In 1996, 78464 million sea urchins were reared in hatcheries and reseeded into the wild. Strongylocentrotus intermedius accounts for $84 \%$ of these, most being released in Hokkaido. Other species reseeded were: S. nudus, Pseudocentrotus depressus, Hemicentrotus pulcherrimus, Anthocidaris crassispina, and Tripneustes gratilla. Of these, only the reseeding programmes for Pseudocentrotus depressus and Hemicentrotus pulcherrimus are of any magnitude. Between 1980 and 1998, the number of Tripneustes gratilla and Anthocidaris crassispina out-planted rarely exceeded $200000 \mathrm{yr}^{-1}$ and there were many years when there were none. The effectiveness of the Japanese reseeding programme has not been evaluated on a national or prefectural scale (Saito 1992, Kitada 1999).

In South Korea, reseeding has only recently begun; 700000 juvenile $A$. crassispina and Strongylocentrotus intermedius of about $10 \mathrm{~mm}$ in size are now produced each year at national hatcheries and released onto reefs on the east coast (National Fisheries Research and Development Institute 2000). No information on the effectiveness of this programme is available. Of the remaining 16 fisheries that have produced more than $1000 \mathrm{t} \mathrm{yr}^{-1}$ at some stage in their history, only in the Philippines has reseeding research been scaled up to be a tool used in management.

In Bolinao, on northern Luzon Island in the Philippines, reseeding and grow-out of Tripneustes gratilla has been conducted since 1993 (Juinio-Meñez et al. 1998). This has 
been done both to re-establish a viable population after severe over-fishing and to provide a source of sea urchins for aquaculture. Since 1997, $40000-80000$ juveniles ( $>10 \mathrm{~mm})$ have been produced per year for reseeding or for small-scale grow-out culture. Since 1998, fishers have developed systems for holding sea urchins in cages on the reef flat and at any one time, 6000 to 10000 sea urchins are growing in these cages. The sea urchins are not harvested until they reach at least $70 \mathrm{~mm}$ and have the opportunity to spawn several times before being harvested, so the grow-out cultures function as reproductive reserves (Juinio-Meñez et al. 1998).

In addition, selected reef areas, including some within established marine reserves have been reseeded since 1996 (Juinio-Meñez et al. 1998). Populations of sea urchins on these reefs have increased significantly in comparison with those in nearby areas. To aid development of management policies for the Philippine enhancement programme, research is determining the genetic structure of $T$. gratilla populations along the western coast of Luzon. Numerical larval dispersal models indicate that the sea urchin populations in this region are not self-seeding and are regularly mixed due to hydrographic regimes associated with monsoons (Juinio-Meñez \& Villanoy 1995). This is corroborated by initial allozyme studies which indicate high levels of gene flow between populations in this region (Malay et al. 2001).

Evaluating the success of reseeding sea urchins is difficult because, unlike abalone and other reseeded species (e.g. Kojima 1995, Kitada 1999), sea urchins show no discernible differences between reseeded and wild individuals that can be detected in sampling programmes. To our knowledge, no methods to tag sea urchins externally have been developed that do not carry a significant risk of increased mortality and growth, both of which would bias estimates of the proportion of reseeded animals in the catch (Ebert 2001). Evaluating the effectiveness of sea urchin reseeding programmes where there are significant wild populations therefore presents significant methodological challenges. Internal tagging using PIT tags (Hagen 1998) and chemical tags such as tetracycline and calcein may offer the only immediate way forward. More fundamentally, the logical framework for reseeding programmes needs to change to be more experimental - size or growth differences between seeded and wild sea urchins in experimental areas and unseeded controls could provide a test of the effects of reseeding (Hilborn 1998, Leber 1999).

In California, the success of small-scale reseedings of Strongylocentrotus franciscanus has been evaluated using cultured juveniles marked with calcein (Ebert et al. 1992, Dixon et al. 1997). An experimental seeding of 5000 individuals at each of four sites indicated that first year mortality was extremely spatially variable and strongly size-dependent. Based on complete collections from large areas around the transplant sites, minimum survival at the four sites varied from $0 \%$ to $0.3 \%$ for $5-\mathrm{mm}$ sea urchins, $0 \%$ to $6.8 \%$ for $10-\mathrm{mm}$ sea urchins, and from $1 \%$ to $22 \%$ for $15-\mathrm{mm}$ individuals. In a second experiment, 10000 calcein tagged juveniles (mean size $19 \mathrm{~mm}$; range, $12-30 \mathrm{~mm}$ ) were released at two sites. At one site there was catastrophic mortality ( $>99 \%)$ in the second half of the first year, possibly due to asteroid predators (Pycnopodia helianthoides). At the second site, 19\% of seeded animals survived their first year. Growth was similar to that observed in wild populations (Ebert et al. 1999), and seeded animals began entering the fishery after $3 \mathrm{yr}$. The modal size of the seeded urchins reached the MLS after $5 \mathrm{yr}$ in the field. The proportion of seeded animals in controlled commercial harvests in the immediate vicinity of the seeded area varied from $6 \%$ after 3 yr to $26 \%$ after 5 yr. Based on exhaustive searches, about $10 \%$ of seeded sea urchins survived for 5 yr (J. Dixon, S. Schroeter \& T. Ebert, unpubl. data). As a result of extremely high early mortality, slow growth, and the expense of culturing animals to an effective 
seeding size of $15 \mathrm{~mm}$ or more, reseeding with hatchery-reared juveniles will probably not be economically feasible for most Strongylocentrotus franciscanus fisheries.

\section{Habitat enhancement}

The aim of habitat enhancement programmes is to expand areas of good habitat for sea urchins and promote colonisation of algae as food (Morikawa 1999). In Japan, stones and/or large cement blocks have been introduced in a number of prefectures to increase the area of appropriate habitat and provide more shelter, for example in Fukui Prefecture (Taki \& Higashida 1964), and in Hokkaido (Kawamura 1973, Agatsuma 1991; see also Mottet 1976, as cited in Tegner 1989).

In South Korea, $7.6 \mathrm{cu} . \mathrm{km}$ of artificial reefs have been established in 151649 ha of fishing grounds since 1971. These reefs are mostly large concrete structures, although steel is being increasingly used, and are made up of modules of $8 \mathrm{~m}^{3}$ each. The reefs have been established on all coasts but particularly on the east and south coasts. Since 1990, artificial reefs have been developed specifically for shallow-water species $(<10 \mathrm{~m}$ depth), particularly abalone, topshells, algae and sea urchins. These reefs are designed to enhance village-based fisheries and now account for approximately $30 \%$ of the reefs established each year. Despite the 30-yr history of this enterprise, the effects on coastal fisheries and ecosystems have not been analysed in any detail.

\section{Transplantation}

The weight of sea urchins caught is only one determinant of the value of the harvest. The time of year, and food quantity and quality also interact to determine size and quality of roe. Nutrients are stored in somatic cells within the gonad before being utilised in body growth or reproduction (Giese 1966, Holland et al. 1967). Most urchins harvested in the world are consumed in Asian markets and are most valuable prior to and in the early stages of gametogenesis when their roe are large but still firm in texture. Their value diminishes when sufficient gametes in the lumen of the gonad change the texture of the roe.

Roe enhancement in wild populations is most commonly achieved by transplanting adult sea urchins from areas with poor gonad development to kelp forests (Tegner 1989 and see below). Moylan (1997) reports that fishers on the west coast of Ireland moved sea urchins to increase roe size. In most other fisheries, e.g. Mexico (J. Palleiro, pers. obs.) and California (Tegner 1989), such work remains at a research scale and has not been commercialised. Sea urchin gonads can readily increase in size over a 3-4 month period at any time of year (e.g. Andrew 1986, Klinger et al. 1997, Vadas et al. 2000) but are most effectively manipulated in the months when nutrients are beginning to be mobilised for gametogenesis.

In Japan, somatic growth and gonadal development have been significantly improved by transplanting adult sea urchins from deep water or barrens habitat in most commercial species: S. intermedius and S. nudus (Kawamura 1965, 1966, Yano et al. 1994, Agatsuma 1997, Kawamata 1998), Hemicentrotus pulcherrimus (Kawana 1938), Pseudocentrotus depressus, and Anthocidaris crassispina (Nakamura \& Yoshinaga 1962). It is possible to increase roe size to $18 \%$ of body weight (the minimum considered commercially viable) in two months in aquaria, but usually this takes three months in the field (Agatsuma 1999). 
In California, the efficacy of transplantation as a means of enhancing the fishery for Strongylocentrotus franciscanus has been tested in a co-operative project with fishers. About 33000 small sea urchins were transplanted from barrens habitat to a kelp forest which had only a sparse population of mostly large sea urchins (Dixon et al. 1999). Survival and growth of the transplanted sea urchins were high. Thirteen months later, an estimated 58\% (95\% CI: $28-87 \%$ ) of the transplanted sea urchins were still alive and these animals grew $15 \mathrm{~mm}$ in that time. This is close to the maximum growth rate observed for red sea urchins between Alaska and San Diego, California (Ebert et al. 1999). Removal of approximately a third of the local population at the source site had no detectable effect on population density 13 months later, largely because of a extremely high recruitment there. Transplanted sea urchins had little effect on the two dominant species of large brown algae; the mean density of Macrocystis pyrifera increased slightly and Eisenia arborea declined by approximately $20 \%$ in the year following the transplantation (Dixon et al. 1999).

Dixon et al. (1999) concluded that transplantation of naturally occurring small sea urchins is a viable alternative to the more costly technique of reseeding hatchery-reared juveniles (see also Nova Scotia, p. 379). Areas of barrens habitat often do not support sea urchins of a marketable size or gonadal quality, but could provide a potentially large supply of animals for transplantation. Balancing these benefits are the possible adverse effects of overgrazing at transplant sites and of increasing rates of mortality by moving sea urchins from areas of barrens habitat which serve as de facto refuges from harvesting. Dixon et al. (1999) suggest that, given the high temporal and spatial variability in sea urchin recruitment, it is important to repeat commercial-scale transplantations to determine the costs and benefits during periods of below average recruitment.

\section{Ecological effects of fishing}

There are numerous examples in the literature of large-scale changes in the ecology of reefs as a result of harvesting ecologically important species, including sea urchins, fishes and predatory whelks. Examples may be found in many regions, for example, on rocky reefs in the Mediterranean (Sala et al. 1998a, but see Sala et al. 1998b), the northeast Pacific (Simenstad et al. 1978), Gulf of Maine (Witman \& Sebens 1992, Vadas \& Steneck 1995), Chile (Castilla \& Moreno 1984, Duran \& Castilla 1989), Australia (Andrew et al. 1998), and on coral reefs in the Caribbean (Hughes 1984) and Kenya (McClanahan \& Shafir 1990, McClanahan 1997). Regardless of the value judgements placed on changes in ecosystems, large-scale commercial sea urchin fisheries may have complex ecological effects, possibly disproportionate to the number removed (e.g. Andrew \& Underwood 1993). Below, we briefly review the ecological effects of fishing for sea urchins and associated species (see also Steneck 1997, Tegner \& Dayton 2000). The management responses to such effects are considered on pp. 402-405).

\section{Effects of harvesting sea urchins}

Most sea urchins harvested in the world's fisheries are hand-collected by divers or taken in the intertidal zone. In such fisheries the effect of harvesting is mediated through changes in 
the relative strength of interactions rather than direct damage to the sea floor (Dayton et al. 1998, Tegner \& Dayton 2000). Many species of sea urchin play important roles in the ecology of subtidal reefs; this literature has been exhaustively reviewed, most recently by Lawrence (2001), and will be only cursorily treated here. Experiments have repeatedly demonstrated strong effects of removing sea urchins but few studies of indirect effects have actually studied fisheries; inferences are usually drawn from the ecological literature and are based on small-scale experiments or the effects of catastrophic, large-scale reductions in sea urchin abundance. The greatest impact of removing many thousands of tons of sea urchins from temperate reefs is usually the rapid development of stands of large brown algae and consequent changes in the relative abundance of fishes and benthic invertebrates (see reviews in Lawrence 2001).

The ecological effects of the fishery in Maine are better understood than in most. Sea urchins are dominant grazers on shallow reefs (e.g. Ojeda \& Dearborn 1989, Steneck \& Dethier 1994, Steneck 1997, Scheibling et al. 1999). As the abundance of sea urchins has declined, the formerly widespread barrens habitat has increasingly been replaced by kelp forests (Vadas \& Steneck 1995, McNaught \& Steneck 1998). McNaught and co-workers have demonstrated that post-settlement mortality, thought to be caused by predation, significantly reduces recruitment of sea urchins within kelp forests (McNaught \& Steneck 1998, McNaught 1999, see also Balch \& Scheibling 2001). Thus, the development of kelp forests following intense fishing reduces recruitment and the productivity of the fishery. Reemergence of kelp forests as a dominant habitat also causes changes in local distribution patterns of other species, such as fishes (Levin 1994) and lobsters (Bologna \& Steneck 1993), which use kelp forests as shelter.

In Baja California there have been large increases in the purple sea urchin (Strongylocentrotus purpuratus) following fishing of its congener, S. franciscanus (J. Palliero, unpubl. data). This change was predicted by Schroeter (1978) who found that red urchins were competitively superior. In New Zealand, harvesting Evechinus chloroticus causes an increase in the abundance of large brown algae (McShane et al. 1994, Villouta 2000, Villouta et al. 2001). From research on an experimental fishery in Fiordland, Villouta (2000) suggested a threshold of 2-3 sea urchins $\mathrm{m}^{-2}$, below which large brown algae are able to reestablish themselves and a large change in community structures follows. The effect of harvesting $E$. chloroticus on other invertebrates and fishes is poorly understood.

In southern California, the fishery for Strongylocentrotus franciscanus interacted with large-scale oceanographic events associated with the 1982-84 El Niño to mitigate the effects of sea urchin grazing (Tegner \& Dayton 1991). Warm water associated with the 1982-84 El Niño reduced recruitment and consequently, the episodes of over-grazing by sea urchins that characterised earlier E1 Niños did not occur. In northern California, the red sea urchin fishery has had a positive effect on kelp forests and abalone. Aerial photographs during the period of intense sea urchin fishing, showed a dramatic increase in the surface canopy from 1982 to 1989. During this period, red abalone (Haliotis rufescens) grew faster and there were more large abalone present than before the sea urchin fishery began (Karpov et al. in press).

In France, Japan, Maine, New Brunswick and New Zealand a small proportion of the total catch is taken by dredging or dragging; in these fisheries harvesting may have a direct effect on the ecology of reefs. This has been studied in Maine and New Brunswick where dragging is used to harvest sea urchins from areas of consolidated cobbles and low-lying rock ledges to depths of $30 \mathrm{~m}$. Sea urchins, as well as other invertebrates and kelps may be abundant in this habitat type (Ojeda \& Dearborn 1989). In Maine, a variety of dragger 
designs are used and together they account for approximately $20 \%$ of the total landings. The heaviest design is a modified scallop dredge or "chain sweep" which is used in eastern Maine and in areas where the currents are stronger. Other designs such as "pipe drags" and "whale mouth drags", have been developed specifically for sea urchins; these have a lighter construction and are increasingly popular (Creaser \& Weeks 1998, Wahle 1999). The underside of a drag consists of chains arrayed in a rectangular grid or web and the sea urchins are "plucked" up through this web. Wheels and pipes in the front of the drag bounce it over boulders and other impediments.

Wahle (1999) described the short-term effects of dragging on cobble substrata and rocky reefs in Maine. Three drag designs were compared in an experiment in which five passes of a commercial dragger over fixed areas of substratum were compared with control areas. The majority of the catch (excluding rocks) in all three designs was sea urchins. Cobbles and boulders, as well as other by-catch accounted for a greater proportion of the total catch using the "chain sweep" drag. In all three designs, algae was only a minor proportion of the catch. The "chain sweep" design caused significant reductions in the abundance of large brown algae, but not in infaunal species or species diversity. The lighter "pipe" and "whale mouth" drags caused less damage, mostly to large kelp (Laminaria spp.) and did not significantly reduce species diversity or the abundance of infauna. Long-term effects and a consideration of dragging intensity were beyond the scope of Wahle's (1999) study but it is likely that repeated dragging will have more significant long-term effects.

In New Brunswick, two sites were experimentally fished to examine the impacts of scallop drags used to harvest sea urchins (Robinson et al. 2001). Immediately after fishing there was a significant decline in sea urchin densities and an increase in the number of broken sea urchin tests. Lobsters were absent from the dragged reef immediately after fishing but had returned within three months. Whelks, crabs and sculpins were more abundant in the dragged areas immediately after fishing, probably in response to the disturbance. The breakage rate of the kelp, L. longicruris increased over the course of the dragging operation. Although there were short-term impacts from a single dragging event, the observable effects on the reef were gone in less than 3 months. The longer-term effects of repeated dragging are unknown.

\section{Effects of other fisheries on sea urchins}

Other fisheries may affect the abundance of sea urchins and consequently the ecology of rocky reefs. Several case histories exist, notably sea otters in the northwestern Pacific (see below), lobsters in Nova Scotia and Maine (Scheibling 1996, Scheibling \& Hatcher 2001), sheepshead and lobsters in California (Cowen 1983, Tegner \& Levin 1983, Dayton et al. 1998), fishes in the northwestern Mediterranean (Verlaque 1984, McClanahan \& Sala 1997, Sala et al. 1998a,b), and lobsters and fishes in New Zealand (Babcock et al. 1999). In all of these instances, harvesting predators is suggested to have precipitated an increase in the abundance of sea urchins and the consequent community changes associated with high densities of sea urchins. The underlying strength of evidence for these inferences is strongest for sea otters. The ecological impacts of removing predators on sea urchin populations has been exhaustively reviewed - here we confine our discussion to the effect of other fisheries on sea urchins.

The increasing abundance and geographical range of sea otters (Enhydra lutris) presents a significant threat to sea urchin fisheries in Russia, Alaska, British Columbia, Washington, 
Oregon and California (Estes \& VanBlaricom 1985, Reidman \& Estes 1990, Watson et al. 1996). Sea otters were once widely distributed around the northern rim of the Pacific Ocean from northern Japan to Baja California (Estes \& VanBlaricom 1985, Estes \& Duggins 1995). Intensive harvesting through the eighteenth and nineteenth centuries had devastating effects and reduced the distribution of sea otters to a few remnant populations within this range (Pitcher 1989). In the wake of this hunting the abundance of sea urchins increased in areas that previously supported sea otters (VanBlaricom \& Estes 1988). Processes that determine the abundance of sea urchins outside the range of sea otters remain less well understood (Foster \& Schiel 1988).

The range expansion of sea otters has partly resulted from active management policies. For example, between 1965 and 1969, the Alaska Department of Fish and Game in cooperation with the U.S. Fish and Wildlife Service, transplanted 402 sea otters to six areas in southeast Alaska from the Aleutian Islands and Prince William Sound (Pitcher 1989). There are now more than 10000 sea otters in the region (Woodby et al. 2000) and their effect on sea urchin populations may be seen near Sitka. Sea otters have been locally common there since the early 1990s when they began expanding their range southward along Baranof Island into sea urchin fishery areas (D. Woodby, unpubl. data). A survey in 1993 indicated a $64 \%$ decline in sea urchin abundance. Because of the presence of sea otters and many cracked tests, this was attributed largely to sea otter predation. Further observations suggest that sea urchins remain at very low numbers in the area. The arrival of sea otters at other fished sites, such as Whale Bay on Baranof Island, and near Cape Chacon on Prince of Wales Island, during the 1990s resulted in similar reductions of sea urchin populations and the loss of these areas from the fishery. Given the recent history of sea otter expansions, the future of the red sea urchin fishery in Alaska is poor. In yet another twist in the sea urchinotter story, sea otters have again declined in numbers at the Aleutian Islands; Estes et al. (1998) attribute this decline to increased predation by killer whales (Orcinus orca).

In Russia, sea otters pose the greatest threat to the sea urchin fishery on the Kamchatka Peninsula where they have effectively removed all large sea urchins from shallow reefs within their range. Their distribution is expanding north from Lotka Cape. Between 1985 and 1988 the northern limit of their distribution was near Utashud Island, but this boundary has since moved more than $80 \mathrm{~km}$ northward, to Asatcha Inlet. As a result of this range extension, the density of sea urchins in water less than $10 \mathrm{~m}$ deep has declined considerably and the maximum size has halved (A. Bazhin, unpubl. data). Associated with these declines in sea urchin density, forests of the kelp Alaria fistulosa have appeared. The appearance of sea otters in Listvenichnaja and Russkaja Inlets, in 1995, caused a collapse of populations of sea urchins there from $1.21 \mathrm{~kg} \mathrm{~m}^{-2}$ to $0.19 \mathrm{~kg} \mathrm{~m}^{-2}$ (A. Bazhin, unpubl. data).

In British Columbia, sea otters were re-introduced to one locality between 1969 and 1972 and have subsequently colonised new areas, increasing in number at about $18.6 \%$ per annum (Watson et al. 1996). Sea otters are now found on the northwest coast of Vancouver Island and the central portion of the British Columbia coast (Watson \& Smith 1996, Watson 2000). As in other areas colonised by sea otters, populations of sea urchins as well as abalone and clams such as geoducks (Panopea abrupta) are greatly diminished. As sea otters continue to increase in numbers and range they will increasingly compete with invertebrate fisheries. In British Columbia the threat is greatest for red sea urchins because of the great overlap in the ranges of the two species, particularly north of Vancouver Island (Watson \& Smith 1996). The fishery for green sea urchins is concentrated in more sheltered waters inside Vancouver Island. Sea otters are considered threatened under both Provincial and Federal laws and are 
a protected species in British Columbia. At present there is no plan to manage sea otters nor to co-manage these interacting species.

Other fisheries, such as those for lobsters and predatory fishes may also have impacts on sea urchin abundance but the evidence is less compelling than for sea otters. The effect of harvesting lobsters and predatory fishes in the Gulf of Maine and Nova Scotia has been a matter of contention for nearly thirty years (Mann \& Breen 1972, Elner \& Vadas 1990, see Chapman \& Johnson 1990, Scheibling 1996 for reviews). Witman \& Sebens (1992) and Vadas \& Steneck (1995) concluded that the large populations that now support the sea urchin fishery in the Gulf of Maine are the result of over-fishing for cod, wolfish and haddock. This conclusion was based on studies conducted along an inshore to offshore gradient. Nearshore reefs and islands generally contained fewer and smaller sized fish, high densities of sea urchins and sparse populations of kelp, whereas offshore islands contained large macroalgal populations, few or no sea urchins and an abundance of large predators. Sea urchins that were tethered along the gradient were taken by fish predators at higher rates on offshore islands than on near-shore reefs. The reduction of large predatory fish in nearshore areas is thought to have occurred primarily during the last three centuries (Aronson 1990, Witman \& Sebens 1992, Vadas \& Steneck 1995). Explorations of Indian middens have revealed an abundance of large fish ( $>90 \mathrm{~kg}$ ), mostly cod. These fish were probably caught in estuarine-coastal waters and were members, at least seasonally, of nearshore trophic webs. It likely that colonial and more recent fishing activities had a positive impact on nearshore sea urchin populations in the Gulf of Maine.

The progressive disappearance of communities dominated by large brown algae in the genus Cystoseira in the Mediterranean began in the 1960s and 1970s (Verlaque 1984). The decline of these communities seems to be due both to increased coastal eutrophication (Hoffmann et al. 1988, Cormaci \& Furnari 1999) and the over-exploitation of sea urchin predators, which allows sea urchins to increase in numbers and ultimately to over-graze Cystoseira meadows, transforming them into areas of barrens habitat (Verlaque 1984, Sala et al. 1998a,b).

Abalone co-occur with sea urchins in many temperate regions and the relationships between co-occurring species pairs appear to vary from competition to mutualism. In California, South Africa and Japan juvenile abalone shelter under the spine canopy of sea urchins (see Tegner \& Dayton 2000 for review) and removal of sea urchins causes a decline in local abundance of abalone. In New South Wales, Australia, sea urchins competitively displace abalone (Andrew \& Underwood 1993, Andrew et al. 1998). When sea urchins were removed from reefs to simulate fishing, the abundance of abalone increased dramatically over a 3-yr period.

In California red abalone (Haliotis rufescens) co-occur with red (Strongylocentrotus franciscanus) and purple (S. purpuratus) sea urchins and may compete for food and shelter (Tegner \& Levin 1983, Karpov et al. in press). Abalone and red sea urchins are segregated in space with the former being more abundant in areas with a high biomass of large brown algae. Evidence for competition comes from Karpov et al.'s (in press) comparisons of abundance and size-structure between fished and unfished reefs in northern California. The reduced abundance of red sea urchins, and subsequent increase in biomass of large brown algae might further increase abalone abundance through increases in food availability (Karpov et al. 1998).

Macroalgae are harvested in several regions where sea urchins are harvested (Vásques 1995) but little is known of the effect of this harvest on sea urchin fisheries. In California and Baja California, Macrocystis pyrifera is harvested, but this is thought to have little effect 


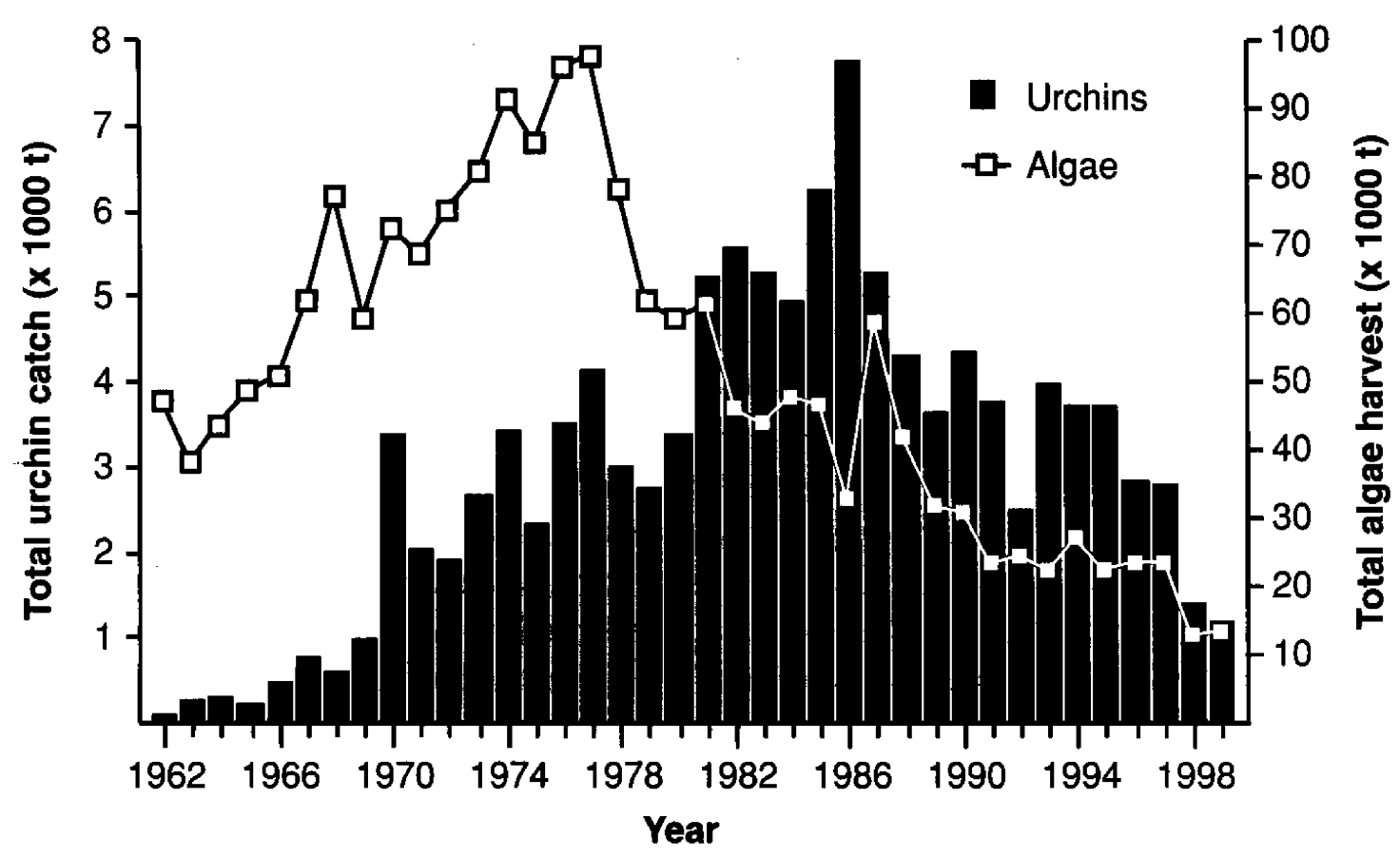

Figure 29 Total catch (t) of sea urchins and total algal production $(t)$ in South Korea.

on the biomass of $M$. pyrifera or on the associated community (Barilotti et al. 1985, Dayton et al. 1998). In South Korea, macroalgae, Laminaria spp., as well as a number of species of smaller algae are harvested on a large scale (Fig. 29). The rise and decline of the fishery for macroalgae is correlated with patterns in the sea urchin fishery; both have been in decline since 1987. Whether the rise and fall of the sea urchin fishery is linked to similar patterns in algal harvest is unknown.

\section{Management}

\section{Single species assessment}

Classical fisheries theory contends that an unfished population is constrained by the carrying capacity of its environment and exists at some dynamic equilibrium about that population size. The productivity of a fished stock is greatest at some lesser population size (Russell 1931, Schaefer 1954) and in the still-common logistic formulation of population growth, the maximum sustainable yield is taken when a stock is approximately half its unfished biomass (Gulland 1971, Hilborn \& Sibert 1988, Hilborn \& Walters 1992). Populations decline under fishing as the accumulated biomass of older and larger animals is removed. This pattern of "fishing down" is typically reflected in large catches during the development phase of a fishery (Perry et al. 1999). Critically, yields taken during the "fish down" phase are often far greater than those that can be sustained in the long term. Declining abundance does not necessarily mean that fishing has diminished the population's capacity to replenish itself and judging the population size at which this may occur is a central preoccupation of fisheries science (Hilborn \& Walters 1992, Hilborn et al. 1995, Myers et al. 1999). 
Catches in many large sea urchin fisheries have declined and are now only a small fraction of what they were at their peak. Because these declines are usually not attributable to management, it may be inferred that the period of "fish down" in these fisheries is either well and truly over or in an advanced stage. Assessments (see earlier fishery summaries) suggest many fisheries or parts thereof are over-fished, particularly in California, France, Maine, Ireland, Japan, South Korea and Washington. For others the evidence is equivocal (e.g. Mexico). Still others appear to be either relatively stable (e.g. British Columbia) or developing (e.g. Alaska, New Zealand); for some it is simply impossible to tell (e.g. Chile). The general pattern in sea urchin fisheries is one of serial depletion of different areas within the fishery, followed by declines and sometimes collapse over periods of years to a decade. An exception to this overall pattern of short-term "boom and bust" is the much longer-term decline in the Japanese fishery, despite large efforts to enhance populations with releases of juveniles, closures, size limits and exclusive access rights held by fishing co-operatives.

Stock assessments have been reported in the literature for only a few fisheries, notably Alaska, British Columbia, California and Washington. Surplus production methods are used in most instances (see fishery summaries for more details). These techniques, developed in the 1950s for finfish, are commonly used in fisheries that are poorly understood, have poor datasets, or are developing (Garcia et al. 1989, Breen \& Kendrick 1998, Perry \& Waddell 1999). Underlying their application to sea urchin fisheries is an assumed relationship between biomass and sustainable yield. In all applications to sea urchin fisheries, conservative assumptions are made about biomass and, furthermore, the estimate sustainable yield is scaled by a "conservation factor" (Garcia et al. 1989). Management advice that flows from these assessments is consistent with the precautionary approach to harvest policy currently advocated for developing invertebrate fisheries (e.g. Walters \& Pearse 1996, Walters 1998, Perry et al. 1999).

\section{Allee effects}

Allee effects may have important consequences for managing sea urchin fisheries. In contrast to the compensatory dynamics assumed in assessments of many fisheries, declining densities may produce significant depensatory responses (Levitan \& Sewell 1998). In sea urchins, these effects may take several forms: (a) a minimum adult density necessary for successful spawning (Pennington 1985, Levitan et al. 1992) and (b) in red sea urchins, juvenile refuge from predation under adult spines (Bernard \& Miller 1973, Tegner \& Dayton 1977, Breen et al. 1985, Sloan et al. 1987). Although strong Allee effects may be present, this does not of itself mean that such effects are important to the dynamics of populations and the management of fisheries. Population bottlenecks later in life may swamp any relationship between density of spawning animals and the number of individuals entering the fishery (see also Ebert 1998).

For several species, fertilisation rates have been shown to be negligible when individuals are more than $4 \mathrm{~m}$ apart (Pennington 1985, Levitan et al. 1992, Styan 1997). Sea urchins are often aggregated, particularly Strongylocentrotus species (Breen \& Mann 1976, Himmelman 1984, Scheibling et al. 1999). Notwithstanding patchy and clumped distributions, these behaviours do not increase the number of individuals, as smaller numbers of patches and reduced patch size can continue to limit fertilisation success (Levitan et al. 1992). In California, the mean density of $S$. franciscanus (including sexually immature animals) in 1991 
was only $0.7 \mathrm{~m}^{-2}$ (S.E. $\left.=0.07\right)$. In contrast, densities at two unfished sites averaged $4.7 \mathrm{~m}^{-2}$ $($ S.E. $=0.30)$ and $4.3 \mathrm{~m}^{-2}($ S.E. $=0.36)$ (Kalvass \& Hendrix 1997). Interpreting these differences is difficult, however, because the aggregation structure of the population is important and this attribute is not well described by transect or other area-based methods.

It may be assumed that populations of sea urchins are more vulnerable to collapse at very low densities but definition of a critical density for fertilisation success will be confounded by oceanographic conditions, the extent to which aggregations of sea urchin are labile and so on. Early studies of fertilisation efficiency were based only on a few experiments and assumed a threshold distance beyond which fertilisation success was very low (Pennington 1985, Levitan et al. 1992). Lundquist (2000) modelled spawning efficiency to describe the effects of density, aggregation and characteristics of gamete dispersion (including hydrodynamic conditions). Studies with this model indicated varying shapes of the larval-production v. adult-stock relationship, but this relationship had the commonly assumed sharp threshold in larval production, only under very specific conditions. Under virtually all natural conditions, the relationship was a gradual change in slope, rather than a sharp threshold. These results were applied to red sea urchins (S. franciscanus) to determine the effect of fishing on larval production (Lundquist 2000). The primary effect was a reduction in density itself, and depletion of high densities at specific locations. Aggregation at low densities compensated somewhat for this loss, but the Allee effect itself contributed only a small part to the decline.

\section{Metapopulations and scales of management}

Most species of exploited sea urchins have relatively long larval lives (in the range of 1440 days; Lawrence 2001) so there is considerable potential for mixing among sub-populations within a fishery. The degree to which that potential is realised will depend on, among other things, the prevailing oceanographic conditions (Ebert et al. 1994, Wing et al. 1998, Botsford 2001). For exploited species, fishing overlies this complexity in population structure. Fleets do not harvest uniformly across the fishery and the interaction between metapopulation structure and harvesting may have unpredictable results. There are only a few instances in which variability in spatial patterns in larval settlement have been analysed (Morgan et al. 2000a). These have been used to analyse the interactions between fishing and metapopulation behaviour in the context of marine reserves (Botsford et al. 1999, Morgan et al. 1999). Although the existence of metapopulation effects has been widely canvassed in the literature, translating this knowledge into improved management is difficult. The critical pieces of information needed for management advice are almost always missing: the degree of connectedness among sub-populations, the source and destinations of larvae, and the dynamics of the fleet (Botsford et al. 1999, Cooper \& Mangel 1999, Wilen et al. 2001).

Sea urchin fisheries are often managed at regional scales $(100 \mathrm{~s}$ to $1000 \mathrm{~s}$ of $\mathrm{km})$. A consequence of this scale of management is that the fishing fleet is able to move within the management unit to maximise catch rates. Small-scale management (arbitrarily defined as less than $10 \mathrm{~km}$ ) has been practised only in Japan, Mexico and South Korea, as well as parts of fisheries in Chile and Nova Scotia. For sea urchin fisheries to maximise both their harvest and the prospects of long-term sustainability they have to move from large-scale capture fisheries to some form of more intensive management. Early explorations of spatial management approaches indicated their potential promise, but they depended on usually unknown 
parameter values. Quinn et al. (1993) demonstrated that permanent closures within a fishery could provide a hedge against over-fishing in the face of increasing effort but the required reserve spacing depended on dispersal distances which were unknown. Botsford et al. (1993) considered rotational fishing to be valuable in populations with a threshold in abundance below which egg production declined dramatically (Botsford et al. 1993), but the dynamics of that effect were unknown.

\section{Recruitment variability}

Large and unpredictable variations in recruitment seem a feature of many species of edible sea urchin (see Lawrence 2001 for reviews, see also Guillou \& Michel 1993). In particular, the relationships between populations size and settlement/recruitment, and subsequent percapita survival and growth are unclear. Recruitment is as well understood for S. franciscanus as for any sea urchin. The pattern of sea urchin settlement on the north coast of California since 1990 appears to be dominated by several atypical oceanographic events in 1992-93 (Ebert et al. 1994). Recruitment appears to be episodic in northern California, Oregon, Washington and British Columbia (Bernard \& Miller 1973, Pearse \& Hines 1987, Sloan et al. 1987, Ebert et al. 1994, Wing et al. 1995) but less so in southern California and Mexico (Tegner \& Dayton 1981, Ebert et al. 1994, see Tegner 2001 for review).

In northern California, episodes of recruitment have been linked to variations in the strength of upwelling on daily timescales and associated cross- and along-shelf transport of larvae (Morgan et al. 2000a). In El Niño years, upwelling is reduced and nearshore water is not advected across the shelf to the same extent. As a result, larvae are either not transported offshore (Roughgarden et al. 1991, Ebert et al. 1994, Wing et al. 1995, Schroeter et al. 1996) or larval settlement processes change in other more complex ways (Lundquist et al. 2000, Botsford 2001). These processes, plus unexplained variation in recruitment among years and places may make $S$. franciscanus vulnerable to recruitment overfishing (Tegner \& Dayton 1977, Botsford et al. 1993, Pfister \& Bradbury 1996, Lai \& Bradbury 1998).

Recruitment of $S$. nudus along the southern coast of Hokkaido is significantly correlated with average water temperature in September of the previous year (Agatsuma et al. 1998). High water temperature in September is thought to increase the abundance of juveniles by shortening the larval period (Agatsuma et al. 1998). Decreased water temperature further affects the fishery by promoting growth of the large brown algae Laminaria religiosa and Eisenia bicyclis in deeper water (Taniguchi 1991, Agatsuma et al. 1994) which in turn promotes faster growth of Strongylocentrotus nudus (Agatsuma et al. 1994, Agatsuma \& Kawai 1997, Sano et al. 1998).

In the northeast Gulf of Maine, consistently poor recruitment of $S$. droebachiensis contrasts with the high recruitment usually recorded in the exposed southwestern region (Harris $\&$ Chester 1996, Balch et al. 1998, Harris et al. 2001). These patterns are likely to be the product of a range of processes acting on spawning success (Wahle \& Peckham 1999, Seward et al. 2000), dispersal, settlement, and mortality of small juveniles and have led some to claim that a sustainable fishery will not be possible in the northeast unless recruitment is augmented by stock enhancement (Harris 2000, Harris et al. 2001). In addition to these geographic differences, recruitment has declined through time in the southwest; following patterns in catch and, in 1999, recruitment was at its lowest level since 1983 (Harris et al. 2001). 
In Ireland, the population of Paracentrotus lividus in Lough Hyne, County Cork, has been monitored intermittently since the early 1960s and has been unfished since 1981. Sea urchins were extremely dense in Lough Hyne in the late 1920s and early 1930s (Renouf 1931). Little qualitative and no quantitative information was collected over the next two decades, but by 1955, densities had declined (Muntz et al. 1965). In 1964, qualitative surveys were implemented, to be abandoned in 1966 because of an explosive increase in the abundance of sea urchins. Densities declined again in the late 1960s and the surveys were re-established in 1971 (Kitching \& Thain 1983, Kitching 1987). Since the mid-1980s the population has remained at levels as low as has been measured to date (Barnes et al. 1999). The $40+$ years of observations show that densities of $P$. lividus in Lough Hyne have varied by four orders of magnitude, mostly in the absence of fishing.

It is clear from these examples that improved understanding of the hydrographic basis of larval supply, settlement and growth can improve fisheries management. Such an approach has been advocated in southern Chile - populations that enjoy some protection from fishing because of their exposure to the southern Pacific Ocean may act as source populations for those in more sheltered waters (Moreno et al. 1987, Clément et al. 1988, Castilla 2000). Large recruitment events have been observed, for example in March-April 1991 in the Mehuin Marine Reserve (Gebauer 1992), as well as other parts of Chile (e.g. González et al. 1987, Guisado \& Castilla 1987, Moreno et al. 1987, Stotz et al. 1992, Zuleta \& Moreno 1994). Although there are many hypotheses concerning the processes that determine settlement and subsequent survival (Zuleta \& Moreno 1994), experimental tests are few and it is likely that the relative importance of these processes will vary along the $4000 \mathrm{~km}$ coastline of Chile. Larval development takes 39 to 48 days depending on temperature (González et al. 1987, Guisado \& Castilla 1987, Bustos et al. 1991).

\section{Minimum and maximum legal sizes}

Minimum legal sizes are in force in all the major fisheries with the exception of those in Alaska, South Korea and New Zealand and smaller fisheries, including Iceland, Ireland, the Philippines, Spain and Tasmania. Size limits have a long history in fisheries management and are traditionally imposed to allow individuals to spawn once or several times before entering the fishery. This conservation objective is complicated in sea urchin fisheries because, unlike in many fisheries, the intermediate-sized individuals are the most valuable. The poor compliance observed in several fisheries, most notably in Chile, in part reflects this conflict. Given the allometric relationship between test diameter and gonad volume (as a proxy for reproductive output), there would seem a good case for greater use of MxLSs in sea urchin fisheries, particularly for fisheries targeting Strongylocentrotus franciscanus (see below). Maximum size limits have been used only in Maine, Washington and British Columbia (for $S$. franciscanus). They were abandoned in British Columbia after a relatively short period. In all instances the MxLS was used in conjunction with a MLS and in Washington attracted compliance problems. Morgan et al. $(1999,2000 \mathrm{~b})$ have shown that yield per recruit is close to its maximum in northern California but may benefit from an increase in the MLS; however, egg production per recruit is down to $20 \%$ of unfished levels.

Tegner \& Dayton (1977) noted that the abundance of juvenile red urchins (S. franciscanus) was highest underneath the test or spine canopies of adults. They suggested that the key issue of harvesting on subsequent recruitment is the number of canopy-providing adults 
remaining. Kato \& Schroeter (1985) subsequently recommended a MxLS as a management tool in the red urchin fishery. Based on population growth models using Washington and Oregon data, Ebert (1998) concluded that survival of large red urchins is more important for population growth than survival of small red urchins. Based on population modelling in Washington, Lai \& Bradbury (1998) concluded that a MxLS reduces variability of yield and the risk of stock collapse for red urchins. Nevertheless, reliance solely on a MxLS would be risky without considerable control over exploitation rates.

\section{Ecosystem Management}

The term "Ecosystem Management" has been used to describe the broadening of fisheries management from a single-species focus to consideration of ecosystem effects (see Larkin 1996, National Fisheries Research and Development Institute (NFRDI) 2000 for recent compilations). Although the term has arguably escaped robust definition, the essence of it is to manage human interactions with ecosystems to preserve ecosystem integrity (itself in need of robust definition). Implicit in "managing" the effects of fishing is an understanding of the processes that regulate populations, which is missing for all but a small number of species and fisheries. Sea urchins are possibly one of the best candidates for multispecies or ecosystem management: they play clear and often dominant roles in the ecology of rocky reefs, their fisheries are typically in shallow water and may be observed directly and manipulated, they interact with other high-value species such as abalone and lobsters, and declines in fisheries provide a clear imperative for change. Nevertheless, with the exception of those in Japan and South Korea, the world's major sea urchin fisheries are managed on a single-species basis. In those countries, sea urchin fisheries are managed as part of a suite of fisheries (including those for crustaceans, abalone, kelp, and fishes) and habitat manipulation is used extensively to increase production. In North America, only in Nova Scotia is ecological information used to develop harvest policy (Miller \& Nolan 2000).

The reasons that sea urchin fisheries are managed mostly without reference to the ecology of reefs are probably as complex and diverse as the social and political institutions in which they are embedded. In many western countries, systems of governance and fishing rights may impede approaches to management that require more than the yield of a single species to be considered. Sea otters bring the complexities of ecosystem management into sharp relief; the evidence for strong ecological interactions is relatively clear, but there are conflicting objectives between fisheries-based legislation, which focus on sustainable yield, and marine mammal conservation, which seeks to protect and rebuild sea otter populations (Gerber et al. 1999). Attempts to balance the objectives of shellfish fisheries and the protection of sea otters in California by restricting the latter to fixed zones have not been successful (Gerber et al. 1999).

In Nova Scotia, sea urchins are most dense in a band that marks the boundary between inshore kelp forests and areas of barrens habitat in deeper water (DFO 2000b, Miller \& Nolan 2000). Sea urchins in this band actively graze kelp and their roe are larger and of better quality than those from barrens habitat in the deeper water (see Scheibling 2000 for review). Individual fishers are given exclusive access rights to stretches of coast and are required to harvest sea urchins so that the boundary between habitats remains stable. Management of this fishery is based on the depth at which these bands are found (an index of exploitation rate) and the length of the band along the shore (an index of the size of the resource; see fishery 
summary for more details). Although this form of management represents a significant improvement, it makes little reference to another ecological process - disease. If populations of sea urchins in Nova Scotia collapse every decade or so because of disease then management finely tuned to sea urchin - algal interactions alone seems to miss a key process.

In many jurisdictions, the governing Acts or Laws require fisheries managers to minimise the ecological effects of fishing and manage fisheries with more than single-species objectives. In the United States, sea urchin fisheries are managed by the relevant State agencies and in all states with significant fisheries (Maine, Washington, Oregon and California), there are provisions for ecological sustainability. Beyond 3 nautical miles, in the U.S. Federal government's jurisdiction, the Sustainable Fisheries Act 1996 seeks a more ecosystem-based approach to fisheries management but operational definitions for these concepts remain elusive (Fluharty 2000). Progress in implementing management plans that embody the ecological provisions of the Act (e.g. "Essential Fish Habitat') has been slow. In Canada, the 1997 Oceans Act encourages the development of management plans that include marine environmental quality guidelines and criteria designed to protect ecosystem health. Development of these criteria is in the preliminary stages and, with the exception of Nova Scotia, management of sea urchin fisheries in North America remains embedded in classical singlespecies methods. The laws governing wild fisheries in Chile, Japan, the Philippines and South Korea (which together accounted for a little over two-thirds of world production in 1998) make no reference to ecosystem effects of fishing or ecosystem management.

\section{Conclusions}

Sea urchin fisheries have a poor record of sustainability. Fisheries have declined in Japan, Maine, California, South Korea, and Washington, as well as several smaller fisheries such as those in Ireland, France and the Philippines. The causes of these declines are likely to be manifold and, in the absence of stock assessments, difficult to isolate. In those fisheries that have been assessed, only the most simple stock assessment methods have been applied, except in Washington where more complex stock assessments have been overtaken by access and property right issues as well as budget constraints. Management is ad hoc and/or ineffective in many sea urchin fisheries. The general pattern in these fisheries is of depletion of different areas within the fishery, often including areas of barrens habitat that contain sea urchins with poor roe recoveries. In the absence of assessments it is difficult to determine whether they are over-fished or whether the declines simply represent the "fish down" of accumulated biomass. Nevertheless, the magnitude of the observed declines suggests that many of those not assessed have been over-fished and are in decline. An exception to the overall pattern of short-term "boom and bust" is the much longer-term decline in some Japanese fisheries, despite enormous enhancement programmes, closures, MLSs and a management regime that provides exclusive access rights to fishing co-operatives.

Sea urchin fisheries present all the familiar challenges for researchers and managers of sedentary stocks (Jamieson \& Campbell 1998) and failure to meet those challenges are as apparent as in other taxa. Strong and persistent spatial structure in stocks paired with largescale or ineffective management and excessive effort from mobile fleets all contribute to declining fisheries and therefore world production. This is particularly the case for the world's largest sea urchin fishery, in Chile. In addition to these attributes, sea urchins 
present further complexities for management because the harvested roe serves both for reproduction and as a nutrient store, and the size and quality of the gonad varies both as a function of the reproductive cycle and the availability and type of food. As a consequence, the value of the roe is only partially known at the time of harvest. These interacting processes introduce small-scale heterogeneity over and above that noted in other taxa.

Ecologically, sea urchins are often the dominant herbivore on shallow reefs and their removal can change communities enormously. Furthermore, changes in the environment over decades or longer may have enormous impacts on the recruitment of sea urchins and indirectly through the outbreak of disease or freshwater runoff. Such episodic events may have profound policy implications; defining an ecologically sustainable, precautionary harvest becomes problematic in the face of large-scale, rapid changes in abundance and community composition.

The biological attributes of sea urchins and the dynamics of their fisheries suggest that, as for so many sedentary invertebrates (Botsford et al. 1997, Orensanz \& Jamieson 1998), the greatest prospect for long-term sustainability lies in small-scale management. In addition, some form of exclusivity of access will promote enhancement and intelligent harvesting to maximise roe value. Management institutions that are capable of quickly responding to large changes in abundance, seemingly independent of fishing, will provide the best hedge against uncertainty.

\section{Dedication}

We dedicate this review to the memory of Dr Mia J. Tegner in recognition of her enduring contribution to our understanding of the ecology of sea urchins and their fisheries.

\section{Acknowledgements}

We are indebted to Sophie Brosset, Amanda Leland, Marchal Malay, John Schaefer and Andrew Sharman for help in assembling information and particularly Dr Paul Breen for discussion and criticism of the manuscript. This review was partially funded by grants (to NLA) from Te Ohu Kai Moana and the New Zealand Ministry of Fisheries.

\section{References}

Agatsuma, Y. 1991. Strongylocentrotus intermedius (A. Agassiz). In Fishes and marine invertebrates of Hokkaido: Biology and Fisheries, K. Nagasawa \& M. Torisawa (eds). Sapporo: Kita-Nihon Kaiyo Center Co. Ltd, 324-329. (In Japanese)

Agatsuma, Y. 1997. Ecological studies on the population dynamics of the sea urchin, Strongylocentrotus nudus. Scientific Reports of the Hokkaido Fisheries Experimental Station 51, 1-66. (In Japanese with English abstract)

Agatsuma, Y. 1999. Gonadal growth of the sea urchin, Strongylocentrotus nudus, from trophically poor coralline flats and fed excess kelp, Laminaria religiosa. Suisanzoshoku 47, 325-330. 
Agatsuma, Y. 2001a. Ecology of Strongylocentrotus intermedius. In Edible sea urchins: biology and ecology, J. M. Lawrence (ed.). Amsterdam: Elsevier Science, 333-346.

Agatsuma, Y. 2001b. Ecology of Strongylocentrotus nudus. In Edible sea urchins: biology and ecology, J. M. Lawrence (ed.). Amsterdam: Elsevier Science, 347-361.

Agatsuma, Y. 2001c. Ecology of Hemicentrotus pulcherrimus, Pseudocentrotus depressus, and Anthocidaris crassispina in southern Japan. In Edible sea urchins: biology and ecology, J. M. Lawrence (ed.). Amsterdam: Elsevier Science, 363-374.

Agatsuma, Y. \& Kawai, T. 1997. Seasonal migration of the sea urchin Strongylocentrotus nudus in Oshoro Bay of southwestern Hokkaido, Japan. Nippon Suisan Gakkaishi 63, 557-562. (In Japanese with English abstract)

Agatsuma, Y., Kawamata, K. \& Motoya, S. 1994. Reproductive cycle of cultured seeds of the sea urchin, Strongylocentrotus intermedius produced from geographically separated population. Suisanzoshoku 42, 63-70. (In Japanese with English abstract)

Agatsuma, Y., Nakao, S., Motoya, S., Tajima, K. \& Miyamoto, T. 1998. Relationship between year-toyear fluctuations in recruitment of juvenile sea urchins Strongylocentrotus nudus and seawater temperature in southwestern Hokkaido. Fisheries Science 64, 1-5.

Allain, J. Y. 1972. La pêche aux oursins dans la monde. Pêche Merit 1133, 625-630.

Andrew, N. L. 1986. The interaction between diet and density in influencing reproductive output in the echinoid Evechinus chloroticus (Val.). Journal of Experimental Marine Biology and Ecology 97, 63-79.

Andrew, N. L. 1988. Ecological aspects of the common sea urchin, Evechinus chloroticus, in northern New Zealand: a review. New Zealand Journal of Marine and Freshwater Research 22, 415-426.

Andrew, N. L. 1989. Contrasting ecological implications of food limitation in sea urchins and herbivorous gastropods. Marine Ecology Progress Series 51, 189-193.

Andrew, N. L. \& Byrne, M. 2001. The ecology of Centrostephanus rodgersii. In Edible sea urchins: biology and ecology, J. M. Lawrence (ed.). Amsterdam: Elsevier Science, 149-160.

Andrew, N. L. \& O'Neill, A. L. 2000. Large-scale patterns in habitat structure on subtidal rocky reefs in New South Wales. Marine and Freshwater Research 51, 255-263.

Andrew, N. L. \& Underwood, A. J. 1993. Density-dependent foraging in the sea urchin Centrostephanus rodgersii on shallow subtidal reefs in New South Wales, Australia. Marine Ecology Progress Series 99, 89-98.

Andrew, N. L., Worthington, D. G., Brett, P. A., Bentley, N., Chick, R. C. \& Blount, C. 1998. Interactions between the abalone fishery and sea urchins in New South Wales. Final Report to the Fisheries Research and Development Corporation, Sydney: New South Wales Fisheries.

Aronson, R. B. 1990. Onshore-offshore patterns of human activity. Palaios 5, 88-93.

Babcock, R. C., Kelly, S., Shears, N. T., Walker, J. W. \& Willis, T. J. 1999. Changes in community structure in temperate marine reserves. Marine Ecology Progress Series 189, 125-134.

Balch, T. \& Scheibling, R. E. 2001. Temporal and spatial variability in settlement and recruitment of echinoderms in kelp beds and barrens in Nova Scotia. Marine Ecology Progress Series. (in press).

Balch, T., Scheibling, R. E., Harris, L. G., Chester, C. M. \& Robinson, S. M. C. 1998. Variation in settlement of Strongylocentrotus droebachiensis in the Northwest Atlantic: effects of spatial scale and sampling method. In Echinoderms: San Francisco, R. Mooi \& M. Telford (eds). Rotterdam: Balkema, 555-560.

Ballesteros, E. \& Garcia Rubies, A. 1987. La pêche aux oursins en Espagne et plus particulièrement en Catalogne. In Colloque International sur Paracentrotus lividus et les oursins comestibles, C. F. Boudouresque (ed.). Marseille: GIS Posidonie, 325-328.

Barilotti, D. C., McPeak, R. H. \& Dayton, P. K. 1985. Experimental studies on the effects of commercial kelp harvesting in central and southern California. California Department of Fish and Game 71, 4-20.

Barker, M. F. 2001. The ecology of Evechinus chloroticus. In Edible sea urchins: biology and ecology, J. M. Lawrence (ed.). Amsterdam: Elsevier Science, 245-260. 
Barnes, D. K. A., Steele, S., Maguire, D. \& Turner, J. 1999. Population dynamics of the urchin Paracentrotus lividus at Lough Hyne, Ireland. In Echinoderm research, M. D. C. Carnevali \& F. Bonasoro (eds). Rotterdam: Balkema, 427-431.

Bay-Schmith, E., Werlinger, C. \& Silva, J. 1981. Ciclo anual de reproducción del recurso Loxechinus albus (Molina) entre la X y XI Región. Informe final a Subsecretaria de Pesca, Universidad de Concepción. Facultad de Recursos Naturales, Universidad de Concepción. Concepción, Chile.

Bazhin, A. G. 1998. Sea urchin (Strongylocentrotus spp.) fisheries in Kamchatka: current condition and problems. In Proceedings of the North Pacific symposium on invertebrate stock assessment and management, G. S. Jamieson \& A. Campbell (eds). Canadian Special Publication of Fisheries and Aquatic Sciences, 417-422.

Bernard, F. R. \& Miller, D. C. 1973. Preliminary investigation on the red sea urchin resources of British Columbia Strongylocentrotus franciscanus (Agassiz). Fisheries Research Board of Canada Technical Report 400, 1-35.

Bologna, P. A. X. \& Steneck, R. S. 1993. Kelp beds as habitat for American lobster (Homarus americanus). Marine Ecology Progress Series 100, 127-134.

Bonardelli, J. C. 1997. Sustainable development of the green sea urchin. Bulletin of the Aquaculture Association of Canada 97, 51-55.

Botsford, L. W. 2001. Physical influences on recruitment to California Current invertebrate populations on multiple scales. ICES Journal of Marine Science. in press.

Botsford, L. W., Castilla, J. C. \& Peterson, C. H. 1997. The management of fisheries and marine ecosystems. Science 277, 509-515.

Botsford, L. W., Hastings, A. \& Gaines, S. D. 2001. Dependence of sustainability on the configuration of marine reserves and larval dispersal distance Ecology Letters 4, 144-150.

Botsford, L. W., Morgan, L. E., Lockwood, D. R. \& Wilen, J. E. 1999. Marine reserves and management of the northern California red sea urchin fishery. California Co-operative Oceanic Fisheries Investigation Report 40, 87-93.

Botsford, L. W., Quinn, J. F., Wing, S. R. \& Brittnacher, J. G. 1993. Rotating spatial harvest of a benthic invertebrate, the red sea urchin, Strongylocentrotus franciscanus. In Proceedings of the international symposium on management strategies for exploited fish populations, G. Kruse et al. (eds). Alaska Sea Grant 93-2, 409-428.

Botsford, L. W., Wing, S. R. \& Largier J. L. 1998. Population dynamics and management implications of larval dispersal. South African Journal of Marine Science 19, 131-142.

Boudouresque, C. F. (ed.) 1987. Colloque International sur Paracentrotus lividus et les oursins comestibles, Marseille: GIS Posidonie.

Boudouresque, C. F., Nédélec, H. \& Shepherd, S. A. 1980. The decline of a population of the sea urchin Paracentrotus lividus in the bay of Port-Cros (Var, France). Travaux Scientifiques Parc National de Port-Cros 6, 243-251.

Boudouresque, C. F. \& Verlaque, M. 2001. Ecology of Paracentrotus lividus. In Edible sea urchins: biology and ecology, J. M. Lawrence (ed.). Amsterdam: Elsevier Science, 177-216.

Bradbury, A., Palsson, W. A. \& Pacunski, R. E. 1998. Stock assessment of the sea cucumber Parastichopus californicus in Washington. In Echinoderms: San Francisco, R. Mooi \& M. Telford (eds). Rotterdam: Balkema, 441-446.

Breen, P. A. 1979. The ecology of red sea urchins in British Columbia. International Symposium of Coastal Pacific Marine Life. West Washington University, Bellingham, Washington.

Breen, P. A., Carolsfeld, W. \& Yamanaka, K. L. 1985. Social behaviour of juvenile red sea urchins, Strongylocentrotus franciscanus (Agassiz). Journal of Experimental Marine Biology and Ecology 92, 45-61.

Breen, P. A. \& Kendrick, T. H. 1998. An evaluation of surplus production analysis for assessing the fishery for New Zealand red rock lobsters (Jasus edwardsii). In Proceedings of the North Pacific symposium on invertebrate stock assessment and management, G. S. Jamieson \& A. Campbell (eds). Canadian Special Publication of Fisheries and Aquatic Sciences 125, 199-212. 
Breen, P. A. \& Mann, K. H. 1976. Destructive grazing by sea urchins in eastern Canada. Journal of the Fisheries Research Board of Canada 33, 1278-1283.

Bückle, F., Guisado, C., Tarifeño, E., Zuleta, A., Córdoba, L. \& Serrano, C. 1978. Biological studies on the Chilean sea urchin Loxechinus albus (Molina) (Echinodermata: Echinoidea) IV. Maturity cycle and seasonal biochemical changes in the gonad. Ciencias Marinas (México) 5, 1-18.

Bustamante, R. \& Castilla, J. C. 1987. The shellfisheries in Chile: an analysis of 26 years of landings. Biología Pesquera, Chile 16, 79-97.

Bustos, E., Godoy, C., Olave, S. \& Troncoso, R. 1991. Desarrollo de técnicas de producción de semillas y repoblación de recursos bentónicos. I. Investigaciones en el erizo chileno Loxechinus albus (Molina, 1782). Programa de Naciones Unidas para el Desarrollo e Instituto de Fomento Pesquero. Santiago, Chile.

Byrne, M. 1990. Annual reproductive cycles of the commercial sea urchin Paracentrotus lividus from an exposed intertidal and a sheltered subtidal habitat on the west coast of Ireland. Marine Biology 104, 275-289.

Byrne, M., Andrew, N. L., Worthington, D. G. \& Brett, P. A. 1998. Reproduction in the diadematoid sea urchin Centrostephanus rodgersii in contrasting habitats along the coast of New South Wales, Australia. Marine Biology 132, 305-318.

Caddy, J. F. 1986. Stock assessment in data-limited situations: the experience in tropical fisheries and its possible relevance to evaluation of invertebrate resources. In North Pacific workshop on stock assessment and management of invertebrates, G. S. Jamieson \& N. Bourne (eds). Canadian Special Publication of Fisheries and Aquatic Sciences 92, 379-392.

CALCOFI 1999. Review of some California fisheries. Sea Urchin 40, 14-15.

Cameron, R. A. \& Schroeter, S. C. 1980. Sea urchin recruitment: effect of substrate selection on juvenile distribution. Marine Ecology Progress Series 2, 243-247.

Campbell, A., Hajas, W. \& Bureau, D. 1999. Quota options for the red sea urchin fishery in British Columbia for fishing season 2000/2001. Canadian Stock Assessment Secretariat Research Document, 99/201.

Campbell, A. \& Harbo, R. M. 1991. The sea urchin fisheries in British Columbia, Canada. In Biology of Echinodermata, I. Yanagisawa (ed.). Rotterdam: Balkema, 191-199.

Castilla, J. C. 1994. The Chilean small-scale benthic shellfisheries and the institutionalisation of new management practices. Ecology International Bulletin 21, 47-63.

Castilla, J. C. 2000. Roles of experimental marine ecology in coastal management and conservation. Journal of Experimental Marine Biology and Ecology 250, 3-21.

Castilla, J. C., Manriquez, P., Alvarado, J., Rosson, A., Espos, C., Soto, R. \& Defeo, O. 1998. Artisanal "Caletas" as units of production and co-managers of benthic invertebrates in Chile. In Proceedings of the North Pacific symposium on invertebrate stock assessment and management, G. S. Jamieson \& A. Campbell (eds). Canadian Special Publication of Fisheries and Aquatic Sciences 125, 407-414.

Castilla, J. C. \& Moreno, C. A. 1984. Sea urchins and Macrocystis pyrifera: experimental test of their ecological relations in southern Chile. Proceedings of the International Echinoderm Conference. Tampa Bay, Florida, 257-263.

Chapman, A. R. O. 1981. Stability of sea urchin dominated barren grounds following destructive grazing of kelp in St Margaret's Bay, eastern Canada. Marine Biology 62, 307-311.

Chapman, A. R. O. \& Johnson, C. R. 1990. Disturbance and organisation of macroalgal assemblages in the northwest Atlantic. Hydrobiologia 192, 77-121.

Chapman, A. S. 1999. From introduced species to invader: what determines variation in the success of Codium fragile spp. tomentosoides (Chlorophyta) in the North Atlantic Ocean? Helgolander wissenschaftliche Meeresuntersuchungen 52, 277-289.

Clément, A., Neshyba, S., Fonseca, T. \& Silva, N. 1988. Oceanographic and metereological factors affecting the cage salmon industry in Southern Chile. Seminario Internacional, Técnicas de cultivo y Manejo del Salmón: Desarrollos recientes. Fundación Chile, Departamento de Recursos Marinos, Fundación Chile, Santiago de Chile. 
Conand, C. 2001. Overview of sea cucumber fisheries over the last decade - what possibilities for a durable management? In Echinoderms 2000. Proceedings of the 10th International Echinoderm Conference, M. F. Barker (ed.). Rotterdam: Balkema, 339-344.

Conand, C. \& Byrne, M. 1993. A review of recent developments in the world sea cucumber fisheries. Marine Fisheries Review 55, 1-13.

Cooper, A. B. \& Mangel, M. 1999. The dangers of ignoring metapopulation structure for the conservation of salmonids. Fishery Bulletin 97, 213-216.

Cormaci, M. \& Furnari, G. 1999. Changes of the benthic algal fiora of the Tremiti islands (southern Adriatic, Italy). Hydrobiologia 398/399, 75-79.

Cota, A., Aguilar, D., Romero, M., Solana, R. \& Uribe, F. 1996. Analis de la pesqueria del erizo rojo y morado en la costa noroccidental de Baja California. Ciencia Pesquera 12, 68-75.

Cowen, R. K. 1983. The effect of sheephead (Semicossyphus pulcher) predation on red sea urchin (Strongylocentrotus franciscanus) populations: an experimental analysis. Oecologia 58, 249-255.

Creaser, E. P. \& Weeks, W. 1998. Sea urchin drag study report. Final report to Maine Department of Marine Resources.

Dalzell, P., Adams, T. J. H. \& Polunion, N. V. C. 1996. Coastal fisheries of the Pacific Islands. Oceanography and Marine Biology: an Annual Review 34, 395-531.

Dayton, P. K. \& Tegner, M. J. 1990. Ecological consequences of the 1982-83 El Niño to marine life. In Bottoms below troubled waters: benthic impacts of the 1982-84 El Niño in the temperate zone, P. W. Glynn (ed.). Amsterdam: Elsevier Oceanography Series, 433-472.

Dayton, P. K., Tegner, M. J., Edwards, P. B. \& Riser, K. L. 1998. Sliding baselines, ghosts, and reduced expectations in kelp forest communities. Ecological Applications 8, 309-322.

Deacon, J. 1973. Habitat selection and competition among abalone and sea urchins at The Sea Ranch, California. MS thesis, University of California, Davis.

DFO 1999. Green sea urchin. Department of Fisheries and Oceans Science Stock Status Report, C611 (1999), Ottawa: Department of Fisheries and Oceans.

DFO 2000a. Southwestern New Brunswick (LFA 36-38) green sea urchins. Department of Fisheries and Oceans Science Stock Status Report, C3-49 (2000), Ottawa: Department of Fisheries and Oceans.

DFO 2000b. Nova Scotia green sea urchin. Department of Fisheries and Oceans Science Stock Status Report, C3-49 (2000), Ottawa: Department of Fisheries and Oceans.

Dix, T. G. 1977a. Prospects for a sea urchin fishery in Tasmania. Australian Fisheries 36, 18-22.

Dix, T. G. $1977 \mathrm{~b}$. Reproduction in Tasmanian populations of Heliocidaris erythrogramma (Echinodermata: Echinometridae). Australian Journal of Marine and Freshwater Research 28, 509-20.

Dixon, J. D., Schroeter, S. C. \& Ebert, T. A. 1997. Survival and growth of laboratory-reared red sea urchins from release to commercial harvest. Technical Report to the California Department of Fish and Game. Sacramento: California Department of Fish and Game.

Dixon, J. D., Schroeter, S. C. \& Ebert, T. A. 1999. Increasing the growth, survival, and gonadal quality of red sea urchins by transplanting to areas of high food availability, and use of large scale transplantation of juvenile red sea urchins as a management tool. Technical Report to the California Department of Fish and Game. Sacramento, California. Sacramento: California Department of Fish and Game.

Dixon, J. D., Schroeter, S. C. \& Kastendiek, J. 1981. Effects of the encrusting bryozoan, Membranipora membranacea, on the loss of blades and fronds by the giant kelp, Macrocystis pyrifera (Laminariales). Journal of Phycology 17, 341-345.

Doherty, P. J. 1999. Recruitment limitation is the theoretical basis for stock enhancement in marine populations. In Stock enhancement and sea ranching, B. R. Howell et al. (eds). Oxford: Fishing News Books, 9-21.

Duran, L. R. \& Castilla, J. C. 1989. Variation and persistence of the middle rocky intertidal community of central Chile, with and without human harvesting. Marine Biology 103, 555-562. 
Ebert, T. A. 1968. Growth rates of the sea urchin Strongylocentrotus purpuratus related to food availability and spine abrasion. Ecology 49, 1075-1091.

Ebert, T. A. 1998. An analysis of the importance of Allee effects in management of the red sea urchin Strongylocentrotus franciscanus. In Echinoderms: San Francisco, R. Mooi \& M. Telford (eds). Rotterdam: Balkema, 619-627.

Ebert, T. A. 2001. Growth and survival of post-settlement sea urchins. In Edible sea urchins: biology and ecology, J. M. Lawrence (ed.). Amsterdam: Elsevier Science, 79-102.

Ebert, T. A., Dixon, J. D. \& Schroeter, S. C. 1992. Experimental outplant of cultured juvenile red sea urchins, Strongylocentrotus franciscanus, in California. Final Technical Report to California Department of Fish and Game.

Ebert, T. A., Dixon, J. D., Schroeter, S. C., Kalvass, P. E., Richmond, N. T., Bradbury, A. \& Woodby, D. A. 1999. Growth and mortality of red sea urchins Strongylocentrotus franciscanus across a latitudinal gradient. Marine Ecology Progress Series 190, 189-209.

Ebert, T. A. \& Russell, M. P. 1992. Growth and mortality estimates for red sea urchin Strongylocentrotus franciscanus from San Nicolas Island, California. Marine Ecology Progress Series 81, 31-41.

Ebert, T. A., Schroeter, S. C., Dixon, J. D. \& Kalvass, P. 1994. Settlement patterns of red and purple sea urchins (Strongylocentrotus franciscanus and $S$. purpuratus) in California, USA. Marine Ecology Progress Series 111, 41-52.

Einarsson, S. 1994. The distribution and density of green sea urchins (Strongylocentrotus droebachiensis) in Icelandic waters. In Council Meeting of the International Council for the Exploration of the Sea, ICES, Copenhagen (Denmark).

Elner, R. W. \& Vadas, R. L. 1990. Inference in ecology: the sea urchin phenomenon in the north-west Atlantic. American Naturalist 136, 108-125.

Estes, J. A. \& Duggins, D. O. 1995. Sea otters and kelp forests in Alaska: generality and variation in a community ecological paradigm. Ecological Monographs 65, 75-100.

Estes, J. A. \& Palmisano, J. F. 1974. Sea otters: their role in structuring nearshore communities. Science 185, 1058-1060.

Estes, J. A., Tinker, M. T., Williams, T. M. \& Doak, D. F. 1998. Killer whale predation on sea otters linking oceanic and nearshore ecosystems. Science 282, 473-476.

Estes, J. A. \& VanBlaricom, G. R. 1985. Sea otters and shellfisheries. In Marine mammals and fisheries, J. R. Beddington et al. (eds). London: Allen and Unwin, 187-235.

FAO 2000a. FAOSTAT Database Gateway. Online. Available HTTP: http://apps.fao.org/fishery/ fprod1-e.htm (accessed February 2000).

FAO 2000b. FAO yearbook. Fishery statistics. Capture production. Volume 86/1. Rome, FAO.

Fluharty, D. 2000. Habitat protection, ecological issues, and implementation of the Sustainable Fisheries Act. Ecological Applications 10, 325-337.

Foster, M. S. \& Schiel, D. R. 1988. Kelp communities and sea otters: keystone species or just another brick the wall? In The community ecology of sea otters, G. R. VanBlaricom \& J. A. Estes (eds). Berlin: Springer-Verlag, 92-115.

Garcia, S., Sparre, P. \& Csirke, J. 1989. Estimating surplus production and maximum sustainable yield from biomass data when catch and effort time series are not available. Fisheries Research $\mathbf{8}$, $13-23$.

Gebauer, P. 1992. Validación experimental de los anillos de crecimiento Loxechinus albus (Molina, 1782) (Echinodermata: Echinoidea) en la Reserva Marina de Mehuin. Chile. Licenciado en Biología Marina, Universidad Austral de Chile.

Gebauer, P. \& Moreno, C. A. 1995. Experimental validation of the growth rings of Loxechinus albus (Molina, 1782) in southern Chile (Echinodermata: Echinoidea). Fisheries Research 21, 423-435.

Gerber, L. R., Wooster, W. S., DeMaster, D. P. \& VanBlaricom, G. R. 1999. Marine mammals: new objectives in U.S. fishery management. Reviews in Fisheries Science 7, 23-38.

Giese, A. C. 1966. On the biochemical constitution of some echinoderms. In Physiology of Echinodermata, R. A. Boolootian (ed.). New York: Interscience, 547-576. 
González, L., Castilla, J. C. \& Guisado, C. 1987. Effect of larval diet and rearing temperature on metamorphosis and juvenile survival of the sea urchin Loxechinus albus (Molina, 1782) (Echinodermata: Echinoidea). Journal of Shellfish Research 6, 109-115.

Guillou, M. \& Michel, C. 1993. Impact de la variabilité du recruitment sur le stock d'oursins commercialisables de l'archipel de Glénan (Sud-Bretagne). Oceanologia Acta 16, 423-430.

Guisado, C. \& Castilla, J. C. 1987. Historia de vida reproducción y avances en el cultivo del erizo comestible Loxechinus albus (Molina, 1782) (Echinoidea: Echinidae). In Manejo y Desarrollo Pesquero, P. Arana (ed.). Valparaíso: Univeridad Católica de Valparaíso, 56-68.

Guisado, C. B. 1995. Estrategias de desarrollo larval y ciclo de vida en dos especies de echinoideos regulares del sur de Chile. Magister en Ciencias, mención Zoología, Universidad Austral de Chile.

Gulland, J. A. 1971. Science and fishery management. Journal du Conseil International pour l'Exploration de la Mer 33, 471-477.

Gutiérrez, J. \& Otsu, I. 1975. Periodicidad en las variaciones biométricas de Loxechinus albus Molina. Revista Biología Marina, Valparaíso 15, 179-199.

Hagen, N. 1987. Sea urchin outbreaks and nematode epizootics in Vestfjorden, northern Norway. Sarsia 72, 213-229.

Hagen, N. 1996. Echinoculture: from fishery enhancement to closed cycle cultivation. World Aquaculture, 6-19.

Hagen, N. 1998. Effects of food availability and body size on out-of-season gonad yield in the green sea urchin. In Echinoderms: San Francisco, R. Mooi \& M. Telford (eds). Rotterdam: Balkema (abstract only).

Harbo, R. \& Hobbs, K. 1990. Shellfish stock assessments for the west coast of Canada in 1990. Green sea urchin fishery. Canadian MS Report on Fisheries and Aquatic Science.

Harris, L. G. 2000. Sea ranching green sea urchins: a system for larval culture, juvenile grow out and out-planting. Online. Available HTTP: http://crdpm.cus.ca/oursin (accessed February 2001).

Harris, L. G. \& Chester, C. M. 1996. Effects of location, exposure, and physical structure on juvenile recruitment of the sea urchin Strongylocentrotus droebachiensis in the Gulf of Maine. Journal of Invertebrate Reproduction 30, 207-215.

Harris, L. G., Williams, C. T., Chester, C. M., Tyrrell, M., Sisson, C. \& Chavanich, S. 2001. Declining sea urchin recruitment in the Gulf of Maine: is overfishing to blame? In Echinoderms 2000. Proceedings of the 10th International Echinoderm Conference. M. F. Barker (ed.). Rotterdam: Balkema, 439-444.

Haya, D. 1988. Biología y ecología de Paracentrotus lividus en la zona intermareal. PhD thesis. University of Oviedo.

Hilborn, R. 1998. The economic performance of marine stock enhancement projects. Bulletin of Marine Science 62, 661-674.

Hilborn, R. \& Sibert, J. 1988. Adaptive management of developing fisheries. Marine Policy 12, 112-121.

Hilborn, R. \& Walters, C. J. 1992. Quantitative fisheries stock assessment: choice, dynamics, and uncertainty. London: Chapman \& Hall.

Hilborn, R., Walters, C. J. \& Ludwig, D. 1995. Sustainable exploitation of renewable resources. Annual Review of Ecology and Systematics 26, 45-67.

Himmelman, J. H. 1984. Urchin feeding and macroalgal distribution in Newfoundland, Eastern Canada. Naturaliste du Canada 111, 337-348.

Himmelman, J. H., Lavergne, Y., Axelson, F., Cardinal, A. \& Bourget, E. 1983. Sea urchins in the Saint Lawrence Estuary: their abundance, size-structure, and suitability for commercial exploitation. Canadian Journal of Fisheries and Aquatic Sciences 40, 474-486.

Hoffmann, L., Clarisse, S., Detienne, X., Goffart, A., Renard, R. \& Demoulin, V. 1988. Evolution of the populations of Cystoseira balearica (Phaeophyceae) and epiphytic Bangiophyceae in the Bay of Calvi (Corsica) in the last eight years. Bulletin Societé Royale Liège 4/5, 263-273.

Holland, L. Z., Giese, A. C. \& Phillips, J. H. 1967. Studies on the perivisceral coelomic fluid protein concentration during seasonal and nutritional changes in the purple sea urchin. Comparative Biochemistry and Physiology 21, 361-371. 
Hughes, T. P. 1984. Population dynamics based on individual size rather than age: a general model with a reef coral example. American Naturalist 123, 778-795.

Hur, S. B., Yoo, S. K. \& Rho, S. 1985. Laboratory tagging experiment of sea urchin, Hemicentrotus pulcherrimus. Bulletin of the Korean Fisheries Society 18, 363-368.

Imamura, K. 1999. The organisation and development of sea farming in Japan. In Stock enhancement and sea ranching, B. R. Howell et al. (eds). Oxford: Fishing News Books, 91-102.

Ivanov, B. G. 1998. Shellfishery biology in Russia: problems and opportunities. In Proceedings of the North Pacific symposium on invertebrate stock assessment and management, G. S. Jamieson \& A. Campbell (eds). Canadian Special Publication of Fisheries and Aquatic Sciences 125, 417422.

Jamieson, G. S. \& Campbell, A. (eds) 1998. Proceedings of the North Pacific symposium on invertebrate stock assessment and management. Canadian Special Publication of Fisheries and Aquatic Sciences 125.

Johnson, C. R. \& Mann, K. H. 1982. Adaptations of Strongylocentrotus droebachiensis for survival on barren grounds in Nova Scotia. In Echinoderms: proceedings of the International Conference, Tampa Bay, J. M. Lawrence (ed.). Rotterdam: Balkema, 277-283.

Juinio, M. A., Meñez, L. A., Villanoy, C. L. \& Gomez, E. D. 1989. Status of giant clam resources of the Philippines. Journal of Molluscan Studies 55, 431-440.

Juinio-Meñez, M. A., Macawaris, N. D. \& Bangi, H. G. 1995. Potentials of sea urchin ranching as a resource management strategy. In Philippine coastal resources under stress. Selected papers from the Fourth Annual Common Property Conference, Manila, Philippines, June 16-19, 1993, M. A. R. Juinio-Meñez \& G. Newkirk (eds). Coastal Resources Research Network, Dalhousie University, Halifax, NS, Canada, and Marine Science Institute, University of the Philippines, Quezon City Philippines, 219-228.

Juinio-Meñez, M. A., Macawaris, N. D. \& Bangi, H. G. 1998. Community-based sea urchin (Tripneustes gratilla) grow-out culture as a resource management tool. In Proceedings of the North Pacific symposium on invertebrate stock assessment and management, G. S. Jamieson \& A. Campbell (eds). Canadian Special Publication of Fisheries and Aquatic Sciences 125, 393-399.

Juinio-Meñez, M. A. \& Villanoy, C. 1995. Sea urchin recruitment studies for management considerations. Proceedings of the LIPI-JSPS Joint Seminar in Marine Science. Jakarta, Indonesia, 15-20.

Kalvass, P. 1992. The northern California commercial sea urchin fishery-a case study. In Sea urchins, abalone, and kelp: their biology, enhancement and management. C. M. Dewees \& L. T. Davies (eds). La Jolla, California Sea Grant College, University of California, p. 31.

Kalvass, P. \& Hendrix, J. M. 1997. The California red sea urchin, Strongylocentrotus franciscanus, fishery: catch, effort and management trends. Marine Fisheries Review 59, 1-17.

Kalvass, P. \& Taniguchi, I. 1993. Relative abundance and size composition of red sea urchin, Strongylocentrotus franciscanus, populations along the Mendocino and Sonoma county coasts, 1991. Resource Agency, California Department of Fish \& Game, Marine Resource Administration Report, 93-1.

Kalvass, P., Taniguchi, I., Buttolph, P. \& DeMartini, J. 1991. Relative abundance and size composition of red sea urchin, Strongylocentrotus franciscanus, populations along the Mendocino and Sonoma county coasts, 1989. Resource Agency, California Department of Fish and Game, Marine Resource Administration Report, 91-3.

Kan, A. 1968. Uni no siokara. In Suisan meisanhin souran, E. Noguchi (ed.). Korin Shoin, Tokyo, 3747. (In Japanese)

Karpov, K. A., Haaker, P., Albin, D., Taniguchi, I. K. \& Kushner, D. 1998. The red abalone, Haliotis rufescens in California: importance of depth refuge to abalone management. Journal of Shellfish Research 17, 863-870.

Karpov, K. A., Tegner, M. J., Rogers-Bennett, L., Kalvass, P. E. \& Taniguchi, I. K. in press. Interactions among red abalones and sea urchins in fished and reserve sites of northern California: implications of competition to management. Journal of Shellfish Research. 
Kato, S. \& Schroeter, S. C. 1985. Biology of the red sea urchin, Strongylocentrotus franciscanus, and its fishery in California. Marine Fisheries Review 47, 1-20.

Kawamata, S. 1998. Effect of wave-induced oscillatory flow on grazing by a subtidal sea urchin, Strongylocentrotus nudus (A. Agassiz). Journal of Experimental Marine Biology and Ecology 224, 31-38.

Kawamura, K. 1965. Present state and problems of transplantation of sea urchins in Hokkaido. Aquaculture 5, 10-22. (In Japanese)

Kawamura, K. 1966. Transplantation experiment of the sea urchin, Strongylocentrotus nudus off Iwanai, southwestern Hokkaido. Hokusuishi Geppo 23, 20-27. (In Japanese)

Kawamura, K. 1969. Sea urchin fisheries and present status of resource management and enhancement in Hokkaido. Hokusuishi Geppo 26, 608-637. (In Japanese)

Kawamura, K. 1973. Fishery biological studies on a sea urchin, Strongylocentrotus intermedius. Scientific Reports of the Hokkaido Fisheries Experimental Station 16, 1-54. (In Japanese with English abstract)

Kawamura, K. 1993. Uni Zouyoushoku to Kakou, Ryutsu. Sapporo: Hokkai Suisan Company. (In Japanese)

Kawana, K. 1938. Propagation of Hemicentrotus pulcherrimus. Suisan Kenkyushi 33, 104-116. (In Japanese)

Keesing, J. 2001. The ecology of Heliocidaris erythrogramma. In Edible sea urchins: biology and ecology, J. M. Lawrence (ed.). Amsterdam: Elsevier Science, 261-270.

Keesing, J. \& Hall, K. 1998. Review of harvests and status of world sea urchin fisheries points to opportunities for aquaculture. Journal of Shellfish Research 17, 1597-1604.

King, C. K., Hoegh-Guldberg, O. \& Byrne, M. 1994. Reproductive cycle of Centrostephanus rodgersii (Echinoidea), with recommendations for the establishment of a sea urchin fishery in New South Wales. Marine Biology 120, 95-106.

Kinoshita, T. 1955. Uni no hanashi: Senkaizoshoku Zatsuwa 4. Hokusuishi Geppo 12, 24-26. (In Japanese)

Kitada, S. 1999. Effectiveness of Japan's stock enhancement programmes: current perspectives. In Stock enhancement and sea ranching, B. R. Howell et al. (eds). Oxford: Fishing News Books, 103-131.

Kitching, J. A. 1987. Ecological studies at Lough Hyne. Advances in Ecological Research 17, 115186.

Kitching, J. A. \& Thain, V. M. 1983. The ecological impact of the sea-urchin Paracentrotus lividus (Lamark) in Lough Ine, Ireland. Philosophical Transactions of the Royal Society of London Series $B$ 300, 513-552.

Klinger, T. S., Lawrence, J. H. \& Lawrence, A. L. 1997. Gonad and somatic production of Strongylocentrotus droebachiensis fed on manufactured feeds. Bulletin of the Aquaculture Association, Canada 97, 35-37.

Kojima, H. 1995. Evaluation of abalone stock enhancement through the release of hatchery-reared seeds Marine and Freshwater Research 46, 689-695.

Korean Fishery Association 2000. Korean Fisheries Yearbook 1998-1999. Seoul, Korea: Dongyang Press.

Lai, H. L. \& Bradbury, A. 1998. Exploitation dynamics and management strategies for a red sea urchin (Strongylocentrotus franciscanus) population. In Proceedings of the North Pacific symposium on invertebrate stock assessment and management, G. S. Jamieson \& A. Campbell (eds). Canadian Special Publication of Fisheries and Aquatic Sciences 125, 85-96.

Larkin, P. A. 1996. Concepts and issues in marine ecosystem management. Reviews in Fish Biology and Fisheries 6, 139-164.

Lawrence, J. H. (ed.) 2001. Edible sea urchins: biology and ecology. Amsterdam: Elsevier Science.

Leber, K. M. 1999. Rationale for an experimental approach to stock enhancement. In Stock enhancement and sea ranching, B. R. Howell, et al. (eds). Oxford: Fishing News Books, 63-75. 
Le Direac'h, J. P. 1987. La pêche des oursins en Méditerranée: historique, techniques, legislation, prodiction. In Colloque international sur Paracentrotus lividus et les oursins comestibles, C. F. Boudouresque (ed.). Marseille: GIS Posidonie, 335-362.

Le Direac'h, J. P., Boudouresque, C. F., Antolic, B., Kocatas, A., Panayotidis, P., Pancucci, A., Semroud, R., Span, A., Zaquali, J. \& Zavodnik, D. 1987. Rapport sur l'exploitation des oursins en Méditerranée. In Colloque international sur Paracentrotus lividus et les oursins comestibles, C. F. Boudouresque (ed.). Marseille: GIS Posidonie, 329-334.

Le Gall, P. 1987. La pêche des oursins en Bretagne. In Colloque international sur Paracentrotus lividus et les oursins comestibles, C. F. Boudouresque (ed.). Marseille: GIS Posidonie, 311324.

Levin, P. S. 1994. Fine-scale temporal variation in recruitment of a temperate demersal fish: the importance of settlement versus post-settlement loss. Oecologia 97, 124-133.

Levitan, D. R. \& Sewell, M. A. 1998. Fertilisation success in free-spawning marine invertebrates: review of the evidence and fisheries implications. In Proceedings of the North Pacific symposium on invertebrate stock assessment and management, G. S. Jamieson \& A. Campbell (eds). Canadian Special Publication of Fisheries and Aquatic Sciences, 125, 159-164.

Levitan, D. R., Sewell, M. A. \& Chia, F.-S. 1992. How distribution and abundance influence fertilisation success in the sea urchin (Strongylocentrotus franciscanus). Ecology 73, 248-254.

Lewis, J. B. 1958. The biology of the tropical sea urchin Tripneustes esculentus Leske in Barbados, British West Indies. Canadian Journal of Zoology 36, 607-621.

Lim, C.P., Matsuda, Y. \& Shigemi, Y. 1995. Co-management in marine fisheries: the Japanese experience. Coastal Management 23, 195-221.

Lozano, J., Galera, J., López, S., Turon, X., Palacín, C. \& Morera, G. 1995. Biological cycles and recruitment of Paracentrotus lividus (Echinodermata: Echinoidea) in two contrasting habitats. Marine Ecology Progress Series 122, 179-191.

Lundquist, C. J. 2000. Effects of density dependence and environoment on recruitment of coastal invertebrates. $\mathrm{PhD}$ thesis, University of California, Davis.

Lundquist, C. J., Botsford, L. W., Morgan, L. E., Diehl, J. M., Lee, T., Lockwood, D. R. \& Pearson, E. L. 2000. Effects El Niño and La Niña on local invertebrate settlement in northern California. CalCOFI Report 41, 167-176.

Mace, P. M. 1994. Relationships between common biological reference points used as thresholds and targets of fisheries management strategies. Canadian Journal of Fisheries and Aquatic Sciences 51, $110-122$.

Mace, P. M. \& Sissenwine, M. P. 1993. How much spawning per recruit is enough? In Risk evaluations and biological reference points in fisheries management, S. J. Smith et al. (eds). Canadian Special Publication in Fisheries and Aquatic Sciences 120, 101-118.

Malay, M. C. D., Juinio-Meñez, M. A. \& Villanoy, C. 2001. Population genetic structure of the sea urchin Tripneustes gratilla from selected sites in western Luzon and Eastern Philippines. In Proceedings of the 9th International Coral Reef Symposium. Bali, Indonesia. in press.

Mann, K. H. \& Breen, P. A. 1972. The relation between lobster abundance, sea urchins and kelp beds Journal of the Fisheries Research Board of Canada 29, 603-609.

McClanahan, T. R. 1997. Predation and the distribution and abundance of tropical sea urchin populations. Journal of Experimental Marine Biology and Ecology 221, 231-255.

McClanahan. T. R. \& Sala, E. 1997. A Mediterranean rocky-bottom ecosystem fisheries model. Ecological Modelling 104, 145-164.

McClanahan, T. R. \& Shafir, S. H. 1990. Causes and consequences of sea urchin abundance and diversity in Kenyan coral reef lagoons. Oecologia 83, 362-370.

McLean, J. G. 1962. Sublittoral ecology of kelp beds of the open coast area near Carmel, California. Biological Bulletin 122, 95-114.

McNaught, D. C. 1999. The indirect effects of macroalgae and micropredation on the post-settlement success of the green sea urchin in Maine. $\mathrm{PhD}$ thesis, University of Maine. 
McNaught, D. C. \& Steneck, R. S. 1998. Settlement and survival of the green sea urchin in Maine: effects of algal habitat. University of Maine, School of Marine Sciences, Final report to the Maine Department of Marine Resources.

McShane, P. E. 1992. Sea urchins in Dusky Sound-prospects for a major kina industry in New Zealand. New Zealand Professional Fisherman 12, 34-40.

McShane, P. E., Stewart, R., Anderson, O. \& Gerring, P. K. 1994. Failure of kina fishery leaves bitter taste. Seafood New Zealand 2, 35-36.

Miller, R. J. 1985. Succession in sea urchin and seaweed abundance in Nova Scotia, Canada. Marine Biology 84, 275-286.

Miller, R. J. \& Mann, K. H. 1973. Ecological energetics of the seaweed zone in a marine bay on the Atlantic coast of Canada. III. Energy transformations by sea urchins. Marine Biology 18, 99-114.

Miller, R. J. \& Nolan, S. C. 2000. History and management of the Nova Scotian sea urchin fishery. DFO Canadian Stock Assessment Secretariat Research Document, 2000/109.

Ministry of Maritime Affairs and Fisheries 1996. Fisheries Law. Seoul, Korea: Fisheries Press.

Ministry of Maritime Affairs and Fisheries 1999. Statistical Year Book of Maritime Affairs and Fisheries. Seoul, Korea: Jungin Press.

Montecinos, M. A. 2000. Las Áreas de Manejo y Explotación de Recursos Bentonicos: Génesis, desarrollo, implementación e implicancias para la conservación de los recursos bentónicos en Chile. Licenciado en Biología Marina, Universidad Austral de Chile.

Moore, D. S., Miller, R. J. \& Meade, L. D. 1986. Survey of shallow benthic habitat: eastern shore and Cape Breton, Nova Scotia. Canadian Technical Report on Fisheries and Aquatic Science 1546, 1-49.

Moreno, C. A., Godoy, C., Villouta, E. \& Lépez, I. 1987. Explotación de recursos bentónicos litorales: una alternativa derivada de la protección de áreas. In Manejo y Desarrollo Pesquero, P. Arana (ed.). Escuela de Ciencias del Mar, Universidad Católica de Valparaíso, Valparaíso, Chile, 51-58.

Moreno, C. A., Sutherland, J. P. \& Jara, F. H. 1984. Man as a predator in the intertidal zone of southern Chile. Oikos 42, 155-160.

Moreno, C. A. \& Vega, R. 1988. Valor científico de las Reservas Marinas Costeras: un ejemplo de estudio ecológico en poblaciones de Loxechinus albus (Molina). Informes UNESCO Ciencias Marinas $47,124-134$.

Moreno, C. A. \& Zuleta, A. 1996. Evaluación del recurso erizo 1995. Universidad Austral de Chile, Final report to the Subsecretaria de Pesca. Valdivia: Universidad Austral de Chile.

Morgan, L. E., Botsford, L. W., Lundquist, C. J. \& Quinn, J. F. 1999. The potential of no-take reserves to sustain the red sea urchin (Strongylocentrotus franciscanus) fishery in northern California. Bulletin of Tohoku National Fisheries Research Institute 62, 83-94.

Morgan, L. E., Botsford, L. W., Wing S. R. \& Smith B. D. 2000b. Spatial variability in growth and mortality of the red sea urchin, Strongylocentrotus franciscanus in northern California. Canadian Journal of Fisheries and Aquatic Sciences 57, 980-992.

Morgan, L. E., Wing, S. R., Botsford, L. W., Lundquist, C. J. \& Diehl, J. M. 2000a. Spatial variability in red sea urchin (Strongylocentrotus franciscanus) recruitment in Northern California. Fisheries Oceanography 9, 83-98.

Morikawa, T. 1999. Status and prospects on the development and improvement of coastal fishing ground. In Marine ranching: global perspectives with emphasis on the Japanese experience. FAO Fisheries Circular 943, 136-239.

Moylan, E. 1997. Gonad conditioning and wild stock enhancement of the purple sea urchin Paracentrotus lividus on the west coast of Ireland. Bulletin of the Aquaculture Association of Canada 97, 38-41.

Muntz, L., Ebling, F. J. \& Kitching, J. A. 1965. The ecology of Lough Ine XIV. Predatory activity of large crabs. Journal of Animal Ecology 34, 315-329.

Myers, R. A., Bowen, K. G. \& Barrowman, N. J. 1999. Maximum reproductive rate of fish at low population sizes. Canadian Journal of Fisheries and Aquatic Sciences 56, 2404-2419.

Nakamura, T. \& Yoshinaga, H. 1962. Sea urchins off the coast of Gaikai in Yamaguchi Prefecture. Aquaculture 9, 189-200. (In Japanese) 
National Fisheries Research and Development Institute 2000. Annual seedling production at national fisheries. Seoul, South Korea: NFRDI Press.

Ojeda, F. P. \& Dearborn, J. H. 1989. Community structure of macroinvertebrates inhabiting the rocky subtidal zone in the Gulf of Maine. Marine Ecology Progress Series 57, 147-161.

Orensanz, J. M. \& Jamieson, G. S. 1998. The assessment and management of spatially structured stocks: an overview of the North Pacific Symposium on invertebrate stock assessment and management. In Proceedings of the North Pacific symposium on invertebrate stock assessment and management, G. S. Jamieson \& A. Campbell (eds). Canadian Special Publication of Fisheries and Aquatic Sciences 125, 441-459.

Palacín, C., Giribet, G., Carner, S., Dantart, L. \& Turon, X. 1998b. Effects of Paracentrotus lividus (Lamarck) manipulation in communities with naturally low sea urchin densities. Journal of Sea Research 39, 281-290.

Palacín, C., Turon, X., Ballesteros, M., Giribet, G. \& López, S. 1998a. Stock evaluation of three littoral echinoid species on the Catalan Coast (Northwestern Mediterranean). P.S.Z.N.: Marine Ecology 19, 163-177.

Palliero, J. S., Aguilar, D. \& Romero, M. 1992. La pesqueria del erizo rojo Strongylocentrotus franciscanus en Baja California, Mexico. In Memorias del Taller Mexico-Australia sobre reclutamiento de recursos bentonicos. Secretaria de pesca-Instituto Poleticnico Nacional, 81-89.

Pearse, J. S. \& Hines, A. H. 1987. Long-term population dynamics of sea urchins in a central California kelp forest: rare recruitment and rapid decline. Marine Ecology Progress Series 39, 275-283.

Pennington, J. T. 1985. The ecology of fertilisation of echinoid eggs: the consequences of sperm dilution, adult aggregation, and synchronous spawning. Biological Bulletin 169, 417-430.

Pentony, M. 1996. Commercial harvesting impacts on the Channel Islands National Park, California, populations of the red sea urchin, Strongylocentrotus franciscanus. MS thesis, Duke University, Durham.

Perry, R. I. \& Waddell, B. J. 1998. Stock assessment and quota recommendations for 1996/97 for the green sea urchin fishery in British Columbia. In Invertebrate working papers reviewed by the Pacific Stock Assessment Review Committee (PSARC) in 1996. Canadian Technical Report on Fisheries and Aquatic Sciences 2221, G. E. Gillespie \& L. C. Walthers (eds), 37-48.

Perry, R. I. \& Waddell, B. J. 1999. Review of the fishery and assessment of green sea urchin stocks in British Columbia, with quota recommendations for 1999/2000. Canadian Stock Assessment Secretariat Research Document, 99/113.

Perry, R. I., Waddell, B. J., Campbell, A. \& Hobbs, K. 1998. Review of fishery-dependent data and quota recommendations for $1995 / 96$ for the green sea urchin fishery in British Columbia. In Invertebrate working papers reviewed by the Pacific Stock Assessment Review Committee (PSARC) in 1995. II. Echinoderms, B. J. Waddell et al. (eds). Canadian Technical Report on Fisheries and Aquatic Sciences 2215, 69-82.

Perry, R. I., Walters, C. J. \& Boutillier, J. A. 1999. A framework for providing scientific advice for the management of new and developing invertebrate fisheries. Reviews in Fish Biology and Fisheries 9, $125-150$.

Pfister, C. A. \& Bradbury, A. 1996. Harvesting red sea urchins: recent effects and future predictions. Ecological Applications 6, 298-310.

Pitcher, K. W. 1989. Studies of southeastern Alaskan sea otter populations: distribution, abundance, structure, range expansion, and potential conflicts with shell fisheries. Alaska Department of Fish and Game, U.S. Fish and Wildlife Service Cooperative Agreement No. 14-16-0009-954. Anchorage, Alaska.

Polovina, J. J. 1989. A system of simultaneous dynamic production and forecast models for multispecies or multi-area applications. Canadian Journal of Fisheries and Aquatic Sciences 46, 961-963.

Prince, J. S. \& LeBlanc, W. G. 1992. Comparative feeding preference of Strongylocentrotus droebachiensis (Echinoidea) for the invasive seaweed Codium fragile spp. tomentosoides (Chlorophyceae) and four other seaweeds Marine Biology 113, 159-163. 
Quinn, J. F., Wing, S. R. \& Botsford, L. W. 1993. Harvest refugia in marine invertebrate fisheries. Models and applications to the red sea urchin, Strongylocentrotus franciscanus. American Zoologist 33, 537-550.

Reidman, M. L. \& Estes, J. A. 1990. The sea otter (Enhydra lutris): behaviour, ecology and natural history. US Fisheries and Wildlife Service Biological Report, 90 (14).

Renouf, L. 1931. Preliminary work of the new marine biological station (Lough Ine, Co. Cork). Journal of Ecology 19, 410-438.

Reynolds, J. A. 1994. Economic analysis of the factors affecting prices and costs in the Californian sea urchin fishery. MS thesis, University of California, Davis.

Richmond, N. T., Schaefer, J., Wood, C. \& McRae, J. 1997. History and status of the Oregon sea urchin fishery. Oregon Department of Fish and Wildlife Marine Resources Program.

Robinson, S. M. C., Bernier, S. \& MacIntyre, A. M. 2001. The impact of scallop drags on sea urchin populations and benthos in the Bay of Fundy, Canada. In Coastal shellfish - a sustainable resource. The Third International Conference on Shellfish Restoration. Burnell, G. (ed.). Dordrecht, Kluwer Academic. in press.

Robinson, S. M. C. \& MacIntyre, A. M. 1993. Sea urchin population survey of Campobello Island, Deer Island and Grand Manan. Report for the Campobello Fishermen's Association and the CanadaNew Brunswick Cooperative Agreement on Fisheries and Aquaculture Development. Biological Station, St. Andrews, New Brunswick.

Robinson, S. M. C. \& MacIntyre, A. M. 1995. Biological fishery information for the rational development of the green sea urchin industry. Final Report for the New Brunswick Dept. Fisheries and Aquaculture and the Canada-New Brunswick Co-operation Agreement on Economic Diversification. Biological Station, St. Andrews, New Brunswick.

Robinson, S. M. C. \& MacIntyre, A. M. 1997. Ageing and growth of the green sea urchin. Bulletin of the Aquaculture Association of Canada 97, 56-60.

Rogers-Bennett, L., Bennett, W. A., Fastenau, H. C. \& Dewees, C. M. 1995. Spatial variation in red sea urchin reproduction and morphology: implications for harvest refugia. Ecological Applications 5, 1171-1180.

Ross, M. A. 1984. A quantitative study of the stony coral fishery in Cebu, Philippines. Marine Ecology Progress Series 5, 75-91.

Roughgarden, J., Pennington, J. T., Stoner, D., Alexander, S. \& Miller, K. 1991. Collisions of upwelling fronts with the intertidal zone: the cause of recruitment pulses in barnacle populations of central California. Acta Oecologia 12, 35-51.

Rowley, R. J. 1989. Settlement and recruitment of sea urchins (Strongylocentrotus spp.) in a sea urchin barren ground and a kelp bed: are populations regulated by settlement or post-settlement processes? Marine Biology 100, 485-494.

Ruddle, K. 1987. Administration and conflict management in Japanese coastal fisheries. FAO Fisheries Technical Paper 273.

Russell, E. S. 1931. Some theoretical considerations on the "overfishing" problem. Journal du Conseil International pour l'Exploration de la Mer 6, 3-20.

Saito, K. 1992. Japan's sea urchin enhancement experience. In Sea urchins, abalone, and kelp: their biology, enhancement and management. C. M. Dewees \& L. T. Davies (eds). La Jolla, California Sea Grant College, University of California. p. 21 only.

Sala, E., Boudouresque, C. F. \& Harmelin-Vivien, M. 1998a. Fishing, trophic cascades, and the structure of algal assemblages: evaluation of an old but untested paradigm. Oikos 82, 425-439.

Sala, E., Ribes, M., Hereu, B., Zabala, M., Alva, V., Coma, R. \& Garrabou, J. 1998b. Temporal variability in abundance of the sea urchins Paracentrotus lividus and Arbacia lixula in the northwestern Mediterranean: comparison between a marine reserve and an unprotected area. Marine Ecology Progress Series 168, 135-145.

Sala, E. \& Zabala, M. 1996. Fish predation and the structure of the sea urchin Paracentrotus lividus (Lamarck) populations in the NW Mediterranean. Marine Ecology Progress Series 140, 71-81. 
Sanderson, J. C., Rossignol, M. L. \& James, W. 1996. A pilot management program to maximise Tasmania's sea urchin (Heliocidaris erythrogramma) resource. Final Report to the Fisheries Research and Development Corporation, 93/221.

Sano, M., Omori, M., Taniguchi, K., Seki, T. \& Sasaki, R. 1998. Distribution of the sea urchin Strongylocentrotus nudus in relation to marine algal zonation in the rocky coastal area of the Oshika Peninsula, northern Japan. Benthos Research 53, 79-87.

Schaefer, M. B. 1954. Some aspects of the dynamics of populations important for the management of commercial fisheries. Bulletin of the Inter-American Tropical Tuna Committee 1.

Scheibling, R. E. 1996. The role of predation in regulating sea urchin populations in eastern Canada. Oceanologica Acta 19, 421-430.

Scheibling, R. E. 2000. Species invasions and community change threaten the sea urchin fishery in Nova Scotia. Online. Available HTTP: http://crdpm.cus.ca/OURSIN/rapide.htm (Accessed February 2001).

Scheibling, R. E. \& Hatcher, B. G. 2001. The ecology of Strongylocentrotus droebachiensis. In Edible sea urchins: biology and ecology, J. M. Lawrence (ed.). Amsterdam: Elsevier Science, 271-306.

Scheibling, R. E. \& Hennigar, A. W. 1997. Recurrent outbreaks of disease in sea urchins Strongylocentrotus droebachiensis in Nova Scotia: evidence for a link with large-scale meteorological and oceanographic events. Marine Ecology Progress Series 152, 155-165.

Scheibling, R. E., Hennigar, A. W. \& Balch, T. 1999. Destructive grazing, epiphytism, and disease: the dynamics of sea urchin - kelp interactions. Canadian Journal of Fisheries and Aquatic Sciences 56, 2300-2314.

Scheibling, R. E. \& Mladenov, P. V. 1987. The decline of the sea urchin Tripneustes gratilla, fishery in Barbados a survey of fishermen and consumers. Marine Fisheries Research 49, 62-69.

Schnute, J. 1977. Improved estimates from the Schaefer production model: theoretical considerations. Journal of the Fisheries Research Board of Canada 34, 583-603.

Schroeter, S. C. 1978. Experimental studies of competition as a factor affecting the distribution and abundance of the purple sea urchin, Strongylocentrotus purpuratus (Stimpson). PhD thesis, University of California, Santa Barbara.

Schroeter, S. C., Dixon, J. D., Ebert, T. A. \& Rankin, J. V. 1996. Effects of kelp forests (Macrocystis pyrifera) on the larval distribution and settlement of red and purple sea urchins Strongylocentrotus franciscanus and S. purpuratus. Marine Ecology Progress Series 133, 125-134.

Seward, L. C. N., Vadas, R. L., Beal, B. F., Dowling, T. \& Townsend, D. 2000. Environmental factors influencing spawning in the green sea urchin, Strongylocentrotus droebachiensis, in Maine, USA. Online. Available HTTP: http://crdpm/cus.ca/oursin (Accessed January 2001).

Simenstad, C. A., Estes, J. A. \& Kenyon, K. W. 1978. Aleuts sea otters and alternate stable state communities. Science 200, 403-411.

Sloan, N. A. 1985. Echinoderm fisheries of the world: a review. In Proceedings of the Fifth International Echinoderm Conference, Galway. B. F. Keegan \& B. D. S. O'Connor (eds). Rotterdam: Balkema, 109-124.

Sloan, N. A., Lauridson, C. P. \& Harbo, R. M. 1987. Recruitment characteristics of the commercially harvested red sea urchin Strongylocentrotus franciscanus in southern British Columbia, Canada. Fisheries Research 5, 55-69.

Smith, B. D., Botsford, L. W. \& Wing, S. R. 1998. Estimation of growth and mortality parameters from size frequency distributions lacking age patterns: an application to the red sea urchin (Stronglocentrotus franciscanus). Canadian Journal of Fisheries and Aquatic Sciences 55, 12361247.

Sonu, S. C. 1995. The Japanese sea urchin market. U.S. Department of Commerce, NOAA Technical Memo, NMFS-SWR-030.

Southward, A. J. \& Southward, E. 1975. The endangered urchins. New Scientist 66, 70-73.

Steneck, R. S. 1997. Fisheries-induced biological changes to the structure and function of the Gulf of Maine ecosystem. Proceedings of the Gulf of Maine ecosystem dynamics scientific symposium and workshop, 151-165. 
Steneck, R. S. \& Dethier, M. N. 1994. A functional group approach to the structure of algal-dominated communities. Oikos 69, 476-498.

Stotz, W., González, S. \& López, C. 1992. Siembra experimental del erizo rojo Loxechinus albus (Molina) en la costa expuesta del centro-norte de Chile: efectos del erizo negro Tetrapygus niger (Molina) sobre la permanencia y crecimiento de juveniles. Investigación Pesquera (Chile) 37, 107-117.

Styan, C. A. 1997. Inexpensive and portable sampler for collecting eggs of free-spawning marine invertebrates underwater. Marine Ecology Progress Series 150, 293-296.

Taki, J. \& Higashida, I. 1964. Investigation and problem on introduction of rocks to fishing grounds to enhance the sea urchin Hemicentrotus pulcherrimus in Fukui Prefecture. Aquaculture 12, 37-47. (In Japanese)

Talaue-McManus, L. \& Kesner, K. P. 1995. Valuation of a Philippine municipal sea urchin fishery and implications of its collapse. In Philippine coastal resources under stress. Selected papers from the Fourth Annual Common Property Conference, Manila, Philippines, June 16-19, 1993, M. A. R. Juinio-Meñez \& G. Newkirk (eds). Coastal Resources Research Network, Dalhousie University, Halifax, NS, Canada, and Marine Science Institute, University of the Philippines, Quezon City Philippines, 229-239.

Taniguchi, K. 1991. Marine afforestation of Eisenia bicyclis (Laminaria; Phaeophyta). NOAA Technical Report, National Marine Fisheries Service No. 102, 47-57.

Taniguchi K. 1996. Fundamental and practice of marine afforestation. Japanese Journal of Phycology 44, 103-108. (In Japanese with English abstract)

Tegner, M. J. 1989. The feasibility of enhancing red sea urchin Strongylocentrotus franciscanus stocks in California; an analysis of the options. Marine Fisheries Review 51, 1-22.

Tegner, M. J. 2001. The ecology of Strongylocentrotus franciscanus and Strongylocentrotus purpuratus. In Edible sea urchins: biology and ecology, J. M. Lawrence (ed.). Amsterdam: Elsevier Science, 307-332.

Tegner, M. J. \& Dayton, P. K. 1977. Sea urchin recruitment patterns and implications of commercial fishing. Science 196, 324-326.

Tegner, M. J. \& Dayton, P. K. 1981. Population structure, recruitment and mortality of two sea urchins (Strongylocentrotus franciscanus and S. purpuratus) in a kelp forest. Marine Ecology Progress Series 5, 255-268.

Tegner, M. J. \& Dayton, P. K. 1991. Sea urchins, El Niños, and the long-term stability of southern California kelp forest communities. Marine Ecology Progress Series 77, 49-63.

Tegner, M. J. \& Dayton, P. K. 2000. Ecosystem effects of fishing in kelp forest communities. ICES Journal of Marine Science 57, 579-589.

Tegner, M. J. \& Levin, L. A. 1983. Spiny lobsters and sea urchins: analysis of a predator-prey interaction. Journal of Experimental Marine Biology and Ecology 73, 125-150.

Travis, J., Coleman, F. C., Grimes, C. B., Conover, D., Bert, T. M. \& Tringali, M. 1998. Critically assessing stock enhancement: an introduction to the Mote Symposium. Bulletin of Marine Science 62, 305-311.

Trinidad-Roa, M. J. 1988. Beche-de-mer fishery in the Philippines. Naga, The ICLARM Quarterly 10, $15-17$.

Turon, X., Giribet, G., López, S. \& Palacín, C. 1995. Growth and population structure of Paracentrotus lividus (Echinodermata: Echinoidea) in two contrasting habitats. Marine Ecology Progress Series 122, 193-204.

Vadas, R. L. \& Beal, B. F. 1999. Temporal and spatial variability in the relationships between adult size, maturity and fecundity in green sea urchins: the potential use of a roe-yield standard as a conservation tool. Report to the Maine Department of Marine Reources. BoothBay Harbour: Maine Department of Marine Resources.

Vadas, R. L., Beal, B., Dowling, T. \& Fegley, J. 2000. Experimental field tests of natural algal diets on gonad index and quality in green sea urchin, Strongylocentrotus droebachiensis: a case for rapid summer production in post-spawned animals. Aquaculture 182, 115-135. 
Vadas, R. L., Beal, B., Dudgeon, S. \& Wright, W. 1997. Reproductive biology of green sea urchins along the coast of Maine. Final Report to NOAA, University of Maine Sea Grant Program. Augusta, Maine Sea Grant.

Vadas, R. L., Smith, B. D., Beal, B. \& Dowling, T. 2001. Sympatric growth morphs and size bimodality in the green sea urchin (Strongylocentrotus droebachiensis). Ecology. in press.

Vadas, R. L. \& Steneck, R. S. 1995. Overfishing and inferences in kelp-sea urchin interactions. In Ecology of fjords and coastal waters, H. R. Skjoldal et al. (eds). Amsterdam: Elsevier Science, 509-524.

VanBlaricom, G. R. \& Estes, J. A. (eds) 1988. The community ecology of sea otters. Berlin: SpringerVerlag.

Van Wagenen, B. 1989. California coastal kelp resources-summer 1989. Ecoscan, Report to California Department of Fish and Game. P. O. Box 1046, Freedom, CA 95019.

Vásques, J. A. 1995. Ecological effects of brown seaweed harvesting. Botanica Marina 38, 251-257.

Vásques, J. A. 2001. Ecology of Loxechinus albus. In Edible sea urchins: biology and ecology, J. M. Lawrence (ed.). Amsterdam: Elsevier Science, 161-176.

Vásques, J. A., Castilla, J. C. \& Santelices, B. 1984. Distributional patterns and diets of four species of sea urchins in giant kelp forest (Macrocystis pyrifera) of Puerto Toro, Navarino Island, Chile. Marine Ecology Progress Series 19, 55-63.

Verlaque, M. 1984. Biologie des juvéniles de l'oursin herbivore Paracentrotus lividus (Lamarck): séléctivité de broutage et impact de l'espèce sur les communautés algales de substrat rocheux en Corse (Méditerranée, France). Botanica Marina 27, 401-424.

Vermeer, L. A., Hunte, W. \& Oxenford, H. A. 1994. An assessment of the potential for communitylevel management of the sea urchin fishery in Barbados. In Proceedings of the 47th Annual Meeting of the Gulf and Caribbean Fisheries Institute, Margarita, Venezuela. Bridgetown, Barbados: University of West Indies.

Villouta, E. 2000. Potential ecological impacts of harvesting kina (Evechinus chloroticus) in Fiordland. New Zealand Department of Conservation Science Advisory Note, 286.

Villouta, E., Chadderton, W. L., Pugsley, C. W. \& Hay, C. H. 2001. The effects of sea urchin grazing in Dusky Sound, Fiordland, New Zealand. New Zealand Journal of Marine and Freshwater Research 35, in press.

Waddell, B. J., Perry, R. I., Scharf, G. \& Ross, G. 1997. Surveys on green sea urchin (Strongylocentrotus droebachiensis) populations in Queen Charlotte Strait, British Columbia, October 1995 and March 1996. Technical Report on Fisheries and Aquatic Sciences, 2143.

Wahle, R. A. 1999. An in-situ study of the impact of sea urchin dragging on the benthos. Final report to the Maine Department of Marine Resources. Boothbay Harbor: Maine Department of Marine Resources.

Wahle, R. A. \& Peckham, S. H. 1999. Density-related reproductive trade-offs in the green sea urchin, Strongylocentrotus droebachiensis. Marine Biology 134, 127-137.

Walters, C. 1998. Evaluation of quota management policies for developing fisheries. Canadian Journal of Fisheries and Aquatic Sciences 55, 2691-2705.

Walters, C. \& Pearse, P. H. 1996. Stock information requirements for quota management systems in commercial fisheries. Reviews in Fish Biology and Fisheries 6, 21-42.

Watson, J. C. 2000. The effects of sea otters (Enhydra lutris) on abalone (Haliotis spp.) populations. Canadian Special Publication of Fisheries and Aquatic Sciences 130, 123-132.

Watson, J. C., Ellis, G. E., Smith, T. G. \& Ford, J. K. B. 1996. Updated status of the sea otter, Enhydra lutris, in Canada. Canadian Field Naturalist 111, 277-286.

Watson, J. C. \& Smith, T. G. 1996. The effects of sea otters on invertebrate fisheries in British Columbia: a review. Canadian Technical Report on Fisheries and Aquatic Sciences 2089, 262 303.

Watts, S. A., McClintock, J. B. \& Agatsuma, Y. 2001. The ecology of Lytechinus variegatus. In Edible sea urchins: biology and ecology, J. M. Lawrence (ed.). Amsterdam: Elsevier Science, 375-394. 
Wilen, J. E., Smith, M., Botsford, L. W. \& Lockwood, D. R. 2001. Avoiding surprises: incorporating fishermen behaviour into management models. Bulletin of Marine Science. in press.

Wing, S. R., Botsford, L. W. \& Quinn, J. F. 1998. The impact of coastal circulation on the spatial distribution of invertebrate recruitment, with implications for management. In Proceedings of the North Pacific symposium on invertebrate stock assessment and management, G. S. Jamieson \& A. Campbell (eds). Canadian Special Publication of Fisheries and Aquatic Sciences, 285-294.

Wing, S. R., Largier, J. L., Botsford, L. W. \& Quinn, J. F. 1995. Settlement and transport of benthic invertebrates in an intermittent upwelling region. Limnology and Oceanography 40, 316-329.

Witman, J. D. \& Sebens, K. P. 1992. Regional variation in fish predation intensity: a historical perspective in the Gulf of Maine. Oecologia 90, 305-315.

Woodby, D. 1991. The red sea urchin test fishery of southern Sitka Sound, 1990. Alaska Department of Fish and Game, Regional Information Report, 1J91-03. Juneau.

Woodby, D. 1998. Adaptive cluster sampling: efficiency, fixed sample sizes, and an application to red sea urchins (Strongylocentrotus franciscanus) in southeast Alaska. In Proceedings of the North Pacific symposium on invertebrate stock assessment and management, G. S. Jamieson \& A. Campbell (eds). Canadian Special Publication of Fisheries and Aquatic Sciences 125, 15-20.

Woodby, D., Larson, R. \& Rumble, J. 2000. Decline of the Alaska abalone fishery and prospects for rebuilding the stock. Canadian Special Publication of Fisheries and Aquatic Sciences 130, 25-31.

Woodby, D. A., Kruse, G. H. \& Larson, R. H. 1993. A conservative application of a surplus production model to the sea cucumber fishery in Southeast Alaska. In Proceedings of the International Symposium on Management Strategies for Exploited Fish Populations, G. Kruse et al. (eds). University of Alaska, Fairbanks: Alaska Sea Grant College Program Report No. 93-02; 191-202.

Yano, K., Akeda, S., Satoh, J., Matsuyama, K., Agatsuma, Y. \& Nakata, A. 1994. Influence of current and water temperature on the feeding behavior of sea urchins. In Techno-ocean 94. International Symposium Proceedings 1, Kobe: Japan Shipbuilding Industry Foundation, 195-198. (In Japanese with English abstract)

Yoo, S. K. 2000. Mariculture. Busan, South Korea: Kooduk Press.

Yoo, S. K., Hur, S. B. \& Ryu, H. Y. 1982. Growth and spawning of the sea urchin, Anthocidaris crassispina. Bulletin of the Korean Fisheries Society 15, 345-358.

Zamora, S. \& Stotz, W. 1992. Ciclo reproductivo de Loxechinus albus (Molina 1782) (Echinodermata: Echinoidea) en Punta Lagunillas, IV Región, Coquimbo, Chile. Revista Chilena de Historia Natural 65, 121-133.

Zegers, J., Oliva, M., Hidalgo, C. \& Rodriguéz, L. 1983. Crecimiento de Loxechinus albus (Molina 1782) (Echinodermata: Echinoidea) en sistema de jaulas suspendidas a media agua. Memoirs of the Latinamerican Aquaculture Society 5, 369-378.

Zuleta, A. \& Moreno, C. A. 1994. Rubilar inves evaluación de stocks y monitoreo pesquería erizo 1990. Informe Final Convenio para Subsecretaría de Pesca y la Universidad Austral de Chile, BIP 20031748. 